\title{
Durable and High-Power Iron-Based Cathodes in Competition with Platinum for Proton- Exchange Membrane Fuel Cells
}

Shengwen $\mathrm{Liu}^{1+}$, Chenzhao $\mathrm{Li}^{2+, 3}$, Michael J. Zachman ${ }^{4+}$, Yachao Zeng ${ }^{1,+}$, Haoran $\mathrm{Yu}^{4}$, Boyang $\mathrm{Li}^{5}$, Maoyu Wang ${ }^{6}$, Jonathan Braaten ${ }^{7}$, Jiawei Liu', Harry M. Meyer III ${ }^{8}$, Marcos Lucero ${ }^{6}$, A. Jeremy Kropf ${ }^{9}$, Qing Gong ${ }^{2}$, Qiurong Shi $^{1}$, Zhenxing Feng ${ }^{6}$, Guofeng Wang ${ }^{5}$, Deborah J. Myers ${ }^{9} *$, Jian Xie ${ }^{2, *}$, David A. Cullen ${ }^{4}, *$, Shawn Litster ${ }^{7}, *$, and Gang $\mathrm{Wu}^{1, *}$

${ }^{1}$ Department of Chemical and Biological Engineering, University at Buffalo, The State University of New York, Buffalo, New York 14260, USA. Email: gangwu@buffalo.edu

${ }^{2}$ Department of Mechanical and Energy Engineering, Purdue School of Engineering and Technology, Indiana University-Purdue University, Indianapolis, Indiana 46202, USA. Email: jianxie@iupui.edu;

${ }^{3}$ School of Mechanical Engineering, Purdue University, West Lafayette, Indiana 47906, USA

${ }^{4}$ Center for Nanophase Materials Sciences, Oak Ridge National Laboratory, Oak Ridge, TN 37831, USA. Email: cullenda@ornl.gov

${ }^{5}$ Department of Mechanical Engineering and Materials Science, University of Pittsburgh, Pittsburgh, PA, 15261 USA

${ }^{6}$ School of Chemical Biological, and Environmental Engineering Oregon State University Corvallis, OR 97331, USA

${ }^{7}$ Department of Mechanical Engineering, Carnegie Mellon University, Pittsburgh, PA, 15213 USA. Email: litster@andrew.cmu.edu

${ }^{8}$ Chemical Sciences Division, Oak Ridge National Laboratory, Oak Ridge, TN 37831, USA

${ }^{9}$ Chemical Sciences and Engineering Division, Argonne National Laboratory, Lemont, IL 60439, United States. Email: dmyers@anl.gov

+ These authors contributed equally 
TOC

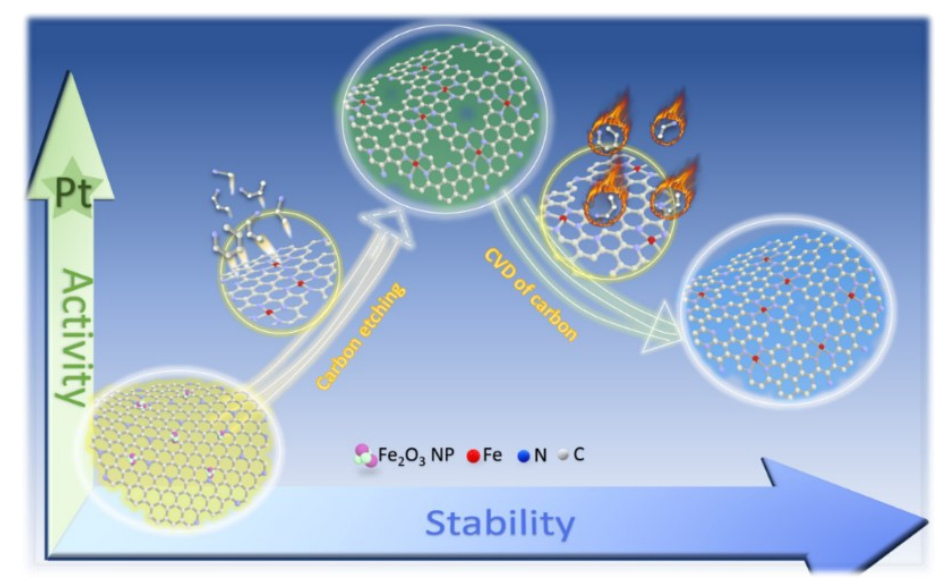

Abstract. Atomically dispersed and nitrogen-coordinated single iron sites $\left(\mathrm{FeN}_{4}\right)$ embedded in carbon (Fe-N-C) catalysts are the most promising platinum group metal (PGM)-free catalysts. However, they have yet to match their Pt counterparts for oxygen reduction reaction (ORR) activity and stability in proton exchange membrane fuel cells (PEMFCs). Here, we developed viable Fe-N-C catalysts, which, for the first time, demonstrated competitive activity to that of Pt/C catalysts and dramatically enhanced stability and durability under practical PEMFC operating conditions. The most active Fe-N-C catalyst achieved a record half-wave potential $\left(E_{1 / 2}=0.915 \mathrm{~V}\right.$ vs. RHE at $0.6 \mathrm{mg}_{\text {cat }} \mathrm{cm}^{-2}$ ) and an ORR mass activity of $10.5 \mathrm{~mA} \mathrm{mg}_{\text {cat }}$ at $0.9 \mathrm{~V}$ in (RDE) tests, exceeding a Pt/C baseline catalyst $\left(60 \mu \mathrm{g}_{\mathrm{Pt}} \mathrm{cm}^{-2}\right)$ by $40 \mathrm{mV}$ in acidic electrolytes. This compelling activity of the Fe-N-C catalyst in aqueous acids on rotating disk electrode (RDE) was successfully transferred to a fuel cell membrane electrode assemblies (MEAs), generating an initial current density of $44.2 \mathrm{~mA} \mathrm{~cm}^{-2}$ exceeding the U.S. DOE 2025 target (i.e., $44 \mathrm{~mA} \mathrm{~cm}^{-2}$ ) at $0.9 \mathrm{~V}_{\text {IR-free }}$ under $\mathrm{O}_{2}$. Under practical hydrogen-air conditions, record $151 \mathrm{~mA} \mathrm{~cm}^{-2}$ at $0.8 \mathrm{~V}$ and peak power density of $601 \mathrm{~mW} \mathrm{~cm} \mathrm{~cm}^{-2}$ were achieved. Importantly, we discovered that depositing nitrogen-carbon species on the catalyst surface via chemical vapor deposition (CVD) dramatically enhanced catalyst stability, evidenced by performance durability after accelerated stress tests (30 000 squarewave voltage cycles under $\mathrm{H}_{2}$ /air) and long-term steady-state life tests ( $>300$ hours at $0.67 \mathrm{~V}$ ). Innovative identical location-scanning transmission electron microscopy (IL-STEM) experiments 
confirmed that the CVD process leads to deposition of nitrogen-doped carbon onto the catalyst surfaces. Along with theoretical modeling, a reconstruction of the carbon structure adjacent to $\mathrm{FeN}_{4}$ sites leads to increased robustness against demetallation and carbon oxidation. This work opens new avenues for developing earth-abundant iron-based catalysts with extraordinary activity and stability, thus competing with Pt and addressing the cost barrier of current PEMFCs.

Keyword: Fe-N-C catalysts; single metal sites; PGM-free catalysts; oxygen reduction reaction; proton-exchange membrane fuel cells

\section{Introduction}

Proton-exchange membrane fuel cells (PEMFCs) are a sustainable and clean energy conversion technology that has already demonstrated outstanding potential for the transportation industry $(1$, 2). The development of platinum group metal (PGM)-free catalysts to replace Pt is a critical next step towards significantly reducing the fuel cell cost for large-scale adoption of this promising technology. Catalysts with atomically-dispersed and nitrogen-coordinated $\mathrm{FeN}_{4}$ sites hosted in a carbon support, often denoted as Fe-N-C, have exhibited encouraging activity for the oxygen reduction reaction (ORR) in challenging acidic media (3-5). However, there remains significant gaps between traditional $\mathrm{Pt}$ catalysts and Fe-N-C catalysts with regards to performance and durability, which are critical hurdles for viable application of Fe-N-C catalysts in PEMFCs. The rational design of advanced catalysts is therefore still essential for improving activity and stability by controlling the formation of $\mathrm{FeN}_{4}$ active sites with optimal local coordination environment during the critical synthesis step of thermal activation.

One grand challenge is to increase the density of $\mathrm{FeN}_{4}$ active sites in these materials to enhance ORR mass activity $(6,7)$. Currently, the $\mathrm{FeN}_{4}$ moiety, in which a single iron atom is coordinated 
with four nitrogen ligands embedded in a carbon matrix, is the leading candidate for the ORR active site candidate for the ORR in acidic electrolytes (7-9). Increasing the density of $\mathrm{FeN}_{4}$ sites is difficult because simply increasing the Fe content in the precursor induces agglomeration and formation of Fe nanoparticles and compounds (e.g., carbides or oxides), resulting in diminished $\mathrm{FeN}_{4}$ site density (10-12). Since Dodelet and his coworkers first identified zinc-based zeolite imidazole framework (ZIF-8) as an effective precursor in 2011 (13), we further developed a chemical doping approach to partially replacing $\mathrm{Zn}$ with active metal ions (i.e., $\mathrm{Fe}$ ) in ZIF-8 nanocrystals, which significantly improved atomic metal site dispersion in Fe-N-C catalysts (5, 9, 14, 15). ZIF-8 precursors can readily host single Fe sites with adequate $\mathrm{N}$ ligation and facilitate the formation of dispersed $\mathrm{FeN}_{4}$ sites in microporous carbon during controlled thermal activation $(11,16,17)$. Recent in situ X-ray absorption spectroscopy (XAS) and ex situ aberration-corrected scanning transmission electron microscopy (STEM) studies suggest that the Fe precursor first likely transforms to $\mathrm{Fe}$ oxides below $300{ }^{\circ} \mathrm{C}$ and then to tetrahedral $\mathrm{Fe}-\mathrm{O}_{4}$ below $600{ }^{\circ} \mathrm{C}$, followed by a reduction to single $\mathrm{Fe}$ sites and coordination with nitrogen ligands to form active $\mathrm{FeN}_{4}$ sites $(9,18)$. This finding inspired us to develop new strategies to design Fe-N-C catalysts for increased active site density using solid-state $\mathrm{Fe}_{2} \mathrm{O}_{3}$ precursors directly. Compared to traditional diffusible $\mathrm{Fe}^{3+}$ ion precursors, we hypothesized that the immobile $\mathrm{Fe}_{2} \mathrm{O}_{3}$ nanoparticles within ZIF-8 nanocrystals could avoid Fe site agglomeration during the critical thermal activation step (9-11). Instead, $\mathrm{Fe}$ sites can be gradually released from the $\mathrm{Fe}_{2} \mathrm{O}_{3}$ and captured by surrounding defected nitrogen ligands, increasing atomically dispersed $\mathrm{FeN}_{4}$ site density.

Besides increasing $\mathrm{FeN}_{4}$ active site density to improve ORR mass activity, enhancing the intrinsic activity of $\mathrm{FeN}_{4}$ active sites is essential for achieving performance comparable to that of $\mathrm{Pt}(3,19)$. Currently, like Pt active sites, the adsorption strength of $\mathrm{O}_{2}$ and ORR intermediates on 
$\mathrm{FeN}_{4}$ active sites is too strong $(20,21)$. The activation energy to break the O-O bond is too high for the favorable $4 \mathrm{e}^{-}$reaction pathway. Regulating the electronic structure of $\mathrm{FeN}_{4}$ active sites to modulate adsorption energies and reduce activation energies is critical for improving the intrinsic activity of the $\mathrm{FeN}_{4}$ sites $(6,19)$. Tuning the geometry of the metal center and its local coordination structure has been extensively studied, including modulation of the number of coordinated nitrogen atoms and doping with additional heteroatoms $(e . g ., \mathrm{B}, \mathrm{S}$ or $\mathrm{P})(8,20,22)$. In particular, the carbon environment surrounding $\mathrm{FeN}_{4}$ active sites could govern their kinetic activity. Small carbon planes with local defects facilitate $\mathrm{O}-\mathrm{O}$ bond breaking promoting ORR activity $(23,24)$. Hence, engineering the local carbon structure around $\mathrm{FeN}_{4}$ sites appears to be crucial for improving the ORR kinetic activity.

The insufficient stability of Fe-N-C catalysts is another severe issue impeding their practical application in PEMFCs. Demetallation of the $\mathrm{FeN}_{4}$ active sites and corrosion/oxidation of the surrounding carbon are regarded as the primary degradation mechanisms of Fe-N-C catalysts during the $\operatorname{ORR}(25,26)$. Graphitized carbon is not only capable of resisting corrosion/oxidation, but also assists in stabilizing $\mathrm{FeN}_{4}$ active sites from demetallation under an oxidizing environment $(27,28)$. Small defect-rich carbon domains are easier to be oxidized, triggering subsequent demetallation of $\mathrm{FeN}_{4}$ active sites, which results in performance degradation in the fuel cell environment $(25,29)$. Therefore, new strategies for regulating local carbon defects to enhance stability without sacrificing ORR activity are highly desired. However, it is very challenging to realize these two competing goals simultaneously.

Therefore, in addition to the solid-state synthesis strategy described above for populating a high density of $\mathrm{FeN}_{4}$ active sites in ZIF-derived carbon, this work presents strategies for tuning carbon structures with $\mathrm{NH}_{4} \mathrm{Cl}$ treatment and a CVD process to achieve compelling balance of activity and 
stability. In the initial step, an Fe-N-C catalyst with high $\mathrm{FeN}_{4}$ active site density is prepared via pyrolysis of an $\mathrm{Fe}_{2} \mathrm{O}_{3} @$ ZIF-8 composite precursor by encapsulating ultra-fine $\mathrm{Fe}_{2} \mathrm{O}_{3}$ nanoparticles $\left(\mathrm{Fe}_{2} \mathrm{O}_{3}\right)$ into $\mathrm{ZIF}-8$ nanocrystals. Second, an $\mathrm{NH}_{4} \mathrm{Cl}$ treatment is applied to the $\mathrm{Fe}-\mathrm{N}-\mathrm{C}$ catalyst to produce abundant defects in the carbon lattice. These defects easily coordinate with $\mathrm{O}$, leading to new $\mathrm{FeN}_{4}-\mathrm{O}$ structures with more favorable thermodynamics and kinetics for the ORR, increasing the catalyst's intrinsic activity. Third, using a chemical vapor deposition (CVD) approach, additional carbon species are deposited onto the catalyst surfaces, which was directly verified identical-location scanning transmission electron microscopy (IL-STEM). This induces a higher degree of $s p^{2}$ graphitization and leads to dramatically improved stability of the $\mathrm{FeN}_{4}$ sites with only a slight compromise in the ORR activity.

These combined strategies lead to a high-performance Fe-N-C catalyst that achieves exceptional ORR activity in acids, exhibiting a record half-wave potential $\left(E_{1 / 2}\right)$ of $0.916 \mathrm{~V}$ in rotating disk electrode (RDE) tests. Membrane electrode assembly (MEA) tests further show that the exceptionally high ORR mass activity in the fuel cell environment $\left(44.2 \mathrm{mAcm}^{-2}\right.$ at $0.9 \mathrm{~V}_{\text {IR-free }}$ under $\mathrm{O}_{2}$ ), exceeding U.S. DOE 2025 target (i.e., $44 \mathrm{~mA} \mathrm{~cm}{ }^{-2}$ ). In addition, under practical air conditions, the MEA delivered a current density of $>150 \mathrm{~mA} \mathrm{~cm}^{-2}$ at $0.8 \mathrm{~V}$ and a peak power density of $601 \mathrm{~mW} \mathrm{~cm}^{-2}$, which is competitive with the performance in the high voltages, kinetic region of an MEA with a $\mathrm{Pt} / \mathrm{C}$ cathode $\left(0.1 \mathrm{mg}_{\mathrm{Pt}} \mathrm{cm}^{-2}\right)$. Importantly, the CVD-processed Fe-N-C catalyst demonstrated outstanding cycling stability (30,000 voltage cycles) and long-term steadystate performance durability ( $>300$ hours) under $\mathrm{H}_{2}$-air conditions.

\section{Results and discussion}

\subsection{ORR activity and stability in acidic electrolytes}


A scheme illustrating the synthesis of catalysts at three different steps is shown in Fig. 1a and Fig. S1. The first Fe-N-C catalyst was directly prepared from a $\mathrm{Fe}_{2} \mathrm{O}_{3} @ \mathrm{ZIF}-8$ composite precursor (Fig. S2) via a thermal activation under Ar atmosphere (Fig. S1a). The catalyst was further treated with ammonium chloride (AC), $\mathrm{NH}_{4} \mathrm{Cl}$ salt at $1100{ }^{\circ} \mathrm{C}$ under an $\mathrm{Ar}$ atmosphere, and the resulting catalyst labeled Fe-N-C-AC (Fig. S1b). Abundant carbon defects and micro/mesopores were created in the Fe-N-C-AC catalyst (Fig. $\mathbf{S 3}$ and Table $\mathbf{S 1}$ ). $\mathrm{NH}_{4} \mathrm{Cl}$ first decomposes and releases a significant amount of $\mathrm{NH}_{3}$ and $\mathrm{HCl}$ gases during the pyrolysis process. $\mathrm{NH}_{3}$ is known to etch carbon structures to create abundant defects $(13,30)$. We found that the $\mathrm{HCl}$ additionally reacts with residual $\mathrm{Fe}$ aggregates in catalysts and facilitates the formation of atomically dispersed $\mathrm{Fe}$ sites (Table S2). Hence, these gases decomposed in-situ from $\mathrm{NH}_{4} \mathrm{Cl}$ produce substantial internal stress and likely form many micropores in the carbon structure (31, 32) (Fig. S4 and Table S3). Furthermore, a CVD process was developed to subsequently deposit a thin layer of carbon species on the Fe-N-C-AC catalyst, with the resulting catalyst denoted as Fe-N-C-AC-CVD (Fig. S1c). The CVD process effectively reinforced the local carbon structures and stabilized $\mathrm{FeN}_{4}$ sites to enhance catalyst stability. As shown in Table S1, compared to the Fe-N-C $\left(684.2 \mathrm{~m}^{2} \mathrm{~g}^{-1}\right)$, the $\mathrm{NH}_{4} \mathrm{Cl}$ treatment increased the surface area $\left(809.1 \mathrm{~m}^{2} \mathrm{~g}^{-1}\right)$ and porosity, increasing both micropore and mesopore volumes for the Fe-N-C-AC catalyst. The CVD leads to reduced surface area (668.6 $\mathrm{m}^{2} \mathrm{~g}^{-1}$ ) and pore volumes. Notably, although the Fe-N-C and the Fe-N-C-AC-CVD exhibited similar surface areas, their local carbon structures show different behaviors causing differences in ORR activity and stability.

Fig. 1b displays aberration-corrected annular dark-field (ADF)-STEM images for these three catalysts, indicating well-dispersed atomic Fe sites (bright dots) in all catalysts. These Fe sites are likely coordinated with N, as verified by EEL point spectra (Fig. S5), when the $\AA$-scale electron 
probe placed on the bright dots (such as those circled in red in Fig. 1b), presenting the co-existing $\mathrm{N}$ and Fe signals. X-ray Photoelectron Spectroscopy (XPS), energy-dispersive X-ray spectroscopy (EDS), and Inductively coupled plasma-optical emission spectroscopy (ICP-OES) analyses indicated that the $\mathrm{NH}_{4} \mathrm{Cl}$ treatment slightly reduces Fe content and increases $\mathrm{N}$ content (Tables $\mathbf{S 2}$ and S4-S5). This was in agreement with changes in the Fe site density determined using electrochemical stripping of a probe molecule (Fig. S6) (33), which the Fe-N-C-AC catalyst has a lower $\mathrm{FeN}_{4}$ active site density (S.D. $\left.=3.95 \times 10^{-5} \mathrm{~mol} \mathrm{~g}^{-1}\right)$ than of the Fe-N-C catalyst $\left(4.12 \times 10^{-5}\right.$ $\left.\mathrm{mol} \mathrm{g}^{-1}\right)$. Despite the slightly lower active site density, the Fe-N-C-AC catalyst delivered much better ORR activity than the Fe-N-C catalyst, suggesting it contained a new type of $\mathrm{FeN}_{4}$ site with enhanced intrinsic activity (TOF of $2.75 \mathrm{e}^{-} \cdot \operatorname{site}^{-1} \cdot \mathrm{s}^{-1}$ at $0.9 \mathrm{~V}$ ). In addition, the $\mathrm{Zn}$ content was dramatically reduced due to the $\mathrm{NH}_{4} \mathrm{Cl}$ treatment, which minimizes the negative influence of the trace of $\mathrm{Zn}$ in catalysts, such as pore blockage and binding with $\mathrm{N}$ ligands (Fig. S7).

The ORR activities and $4 \mathrm{e}^{-}$selectivities of these three catalysts (Fe-N-C, Fe-N-C-AC, and Fe$\mathrm{N}$-C-AC-CVD) were evaluated using a rotating ring-disk electrode (RRDE) in $\mathrm{O}_{2}$-saturated $0.5 \mathrm{M}$ $\mathrm{H}_{2} \mathrm{SO}_{4}$ electrolyte. As shown in Fig. 1c, the $\mathrm{Fe}_{2} \mathrm{O}_{3}$ derived Fe-N-C catalyst exhibited good ORR activity with an $E_{1 / 2}$ of $0.84 \mathrm{~V}$ under defined testing conditions $\left(0.6 \mathrm{mg}_{\mathrm{catcm}} \mathrm{cm}^{-2}, 900 \mathrm{rpm}, 25^{\circ} \mathrm{C}\right.$ in $\left.0.5 \mathrm{M} \mathrm{H}_{2} \mathrm{SO}_{4}\right)$ comparable to most Fe-N-C catalysts reported recently $(5,9,15)$. The effect of $\mathrm{Fe}_{2} \mathrm{O}_{3}$ content ranging from 5 to $20 \mathrm{mg}$ in the $\mathrm{Fe}_{2} \mathrm{O}_{3} @$ ZIF-8 precursor was investigated to achieve the highest activity (Fig. S8). The typical catalyst lost $34 \mathrm{mV}$ of $E_{1 / 2}$ after a typical accelerated stress test (AST) of 30000 potential cycles from 0.6 to $1.0 \mathrm{~V}$ in $\mathrm{O}_{2}$-saturated $0.5 \mathrm{M} \mathrm{H}_{2} \mathrm{SO}_{4}$. The degradation was typical for Fe-N-C catalysts (4). Notably, the $\mathrm{NH}_{4} \mathrm{Cl}$-treated Fe-N-C-AC catalyst showed significantly enhanced activity achieving a high $E_{1 / 2}$ of $0.915 \mathrm{~V} v s$. RHE and a kinetic current density of $6.3 \mathrm{~mA} \mathrm{~cm}-2\left(10.3 \mathrm{mAmg}_{\mathrm{cat}}{ }^{-1}\right)$ at $0.9 \mathrm{~V}$ (Fig. S9), which are superior to all 
previously reported Fe-N-C catalysts (Table S6). The ORR activity of a Fe-N-C catalyst prepared from traditional $\mathrm{Fe}^{3+}$ doping could also be promoted via the $\mathrm{NH}_{4} \mathrm{Cl}$ treatment (Fig. S10), demonstrating that regulating the carbon structure using an $\mathrm{NH}_{4} \mathrm{Cl}$ treatment is universally effective. The Fe-N-C-AC catalyst suffered a significant activity loss of up to $124 \mathrm{mV}$ after the identical AST, which is much less stable than the catalyst without $\mathrm{NH}_{4} \mathrm{Cl}$ treatment. The comparison highlights the fact that highly active catalysts typically have poor stability during the ORR, and this trade-off between activity and stability for Fe-N-C catalysts remains a quandry (34).

Compared to the Fe-N-C-AC catalyst, the Fe-N-C-AC-CVD catalyst exhibited decreased activity (e.g., $E_{1 / 2}$ of $\left.0.846 \mathrm{~V}\right)$. The catalyst stability was dramatically enhanced, however, despite the slightly ompromised activity, losing only $17 \mathrm{mV}$ after the standard AST. Only $5 \mathrm{mV}$ of loss occurred in the first 10000 cycles, a significant improvement over the Fe-N-C-AC catalyst (124 $\mathrm{mV}$ ) and previously reported Fe-N-C catalysts $(30-40 \mathrm{mV})$. Interestingly, we found that the presence of $\mathrm{N}$ species in the precursor used for the CVD is essential to achieve an optimal balance of activity and stability. Performing the CVD process using N-free carbon species resulted in more significant activity loss. (Figs. S11-12 and Table S7). Additionally, directly performing the CVD treatment on the Fe-N-C catalyst without $\mathrm{NH}_{4} \mathrm{Cl}$ treatment also led to improved ORR stability but resulted in much lower activity $\left(E_{1 / 2}=0.77 \mathrm{~V}\right)($ Fig. S13 $)$ due to a less porous structure and a low specific surface area (Fig. S14). These comparisons demonstrated the importance of the combined $\mathrm{NH}_{4} \mathrm{Cl}$ and $\mathrm{CVD}$ treatments for simultaneously achieving enhanced activity and stability. Notably, all the catalysts produced a low $\mathrm{H}_{2} \mathrm{O}_{2}$ yield of $<2 \%$ (Fig. S15), suggesting a complete $4 \mathrm{e}^{-}$ORR pathway on $\mathrm{FeN}_{4}$ sites regardless of local carbon structures. 


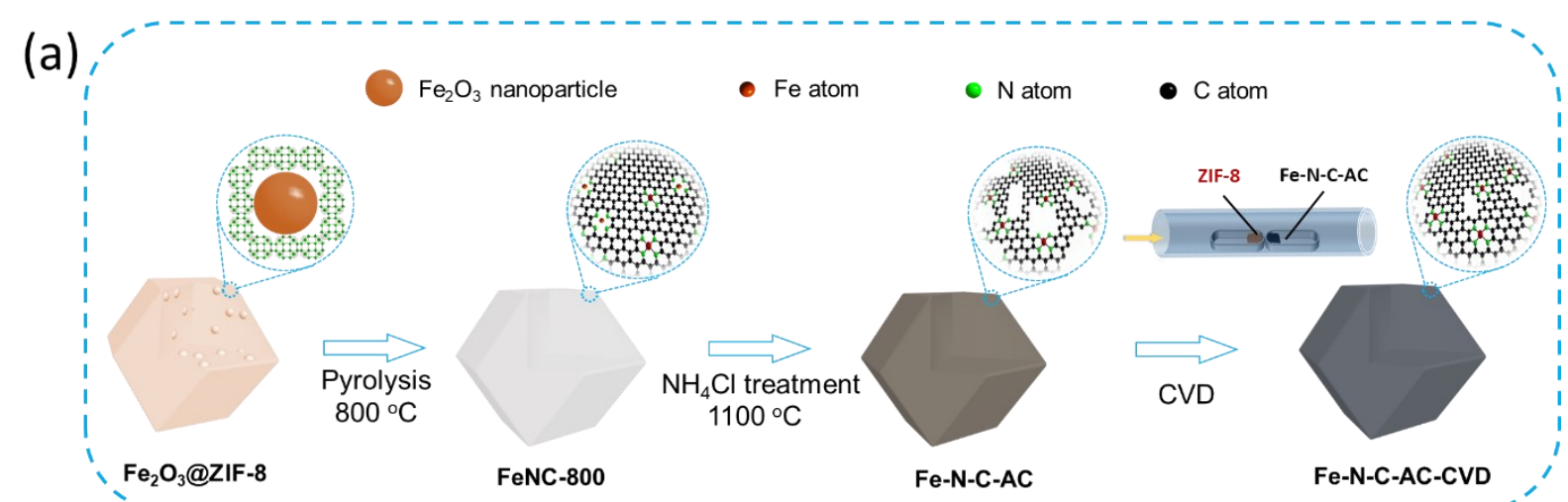

(b)
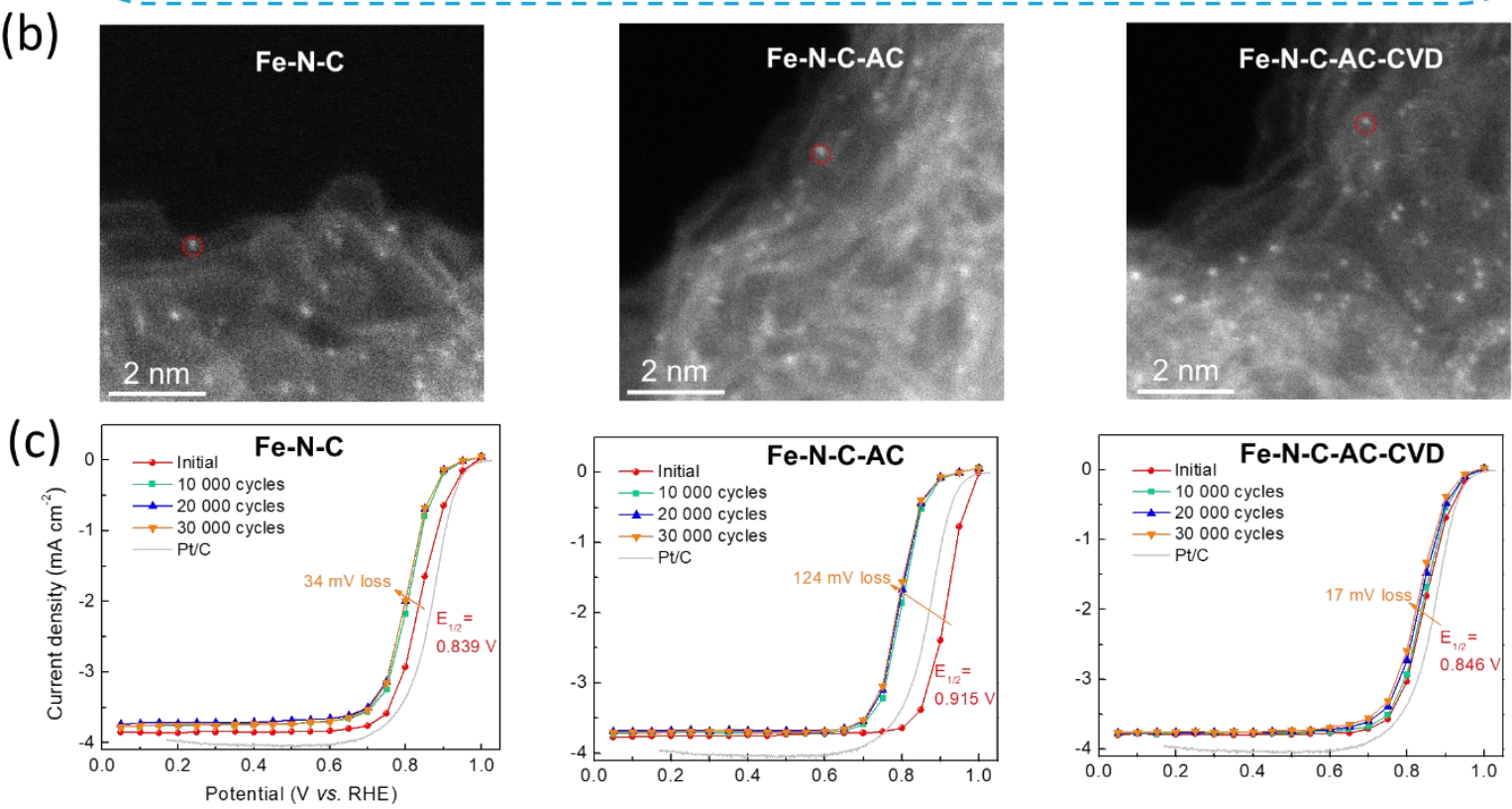

Fig. 1. (a) Schematic of the synthesis of Fe-N-C-AC and Fe-N-C-AC-CVD catalysts. (b) Aberration-corrected ADF-STEM images of the Fe-N-C, Fe-N-C-AC, and Fe-N-C-AC-CVD catalysts, respectively. Red circles indicate examples of the types of locations where EEL point spectra were acquired, such as those shown in Fig. S5. (c) Stability results of these three catalysts from accelerated stress tests (AST) by cycling the potential $\left(0.6-1.0 \mathrm{~V}, 30000\right.$ cycles) in $\mathrm{O}_{2-}$ saturated $0.5 \mathrm{M} \mathrm{H}_{2} \mathrm{SO}_{4}$.

To better understand the degradation mechanisms of these Fe-N-C catalysts, we tracked changes in $\mathrm{FeN}_{4}$ site densities during the ASTs using an in situ electrochemical quantification 
method (33). As shown in Figs. S6 and S16, the FeN 4 site density loss was consistent with their $E_{1 / 2}$ loss for each catalyst. The most active Fe-N-C-AC catalyst suffered a larger and faster FeN 4 site loss $(20 \%)$ after 10000 cycles relative to the most stable Fe-N-C-AC-CVD catalyst $(2.6 \%$ loss). Thus, demetallation of the $\mathrm{FeN}_{4}$ active sites is the primary degradation mechanism. We also investigated demetallation in $0.5 \mathrm{M} \mathrm{H}_{2} \mathrm{SO}_{4}$ electrolytes with different atmospheres, $\mathrm{N}_{2}$ vs. $\mathrm{O}_{2}$,

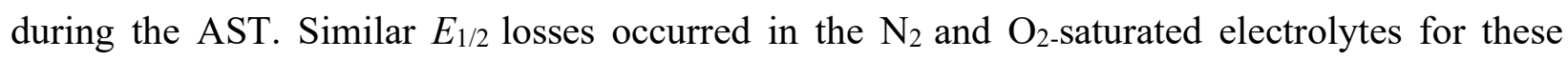
catalysts (Fig. S17). The similar activity loss suggests that, unlike previous reports $(25,35,36)$, $\mathrm{H}_{2} \mathrm{O}_{2}$ is likely not the main culprit causing catalyst degradation. Instead, the demetallation driven by electrochemical potentials is the root cause. Recently, Jaouen and colleagues pointed out that a high-spin $\mathrm{FeN}_{4} \mathrm{C}_{12}$ site (denoted as $\mathrm{S} 1$ ) and a low- or intermediate-spin $\mathrm{FeN}_{4} \mathrm{C}_{10}$ site (denoted as S2) often co-exist in Fe-N-C catalysts (Fig. S18) $(37,38)$. The former site, more intrinsically active for the ORR but not stable, undergoes a redox transition associated with conversion of high-spin $\mathrm{Fe}(\mathrm{III}) \mathrm{N}_{4} \mathrm{C}_{12}$ with an axial oxygen adsorbate to high-spin $\mathrm{Fe}(\mathrm{II}) \mathrm{N}_{4} \mathrm{C}_{12}$ species. In contrast, the more stable S2 site is potential-independent, not undergoing redox transition during the ORR. Hence, the $\mathrm{Fe}(\mathrm{II}) / \mathrm{Fe}(\mathrm{III})$ redox transitions of $\mathrm{FeN}_{4}$ sites are a critical property of the more active $\mathrm{S} 1$ sites. As shown in Fig. S19, the cyclic voltammograms (CVs) of the Fe-N-C and Fe-N-C-AC catalysts were dominated by $\mathrm{Fe}(\mathrm{II}) / \mathrm{Fe}(\mathrm{III})$ redox peaks between $0.6-0.7 \mathrm{~V}$, likely associated with $\mathrm{S} 1 \mathrm{FeN}_{4}$ sites. In contrast, the Fe-N-C-AC-CVD catalyst exhibited neglectable $\mathrm{Fe}(\mathrm{II}) / \mathrm{Fe}(\mathrm{III})$ redox peaks, suggesting insignificant density of S1 sites but dominant S2 sites. The limited $\mathrm{FeN}_{4}$ active site loss observed with the Fe-N-C-AC-CVD catalyst during the AST stability test confirmed our hypothesis that the CVD method can convert highly active $\mathrm{FeN}_{4}$ sites to stable sites resistant to demetallation. Thus, one effect of the CVD deposition of a thin layer of carbon is to convert highly 
active S1 to more stable S2 sites, which agrees with the catalyst's remarkably improved stability but decreased activity (Fig. 1c).

\subsection{Fuel cell MEA studies}

These three Fe-N-C catalysts were incorporated into MEAs for fuel cell activity and performance evaluation. The mass activity of catalysts in MEAs was determined under $\mathrm{H}_{2}-\mathrm{O}_{2}$ conditions (Fig. S20). In good agreement with RDE tests in acidic electrolytes, the Fe-N-C-AC catalyst exhibited the best initial performance. An initial current density of $44.2 \mathrm{~mA} \mathrm{~cm}^{-2}$ (Fig. 2a) and an average of $41.1 \mathrm{~mA} \mathrm{~cm}^{-2}$ from three consequentive polarization curves (Fig. S21) was measured at $0.9 \mathrm{~V}_{\mathrm{IR}}$ free with a pressure of water-saturated $\mathrm{O}_{2}$ of $150 \mathrm{kPa}_{\mathrm{abs}}$. After further correcting for hydrogen crossover (39), the activity, for the first time, has met the challenging DOE 2025 target (44 mA $\mathrm{cm}^{-2}$ ). Fuel cell performance using practical $\mathrm{H}_{2} /$ air was further evaluated. The Fe-N-C-AC catalyst generated the highest $\mathrm{H}_{2}$-air cell performance (Fig. 2b). In particular, the current density at 0.80 $\mathrm{V}$ achieved $151 \mathrm{~mA} \mathrm{~cm}{ }^{-2}$, which was even higher than that of a commercial $\mathrm{Pt} / \mathrm{C}\left(0.1 \mathrm{mg}_{\mathrm{Pt}} \mathrm{cm}^{-2}\right)$ cathode (Fig. 2c). The peak power density reached a value of $601 \mathrm{~mW} \mathrm{~cm}^{-2}$, which is the highest among reported Fe-N-C catalysts $(4,6,40)$. As for the less active, but most stable Fe-N-C-ACCVD catalyst, the MEA also exhibited a good mass activity of $23 \mathrm{~mA} \mathrm{~cm}{ }^{-2}$ at $0.9 \mathrm{~V}_{\text {IR-free. }} \mathrm{H}_{2}$-air performance was promising, generating $85 \mathrm{~mA} \mathrm{~cm}^{-2}$ at $0.80 \mathrm{~V}$ and a peak power density of 535 $\mathrm{mW} \mathrm{cm}^{-2}$. 


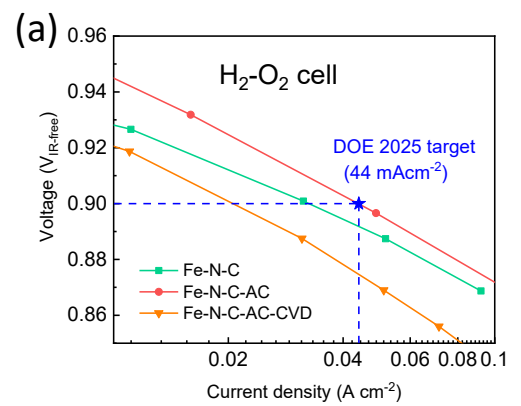

(b)
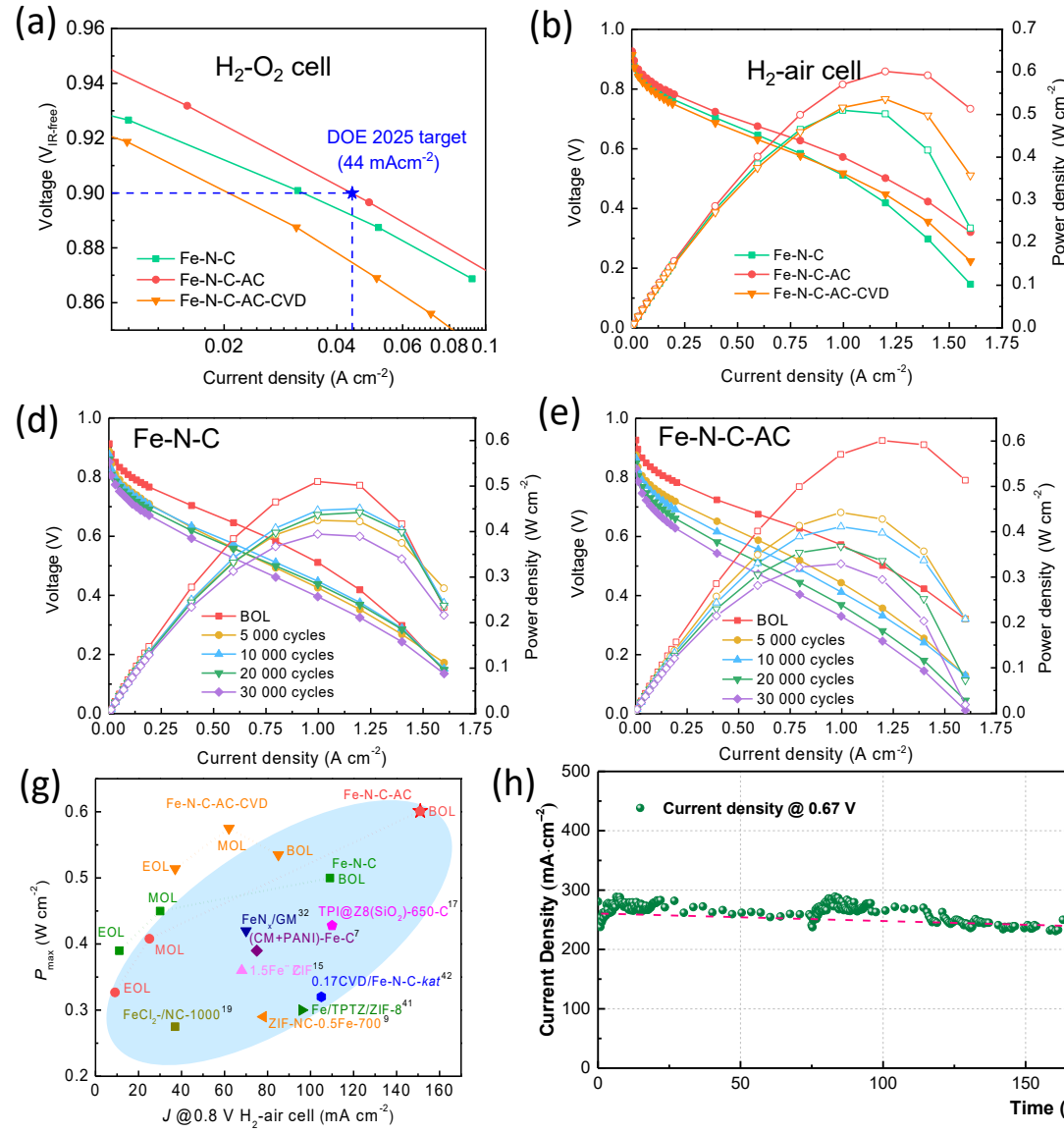

(e)

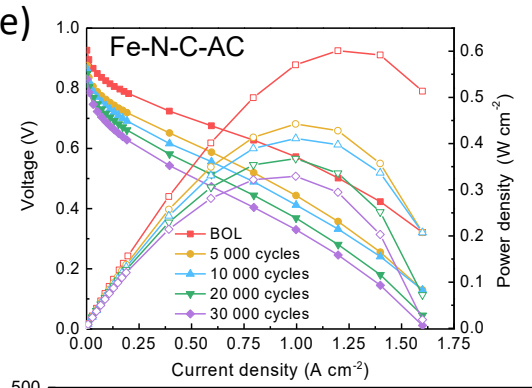

(h)

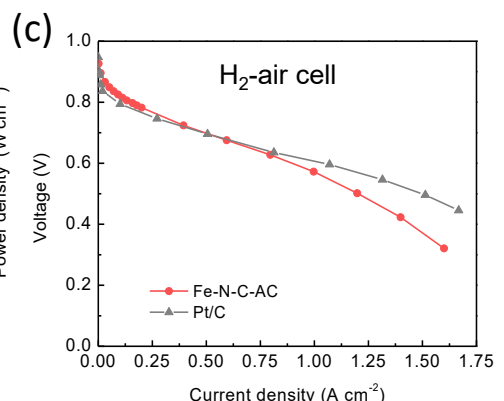

(f)

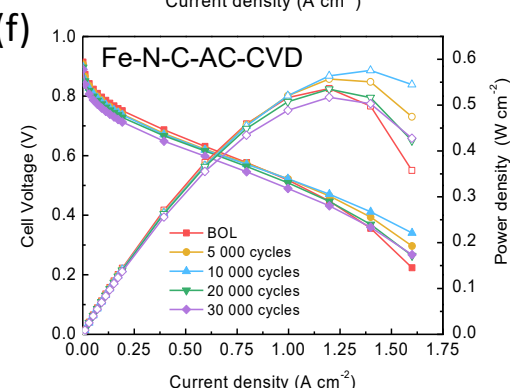

Current density $\left(\mathrm{A} \mathrm{cm}^{-2}\right)$

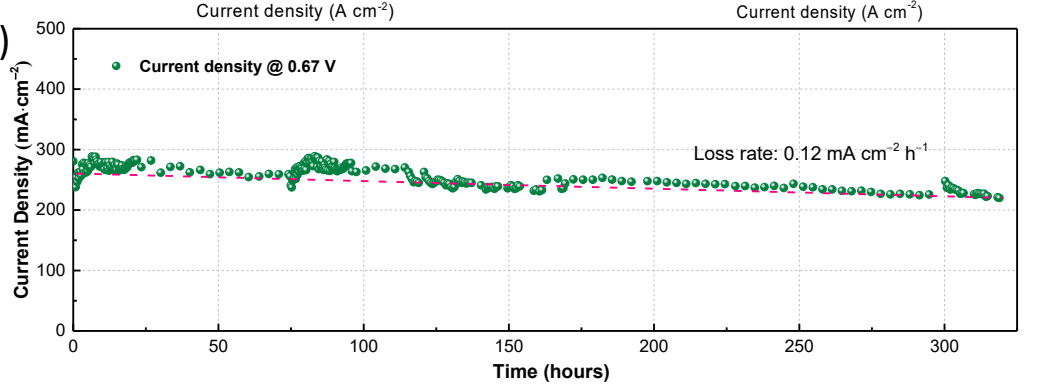

Fig. 2 MEA performance of the Fe-N-C, Fe-N-C-AC, and Fe-N-C-CVD cathode catalysts. (a) Determination of the activities at $0.9 \mathrm{~V}_{\text {IR-free }}$ in MEA at $150 \mathrm{kPa}_{\text {abs }}$ cathode pressure; the blue star denotes the U.S. DOE 2025 target $\left(44 \mathrm{~mA} \mathrm{~cm}^{-2}\right.$ ). (b) $\mathrm{H}_{2}$-air fuel cell I-V polarization (solid symbols and lines) and power density (hollow symbols and lines) are recorded under $150 \mathrm{kPa}_{\mathrm{abs}}$ of water saturated air with the cathode of the three catalysts at the flow rate of air $500 \mathrm{sccm}$ and $\mathrm{H}_{2} 300 \mathrm{sccm}$. (c) Comparison of the Fe-N-C-AC $\left(4.0 \mathrm{mg} \mathrm{cm}^{-2}\right)$ and commercial Pt/C $\left(0.1 \mathrm{mg}_{\mathrm{Pt}} \mathrm{cm}^{-}\right.$ ${ }^{2}$ ) cathodes in $\mathrm{H}_{2}$-air fuel cell. (d-f) $\mathrm{H}_{2}$-air fuel cell polarization plots of (d) Fe-N-C, (e) Fe-N-CAC, and (f) Fe-N-C-AC-CVD catalyst cathodes recorded after various numbers of cycles during the 30000 square-wave voltage cycles between $0.6 \mathrm{~V}$ and open-circuit voltage (OCV) $(\sim 0.92 \mathrm{~V})$ under ambient pressure $\left(100 \mathrm{kPa}_{\text {abs }}\right)$ at a flow rate of air $400 \mathrm{sccm}$ and $\mathrm{H}_{2} 200 \mathrm{sccm}$. (g) Fuel cell performance comparison between Fe-N-C, Fe-N-C-AC, and Fe-N-C-AC-CVD catalysts and those 
reported in the literature $(7,9,15,18,31,40-42)$, including the area metric current density at 0.8 $\mathrm{V}$ ( $x$-axis) and peak power density ( $y$-axis) in $\mathrm{H}_{2}$-air cells. The black, red, and orange curves represent the degradation trend of the three catalysts, respectively. (h) Long-term fuel cell life test under $\mathrm{H}_{2}$-air conditions at a constant potential of $0.67 \mathrm{~V}\left(150 \mathrm{kPa}_{\text {abs }}\right.$ pressure and flow rates of air $200 \mathrm{sccm}$ and $\mathrm{H}_{2} 200 \mathrm{sccm}$ ). All fuel cell cathodes: loading $~ 4.0 \mathrm{mg} \mathrm{cm}^{-2} ; 100 \% \mathrm{RH} ; 0.6 \mathrm{I} / \mathrm{C}$; $150 \mathrm{kPa}_{\mathrm{a} a \mathrm{~s}}$ total pressure. Anodes: $\mathrm{Pt} / \mathrm{C}, 0.20 \mathrm{mg}_{\mathrm{Pt}} \mathrm{cm}^{-2}, 100 \% \mathrm{RH} ; 150 \mathrm{kPa}_{\mathrm{abs}}$ pressure. Membrane: Nafion ${ }^{\mathrm{TM}}$ 212. Temperature: $80{ }^{\circ} \mathrm{C}$. MEA area: $5.0 \mathrm{~cm}^{2}$.

MEA stability was further evaluated using square-wave voltage cycling between $0.6 \mathrm{~V}$ and OCV ( 0.92 V)for 30000 cycles under $\mathrm{H}_{2} /$ air flows. Polarization plots (I-V) were tracked and plotted during the stability AST (Figs. 2d-f). Current densities at $0.8 \mathrm{~V}$ were recorded for each catalyst in Fig. S22a and Table S8. The highly active Fe-N-C-AC-catalyst suffered a significant performance degradation, losing $75 \%$ of its current densty at $0.8 \mathrm{~V}$ after 5000 cycles and $94 \%$ after 30000 cycles (Fig. S22b and Table S8). The rapid performance loss is consistent with the ORR stability loss in the aqueous acidic electrolyte, suggesting that the catalyst degradation is primarily responsible for MEA performance loss. In contrast, the Fe-N-C-AC-CVD cathode presented significantly enhanced MEA stability, retaining $79(7.1 \%$ loss $)$ and $37 \mathrm{~mA} \mathrm{~cm}^{-2}(56 \%$ loss) at $0.8 \mathrm{~V}$ after 5000 and 30000 cycles, respectively. The peak power density is well preserved at $514 \mathrm{~mW} \mathrm{~cm}^{-2}$ after 30000 cycles. At a current density of $0.8 \mathrm{~A} \mathrm{~cm}^{-2}$, the Fe-N-C-AC-CVD cathode only lost $30 \mathrm{mV}(5.1 \%)$ after 30000 cycles, which, for the first time, successfully met the U.S. DOE's 2025 target ( $\leq 30 \mathrm{mV}$ loss @0.8 A cm$\left.{ }^{-2}\right)$ for transportation applications (43). The fuel cell performances of the three catalysts at beginning-of-life (BOL) and end-of-test (EOL) were compared with other reported Fe-N-C catalysts (Fig. 2g). Despite the relatively low initial MEA 
performance of the Fe-N-C-AC-CVD catalyst, its EOL performance is comparable to that of a $\mathrm{Pt} / \mathrm{C}$ cathode $\left(0.1 \mathrm{mg}_{\mathrm{Pt}} / \mathrm{cm}^{2}\right)$ after 30000 AST cycles $($ Fig. S23). Notably, the Fe-N-C-AC-CVD cathode's peak power density at EOL was much higher than most reported Fe-N-C catalysts at BOL.

To further evaluate the durability of the most stable CVD-processed catalyst, we carried out long-term MEA stability tests for more than 300 hours at $0.67 \mathrm{~V}$, a practical voltage for fuel cell systems typically associated with peak power density, in an $\mathrm{H}_{2}$-air cell (Fig. 2h). Overall, 86.6\% of the original performance was retained after a 319-hour life test, showing a slow current-density decay rate of $0.12 \mathrm{~mA} \mathrm{~cm}^{-2} \mathrm{~h}^{-1}$. The corresponding polarization plots recorded at different time intervals are shown in Fig. S24. The current density loss at $0.8 \mathrm{~V}$ was ca. $15 \mathrm{~mA} \mathrm{~cm}{ }^{-2}$ after the first 40 hours, but the loss rate decreases with increasing hold time (e.g., $16 \mathrm{~mA} \mathrm{~cm}{ }^{-2}$ after 150 hours and $40 \mathrm{~mA} \mathrm{~cm}^{-2}$ at the end of the 319-hour test). Unlike other traditional Fe-N-C catalysts showing rapid initial degradation $(6,15,44)$, the Fe-N-C-AC-CVD cathode did not suffer from quick degradation, suggesting dominant $\mathrm{FeN}_{4}$ sites with intrinsically high stability. The steadystate long-term stability test further confirmed the effectiveness of the CVD approach for significantly enhancing catalyst performance durability. To the best of our knowledge, this is the first durability demonstration of Fe-N-C catalysts at such a high voltage (i.e., $0.67 \mathrm{~V})$, representing a breakthrough in PGM-free catalyst development for fuel cell applications.

We studied fresh and aged MEAs of these Fe-N-C catalysts using X-ray nano-computed tomography (nano-CT) to determine possible changes in their macroscopic properties (pore size, pore distribution, catalyst geometry, and ionomer distribution) that cause the performance degradation. Fig. 3a shows a rendering of a laser-milled pillar from a fresh Fe-N-C-AC-CVD MEA, imaged in phase contrast, and the extracted sub-volumes used for the macroscopic void volume 
fraction analysis in Figs 3b-e. The Porespy toolbox(45) was applied to the extracted sub-volumes shown in Figs. 3b-e, yielding the void volume fraction distributions in Fig. 3f. We observed no statistically significant change in total macroporosity or void distribution shape between the fresh and aged MEAs for both the Fe-N-C-AC and the Fe-N-C-AC-CVD cathodes. This indicates that the performance degradation of both the Fe-N-C-AC and Fe-N-C-AC-CVD cathodes in MEAs occurs on a scale smaller than the $150 \mathrm{~nm}$ resolution of our nano-CT instrument using the large field of view optics. This nano-CT analysis is consistent with analysis by electron microscopy (Fig. S25 and Table S9) that showed no significant degradation at the primary particle scale.

Electrochemical impedance spectroscopy (EIS) was recorded for an in-depth kinetic analysis of the ORR and to provide for insight into the MEA degradation mechanism (46). The resulting Nyquist plots at $0.8 \mathrm{~A} \mathrm{~cm}^{-2}$ for MEAs of three Fe-N-C catalysts during the AST are compared in Figs. 3g-i and Fig. S26. The Fe-N-C-AC-CVD MEA $\left(0.28 \Omega \mathrm{cm}^{2}\right)$ had the lowest charge transfer resistance compared to the Fe-N-C $\left(0.52 \Omega \mathrm{cm}^{2}\right)$ and Fe-N-C-AC $\left(0.34 \Omega \mathrm{cm}^{2}\right)$ catalysts after 30 000 cycles, indicating that the stable Fe-N-C-AC-CVD catalyst is kinetically active after the AST. From the above comparative analysis, MEA performance degradation is primarily due to instability of the catalyst, suggesting development of a durable catalyst is crucial for promoting MEA durability (47). To further elucidate possible catalyst degradation mechanisms causing catalyst dementallation, we further carried out MEA stability AST tests under $\mathrm{H}_{2} / \mathrm{N}_{2}$ conditions (Fig. S27). Performance losses for all catalysts after the ASTs under $\mathrm{H}_{2} / \mathrm{N}_{2}$ are nearly comparable to those under $\mathrm{H}_{2} /$ air. These results are in good agreement with $\mathrm{RDE}$ stability studies in both $\mathrm{O}_{2}$ and $\mathrm{N}_{2}$-saturated aqueous acids. The comparison (Table S10) indicated that, regardless of catalyst treatment, $\mathrm{FeN}_{4}$ site degradation is related to electrochemically driven demetallation due to voltage/potential changes, rather than oxidation by $\mathrm{O}_{2}, \mathrm{H}_{2} \mathrm{O}_{2}$, or induced radical groups. Still, the 
Fe-N-C-AC-CVD catalyst has the highest resistance to electrochemical oxidation (Fig. S28), consistent with the RDE and MEA stability AST studies.
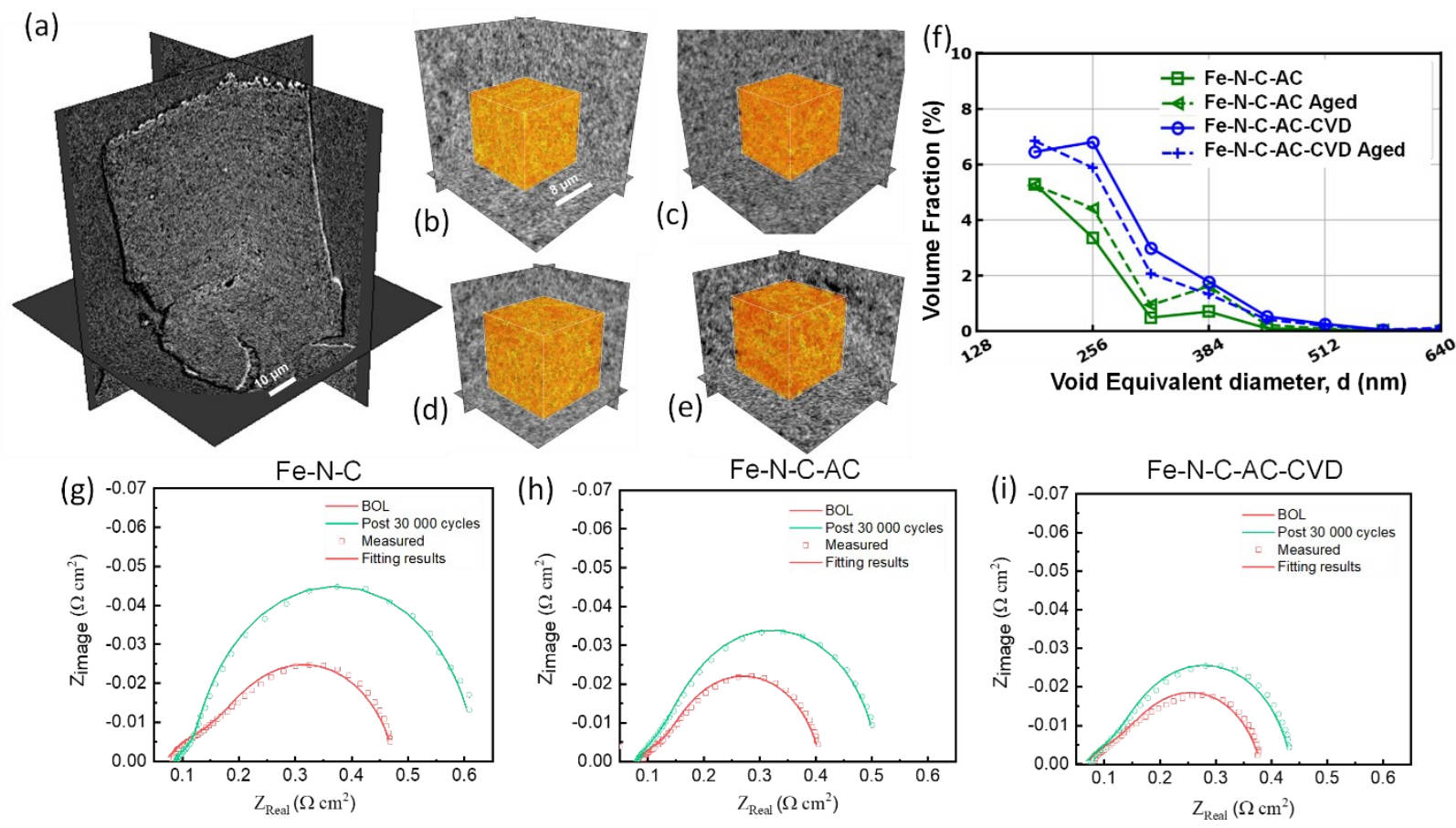

Fig 3. Phase-contrast renderings of a) the full laser-milled pillar from the Fe-N-C-AC-CVD sample and extracted sub-volumes of b) Fe-N-C-AC, c) Fe-N-C-AC aged, d) Fe-N-C-AC-CVD, and e) Fe-N-C-AC-CVD aged samples. f) Macroscopic void feature distributions from sub-volumes shown in b-e. Note that the bright pixels in the phase-contrast renderings (a-e) correspond to solids and dark pixels correspond to voids. (g-i) Comparison of measured and simulated EIS at the BOL and after 30, 000 cycles during the AST at the current density of $0.8 \mathrm{~A} \mathrm{~cm}^{-2}$ for MEAs from (g) the Fe-N-C, (h) the Fe-N-C-AC, and (i) the Fe-N-C-AC-CVD cathode catalysts. 


\subsection{Elucidating the enhanced activity and stability}

We performed in situ STEM heating experiments in the temperature range of 25 to $700{ }^{\circ} \mathrm{C}$ to observe the evolution process of the $\mathrm{Fe}_{2} \mathrm{O}_{3}$ nanoparticles to atomically-dispersed $\mathrm{FeN}_{4}$ sites. Representative ADF-STEM images and EEL point spectra in this temperature range are shown in Figs. 4a and 4b, respectively. The $\mathrm{Fe}_{2} \mathrm{O}_{3} @ \mathrm{ZIF}-8$ composite precursor presented several $\mathrm{Fe}_{2} \mathrm{O}_{3}$ nanoparticles anchored on the ZIF-8 nanocrystal (Figs. S29-30). When increasing the temperature to $300{ }^{\circ} \mathrm{C}$, the $\mathrm{Fe}_{2} \mathrm{O}_{3}$ in the precursor remained intact. Electron energy-loss (EEL) point spectra confirmed that the observed nanoparticles $(\sim 5 \mathrm{~nm})$ were iron oxide. Upon further heating to $500{ }^{\circ} \mathrm{C}$, the $\mathrm{Fe}_{2} \mathrm{O}_{3}$ particle was no longer visible, indicating that the $\mathrm{Fe}_{2} \mathrm{O}_{3}$ was transformed into atomically-dispersed Fe sites, represented by bright dots distributed in the carbon. Simultaneously, the ZIF-8 nanocrystals began to be carbonized to nitrogen-doped carbon nanoparticles. At $500^{\circ} \mathrm{C}$, EEL point spectra acquired with the $\AA$-scale electron probe positioned on an isolated bright atom simultaneously detected $\mathrm{Fe}$ and $\mathrm{N}$, suggesting that the dispersed Fe atoms have a strong affinity for $\mathrm{N}$ dopants and defects and possibly indicating the initial formation of the $\mathrm{FeN}_{4}$ site (48). Similar EEL point spectra at $700{ }^{\circ} \mathrm{C}$ further confirmed atomic $\mathrm{FeN}_{x}$ sites. The corresponding ORR activities (Fig. S31) of the ex-situ Fe-N-C- $T$ pyrolyzed at different temperatures ( $T=300,500$, $700,800,900$, and $1100{ }^{\circ} \mathrm{C}$ ) verified that the active $\mathrm{FeN}_{4}$ sites begin to form at $500{ }^{\circ} \mathrm{C}$ and are optimized at $700{ }^{\circ} \mathrm{C}$. The in situ STEM data provided direct evidence of the evolution of $\mathrm{Fe}_{2} \mathrm{O}_{3}$ to atomic $\mathrm{FeN}_{x}$ sites, including $\mathrm{Fe}_{2} \mathrm{O}_{3}$ decomposition and $\mathrm{Fe}-\mathrm{N}$ bond formation.

Our finding indicates that $\mathrm{Fe}_{2} \mathrm{O}_{3}$ surrounded by sufficient defected nitrogen facilitates the formation of $\mathrm{FeN}_{4}$ active sites. As shown in Figs. $\mathbf{S 6}$ and $\mathbf{S 3 2}$, the $\mathrm{Fe}_{2} \mathrm{O}_{3}$-derived Fe-N-C-AC catalyst exhibited a higher $\mathrm{FeN}_{4}$ active site density (S.D. $=3.95 \times 10^{-5} \mathrm{~mol} \mathrm{~g}^{-1}$ ) when compared to the previous $\mathrm{Fe}^{3+}$ doped $\mathrm{ZIF}-8$-derived catalyst with the identical $\mathrm{NH}_{4} \mathrm{Cl}$ treatment (FeZIF-AC) 
(S.D. $\left.=2.53 \times 10^{-5} \mathrm{~mol} \mathrm{~g}^{-1}\right) .(15)$ A TOF of $2.79 \mathrm{e}^{-} \cdot \mathrm{site}^{-1} \cdot \mathrm{s}^{-1}$ for the ORR at $0.9 \mathrm{~V}$ over FeN 4 sites in the Fe-N-C-AC catalyst was calculated based on the $\mathrm{H}_{2}-\mathrm{O}_{2}$ MEA data. This TOF value is higher than those reported Fe-N/C $(33,40,49)$. This further confirms that the solid-state $\mathrm{Fe}_{2} \mathrm{O}_{3}$ is more desirable than traditional Fe ion doping as the Fe source for generating more active $\mathrm{FeN}_{4}$ sites (Fig. S14).

XAS further confirmed the atomic dispersion of $\mathrm{Fe}$ in the catalyst, and quantified the local coordination number (50). The Fourier transform of the extended X-ray absorption fine structure (EXAFS) verifies that both the Fe-N-C-AC and Fe-N-C-AC-CVD are substantially free of Fe particles, as indicated by the absence of an Fe-Fe scattering path. The Fourier transform is dominated by a scattering path at $\sim 1.4 \AA$, which can be attributed to single Fe atoms coordinated to low atomic number elements, such as N, C, and O. This scattering path lengths agrees well with that in the Fe phthalocyanine standard and taken in concert with the EELS data showing N colocated with Fe, this scattering path can be attributed to Fe-N (Fig. 4c). Model-based EXAFS fitting was carried out to elucidate the local Fe bonding environment, which indicates that Fe is indeed coordinated with four $\mathrm{N}$ atoms (Tables $\mathbf{S 1 1}$ and 12. Fig. S33). There are slight differences in the EXAFS of the Fe-N-C-AC and Fe-N-C-AC-CVD catalysts, with the CVD catalyst showing a slightly higher oxidation state and scattering intensity at $\sim 1.4 \AA$. The Fe K-edge X-ray absorption near edge structure (XANES) (Fig. 4d) showed that Fe in the Fe-N-C-AC and the Fe-N-C-ACCVD catalysts has an oxidation state intermediate between the Fe(II) oxide and Fe(III) phthalocyanine- $\mathrm{O}_{2}$ standards. Linear combination fitting of the XANES regions of the spectra for the catalysts to these two standards showed the Fe-N-C-AC to be comprised of $75 \% \mathrm{Fe}^{3+}$ and $25 \%$ $\mathrm{Fe}^{2+}$ (average oxidation state of 2.75) and the Fe-N-C-AC-CVD $79 \% \mathrm{Fe}^{3+}$ and $21 \% \mathrm{Fe}^{2+}$ (average oxidation state of 2.79). The oxide rather than Fe(II)-phthalocyanine was used as the Fe(II) 
standard because the XANES region of Fe(II) phthalocyanine exhibits a strong pre-edge feature imparted by its square planar geometry which distorts its edge energy and XANES region.

The carbon structures of these catalysts were also studied to understand their effects on catalyst activity and stability. The $s p^{2} / s p^{3}$ ratio of the three catalysts was first compared using the Auger electron spectroscopy (AES) D-parameter, which is the distance between the peak maximum and minimum of the first derivative of the C KLL. Fig. 4e shows the X-ray-induced C KLL Auger data collected on the Fe-N-C, Fe-N-C-AC, and Fe-N-C-AC-CVD catalysts. For pure $s p^{3}$ carbon (diamond), the $D$-parameter equals $\sim 13 \mathrm{eV}$, while for pure $s p^{2}$ (HOPG), the $D$-parameter is $\sim 21$ $\mathrm{eV}$. Average $D$-parameters were determined for the Fe-N-C (17.25 eV), Fe-N-C-AC (17.40 eV), and Fe-N-C-AC-CVD $(18.45 \mathrm{eV})$ catalysts. The Fe-N-C-AC-CVD catalyst had the highest $s p^{2}$ content, which may explain its high stability since it should have the most stable carbon structures surrounding $\mathrm{FeN}_{4}$ sites.

The $s p^{2}$ content and chemical state of the carbon structures in these catalysts were also determined from C 1s spectra by XPS (Fig. S34 and Table S13). Consistent with the AES analysis, the Fe-N-C-AC-CVD catalyst contained the highest $s p^{2}$ content, followed by the Fe-N-C-AC and Fe-N-C catalysts, respectively. The changes in $s p^{2}$ content among the three catalysts suggests that the $\mathrm{NH}_{4} \mathrm{Cl}$ treatment may create carbon defects and micropores via removing more $s p^{3}$ carbon than $s p^{2}$ carbon, while the CVD may increases $s p^{2}$ carbon domains adjacent to $\mathrm{FeN}_{4}$ sites. The fitting of the N 1s XPS spectra (Fig. S34c and Table S13) further showed increased graphitic-N and decreased pyridinic-N content of the Fe-N-C-AC-CVD catalyst. Raman spectroscopy analysis (Fig. S35) agrees with the AES and XPS results also showing that the Fe-N-C-AC-CVD catalyst has the highest $s p^{2}$ content. 

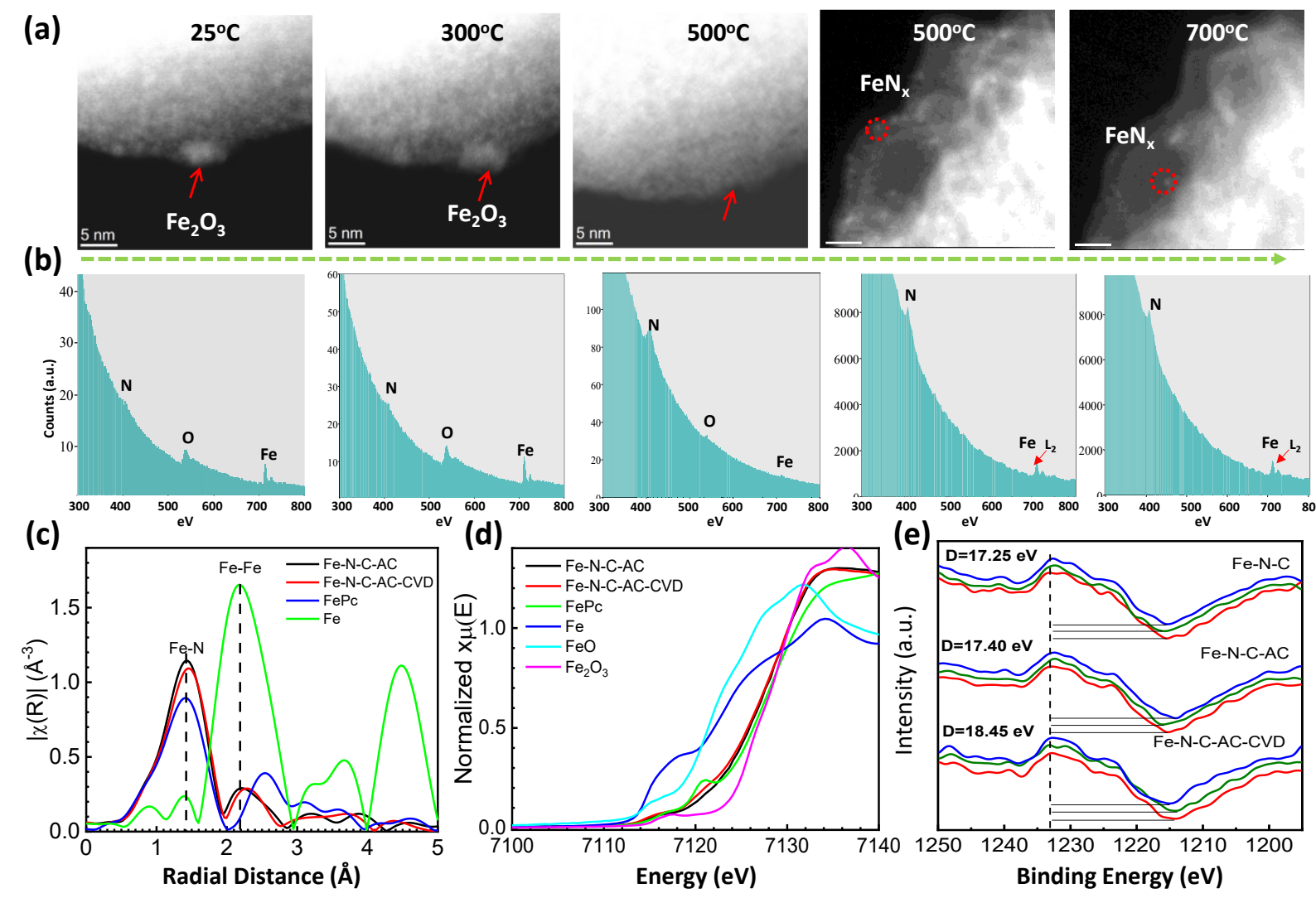

Fig. 4 (a) ADF-STEM images and (b) corresponding EEL point spectra captured during in situ heating treatment of the $\mathrm{Fe}_{2} \mathrm{O}_{3} @ \mathrm{ZIF}-8$ precursor, showing $\mathrm{Fe}_{2} \mathrm{O}_{3}$ nanoparticles (red arrows) at 25, 300,500 , and $700{ }^{\circ} \mathrm{C}$. (c) Fourier-transformed EXAFS in R-space for the catalysts before and after the CVD process. (d) Fe K-edge XANES spectra for catalysts before and after the CVD process and other relevant references. (e) X-ray induced C KLL Auger spectra of Fe-N-C, Fe-N-C-AC, and Fe-N-C-AC-CVD, comparing D-parameters measured from C KLL Auger spectra.

ADF and bright-field (BF)-STEM images (Fig. 1b and Figs. S36-37) revealed that all three catalysts' surfaces are composed of crumpled few-layer graphitic structures. To investigate the effects of the CVD treatment on this carbon structure, STEM imaging and electron energy-loss spectroscopy (EELS) were carried out on the same regions of the Fe-N-C-AC catalyst before and after CVD treatment, as shown in Fig. 5 with additional details provided in Figs. S38-42. After 
the CVD treatment (performed at $1100{ }^{\circ} \mathrm{C}$ for one hour under an $\mathrm{Ar}$ atmosphere), the overall catalyst morphology remained almost unchanged. However, careful inspection of the particle surfaces (Figs. 5a-b and Fig. S40) revealed additional graphitic layers were presented on the particle surfaces, forming a shell-like structure, while the interior features of the particles remain relatively unchanged.
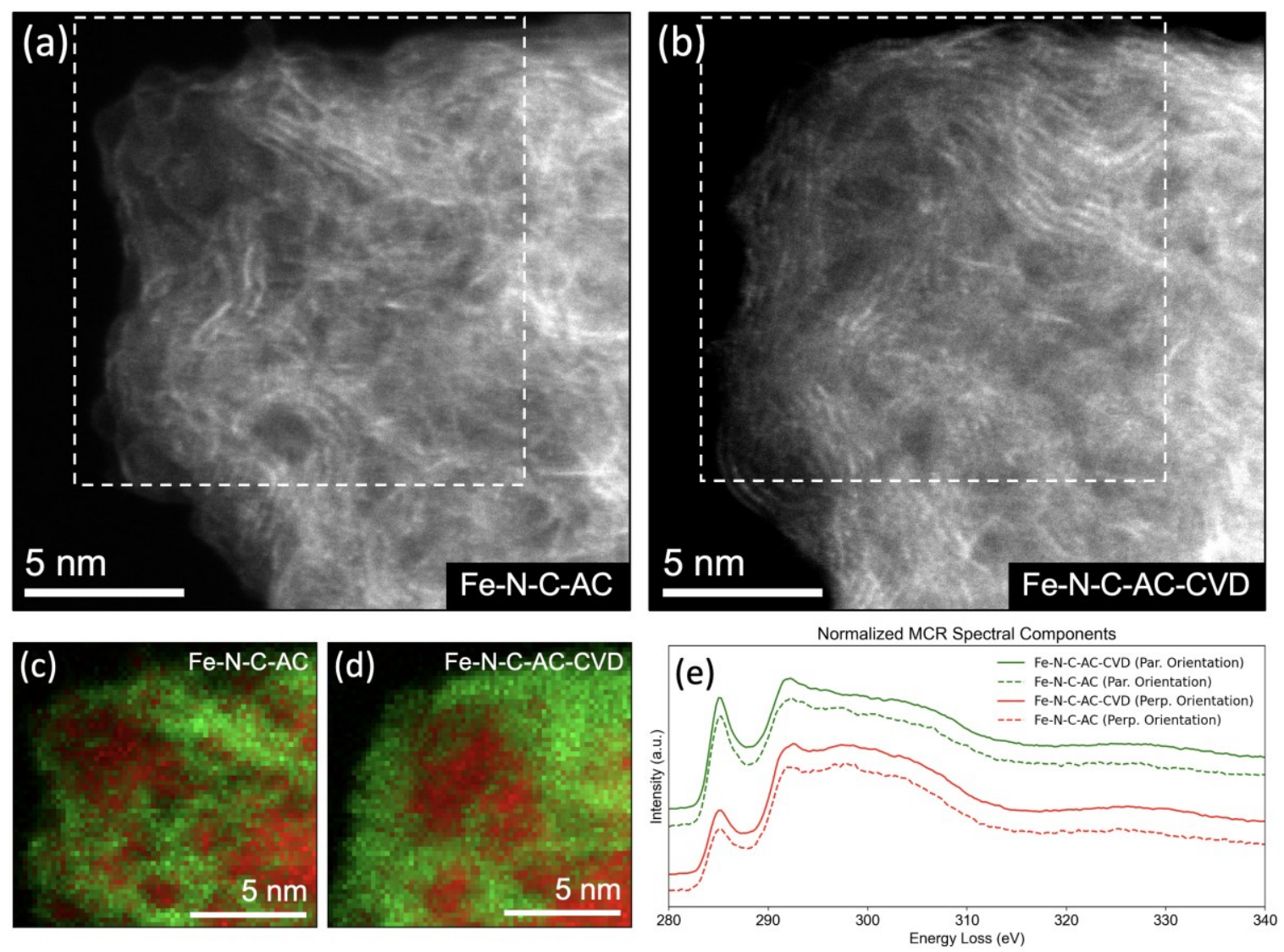

Fig.5 Annular dark-field IL-STEM images (a, b) and carbon K-edge EELS orientational mapping by multivariate curve resolution $(\mathrm{MCR})(\mathrm{c}, \mathrm{d})$ of the Fe-N-C-AC/Fe-N-C-AC-CVD catalyst before and after the CVD process, respectively. (e) Spectral components corresponding to the maps in (c, d). In (c)-(e), red indicates domains with graphitic sheets oriented perpendicularly to the beam direction, while green indicates domains with sheets parallel to the beam. 
The shell-like nature of the additional graphitic layers formed during the CVD process was further confirmed by EELSmapping, as shown in Figs. 5c-e. Performing multivariate curve resolution (MCR) on the EELS data, which allows regions of the sample containing distinct spectra to be identified and separated, enabled mapping of the change in graphitic layer orientation (Fig. S41)(51, 52). The red regions in Figs. 5c-d correspond to graphitic layers oriented perpendicularly to the electron beam (i.e., parallel to the page), whereas the green regions correspond to graphitic layers that are parallel to the electron beam (i.e., into the page). A comparison of Figs. $\mathbf{5 c}$ and $\mathbf{5 d}$ indicates that, in extreme cases, additional graphitic layers are deposited during the CVD process to form a shell-like structure on the particle surface, as indicated by the more pronounced green region present after the CVD process. Within the sensitivity of the measurement, the fine structure of the corresponding spectra for the parallel and perpendicular graphitic regions displayed in Fig. 5e are the same, consistent with XPS results showing only a modest, albeit highly impactful, increase in the degree of $s p^{2}$ carbon.

The emergence of similar shell-like structures up to $1 \mathrm{~nm}$ thick after the CVD process was observed in other regions of the catalyst, as well (Fig. S40). These regions were marked by a slight increase in $\mathrm{N}$ content compared to interior regions of the catalyst, indicating that this shell-like structure consists of additional material deposited on the particle surface. Specifically, the dashed line in denotes the change of a particle surface after the CVD process, gaining approximately 1.0 $\mathrm{nm}$ of additional material. The nitrogen content of the particle surface after the CVD treatment was analyzed by STEM-EDS (Fig. S42). As shown in Table S14, the region near the particle surface shows 3.1 and 3.8 at. $\% \mathrm{~N}$ for locations 1 and 2, respectively, while the particle interior contains 2.1 and 2.3 at. $\%$ at these locations. Therefore, the higher $\mathrm{N}$ content at the particle surface 
suggests that the graphitic layers deposited during the CVD process are N-doped. The deposition of additional N-doped graphitic layers on the catalyst surface, as well as other possible modifications, such as the reconstruction of carbon structures near the $\mathrm{FeN}_{4}$ sites, dramatically enhance catalyst stability.

\subsection{Theoretical elucidation of $\mathrm{FeN}_{4}$ sites their local environment changes}

The first-principles density functional theory (DFT) calculations were performed to elucidate how the atomic local carbon structure surrounding $\mathrm{FeN}_{4}$ active sites affects their activity and stability. As discussed previously (38), two distinct $\mathrm{FeN}_{4}$ active sites are possible in Fe-N-C catalysts, namely $\mathrm{S} 1$ type porphyrin-like $\mathrm{FeN}_{4}$ containing four pyrrolic $\mathrm{N}$ and $\mathrm{S} 2$ type $\mathrm{FeN}_{4}$ containing four pyridinic N in Fe-N-C catalysts. As shown in Fig. 6a, we constructed various $\mathrm{S} 1$ and $\mathrm{S} 2$ type $\mathrm{FeN}_{4}$ sites in these three experimental catalysts. Specifically, we constructed an $\mathrm{S} 1$ type $\mathrm{FeN}_{4}$ site hosted by micropores (denoted as $\mathrm{FeN}_{4} \mathrm{C}_{12}$ and shown in Figs. S43a) and an $\mathrm{S} 2$ type $\mathrm{FeN}_{4}$ site with a Stone-Wales defect nearby (denoted as $\mathrm{FeN}_{4} \mathrm{C}_{10}-\mathrm{C}$ and shown in Figs. S44a) to model the carbon structure with some degree of structural defects in the Fe-N-C catalyst. Due to the highly defective carbon structure found in the Fe-N-C-AC catalyst, we also constructed S1 and S2 FeN 4 sites near two micropores with an $\mathrm{O}$ atom located at the edge of one pore (denoted as $\mathrm{FeN}_{4} \mathrm{C}_{12}-\mathrm{O}$ and $\mathrm{FeN}_{4} \mathrm{C}_{10}-\mathrm{O}$, respectively), as shown in Figs. S43b and $\mathbf{S 4 4 b}$. It is plausible that $\mathrm{FeN}_{4} \mathrm{C}_{12}-\mathrm{O}$ or $\mathrm{FeN}_{4} \mathrm{C}_{10}$-O site can be expeditiously formed from the $\mathrm{FeN}_{4} \mathrm{C}_{12}$-vac and the $\mathrm{FeN}_{4} \mathrm{C}_{10}$-vac site upon exposure to air, after the pyrolysis, or at the beginning of the ORR when exposed to $\mathrm{O}_{2}$ as described in Fig. S45. Due to the absence of Fe(II)/Fe(III) redox peaks in cyclic voltammograms (Fig. S19), we assumed only one type of $\mathrm{FeN}_{4}$ site embedded in an intact graphene layer (denoted as $\mathrm{FeN}_{4} \mathrm{C}_{10}$ ) in the Fe-N-C-CVD catalyst (Fig. S44c). 
We predicted free energy evolution for the ORR on the modeled $\mathrm{S} 1$ and $\mathrm{S} 2$ type $\mathrm{FeN}_{4}$ sites for the $4 \mathrm{e}^{-}$associative ORR pathway (Figs. 6b-c). The calculated adsorption energies on the modeled $\mathrm{FeN}_{4}$ sites are shown in Table S15, and corresponding atomic structures of adsorbed ORR species are exhibited in Figs. S46-S49. The computational hydrogen electrode method developed by Norskov et. al (53), was used to calculate the free energy change for all elementary steps. Fig. 6b shows that the ORR on the $\mathrm{FeN}_{4} \mathrm{C}_{12}-\mathrm{O}$ site in the Fe-N-C-AC catalyst is an exothermic reaction when the electrode potential is lower than the limiting potential of $0.81 \mathrm{~V}$, higher than that calculated for the $\mathrm{FeN}_{4} \mathrm{C}_{12}(0.73 \mathrm{~V})$. The higher the limiting potential, the more thermodynamically favorable the ORR. As for the $\mathrm{S} 2$ type $\mathrm{FeN}_{4}$ site (Fig. 6c), the ORR limiting potentials on the $\mathrm{FeN}_{4} \mathrm{C}_{10}-\mathrm{C}(0.67 \mathrm{~V}), \mathrm{FeN}_{4} \mathrm{C}_{10}-\mathrm{O}(0.75 \mathrm{~V})$, and $\mathrm{FeN}_{4} \mathrm{C}_{10}(0.65 \mathrm{~V})$ sites were calculated corresponding to the catalysts as-synthesized, $\mathrm{NH}_{4} \mathrm{Cl}$ treated, and $\mathrm{CVD}$ processed. Moreover, climbing image nudged elastic band (CI-NEB) calculations were performed to predict the activation energy for the $\mathrm{OOH}$ dissociation on these $\mathrm{FeN}_{4}$ sites. Fig. S50 shows the atomistic details of the $\mathrm{OOH}$ dissociation on the active sites. Fig. $\mathbf{6 b}$ shows that the $\mathrm{OOH}$ dissociation step requires overcoming an energy barrier of $0.73 \mathrm{eV}$ and $0.71 \mathrm{eV}$ on $\mathrm{S} 1$ type $\mathrm{FeN}_{4} \mathrm{C}_{12}$ (as-synthesized) and $\mathrm{FeN}_{4} \mathrm{C}_{12}-\mathrm{O}$ site (after $\mathrm{NH}_{4} \mathrm{Cl}$ treatment), respectively. Meanwhile, the activation energies for $\mathrm{OOH}$ dissociation on $\mathrm{S} 2$ type $\mathrm{FeN}_{4} \mathrm{C}_{10}-\mathrm{C}$ (as-synthesized), $\mathrm{FeN}_{4} \mathrm{C}_{10}-\mathrm{O}\left(\mathrm{NH}_{4} \mathrm{Cl}\right.$ treated), and $\mathrm{FeN}_{4} \mathrm{C}_{10}$ (CVD processed) sites are predicted to be $0.71,0.59$, and $0.59 \mathrm{eV}$, respectively. All these predicted energy barriers are surmountable at room temperature, suggesting that $\mathrm{O}-\mathrm{O}$ breaking step is kinetically feasible on $\mathrm{S} 1$ and $\mathrm{S} 2$ type $\mathrm{FeN}_{4}$ sites. These results suggest that $\mathrm{FeN}_{4} \mathrm{C}_{12}-\mathrm{O}$ and $\mathrm{FeN}_{4} \mathrm{C}_{10}-\mathrm{O}$ site exhibits the highest intrinsic ORR activity among $\mathrm{S} 1$ and $\mathrm{S} 2$ type $\mathrm{FeN}_{4}$ sites, respectively, explaining the observed high ORR activities for the Fe-N-C-AC catalyst shown in Fig. 1c. 
Furthermore, a previous study suggests that the leaching of $\mathrm{Fe}$ from $\mathrm{FeN}_{4}$ sites leads to ORR activity loss (54). The proposed demetallation process is depicted in Fig. S51, in which the Fe ion moves away from an $\mathrm{N}_{4}$-coordination into an inactive $\mathrm{N}_{2}$-coordination. We believe that this step is critical for the kinetic of the demetallation process. As presented in Table S16, the Gibbs free energy change for the demetallation process is predicted to be $0.05 \mathrm{eV}$ on $\mathrm{FeN}_{4} \mathrm{C}_{12}$ and $-0.05 \mathrm{eV}$ on the $\mathrm{FeN}_{4} \mathrm{C}_{12}-\mathrm{O}$ site. In contrast, Table $\mathrm{S} 17$ shows that $\mathrm{S} 2$ type $\mathrm{FeN}_{4} \mathrm{C}_{10}-\mathrm{C}, \mathrm{FeN}_{4} \mathrm{C}_{10}-\mathrm{O}$, and $\mathrm{FeN}_{4} \mathrm{C}_{10}$ sites exhibit a Gibbs free energy change for the demetallation process of 1.25, 0.80, and $1.33 \mathrm{eV}$, respectively, much higher than those on $\mathrm{S} 1$ type $\mathrm{FeN}_{4}$ sites. This result indicates that $\mathrm{S} 2$ sites exhibit higher stability against demetallation than S1 sites, agreeing with previous experimental results(38). In addition, we predict that the stability against demetallation on S1 sites could not be enhanced via modifying the local carbon structure, as shown in Fig. S52. Among three $\mathrm{S} 2$ type $\mathrm{FeN}_{4}$ sites, $\mathrm{FeN}_{4} \mathrm{C}_{10}-\mathrm{O}$ shows the lowest free energy barrier for the demetallation, whereas the highly graphitized $\mathrm{FeN}_{4} \mathrm{C}_{10}$ site shows the highest stability. These results suggest that a micropore near the $\mathrm{FeN}_{4}$ site would lower the stability, and more graphitized carbon near the $\mathrm{FeN}_{4}$ site would enhance stability against demetallation. Therefore, this theoretical prediction provides a possible explanation for the rapid activity loss of the highly active Fe-N-C-AC catalyst and the enhanced stability of the Fe-N-C-AC-CVD catalyst. 
(a)

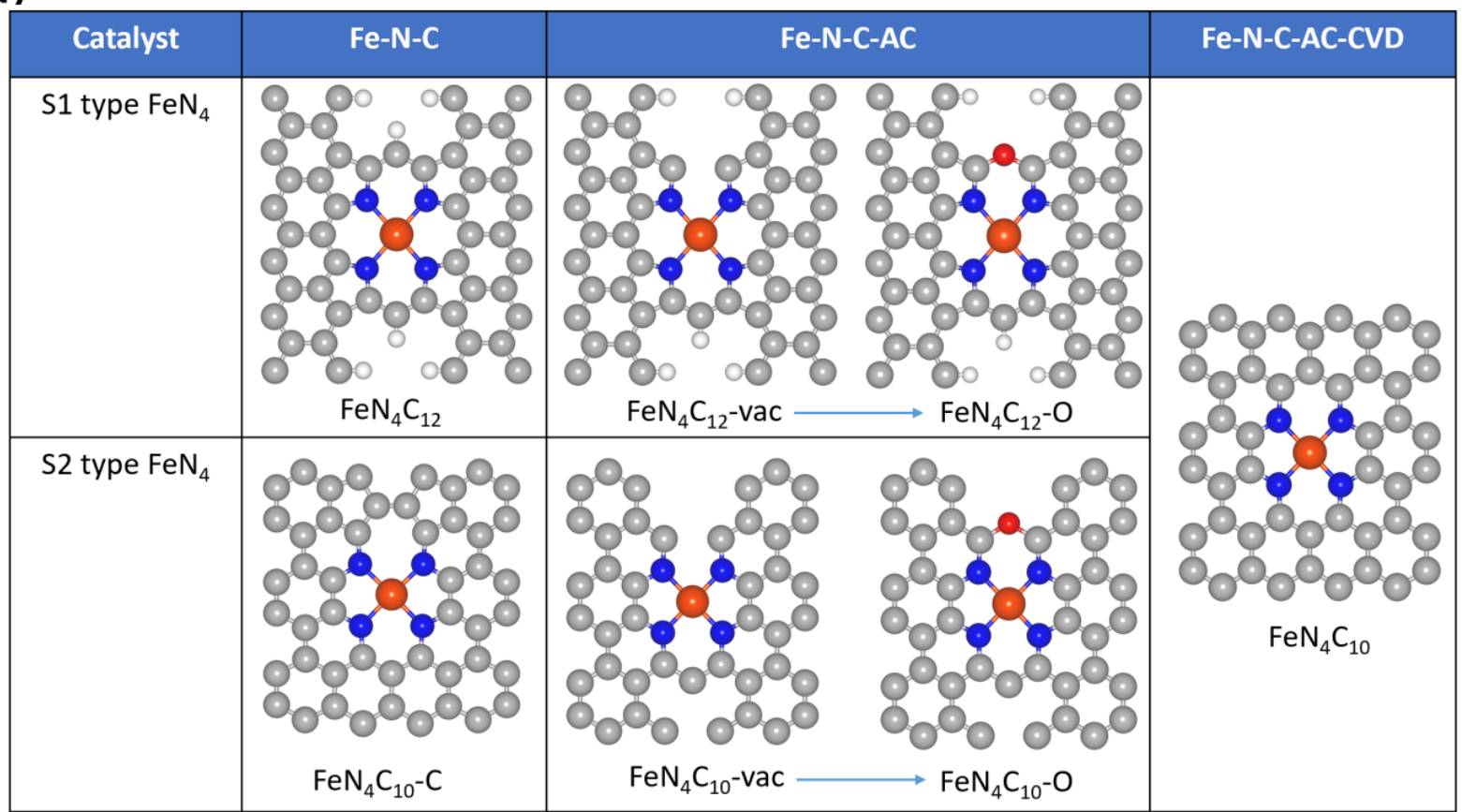

(b)

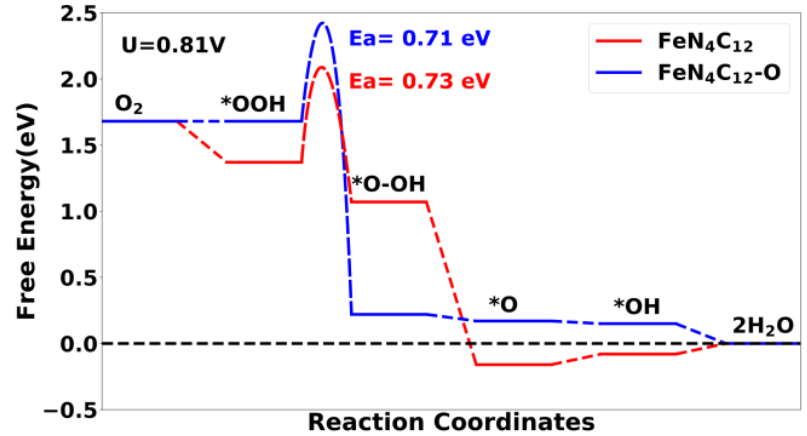

(c)

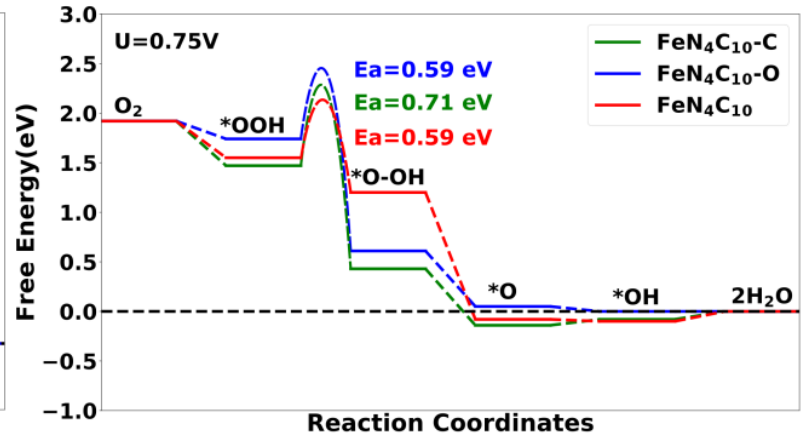

Fig.6 (a) Atomistic models of various $\mathrm{S} 1$ and $\mathrm{S} 2$ type $\mathrm{FeN}_{4}$ sites proposed to exist in different FeN-C catalysts. Predicted free energy evolution for ORR through $4 \mathrm{e}^{-}$associative pathway on (b) two $\mathrm{S} 1$ type $\mathrm{FeN}_{4}$ sites under electrode potential of $\mathrm{U}=0.81 \mathrm{~V}$ and (c) three $\mathrm{S} 2$ type $\mathrm{FeN} 4$ sites under electrode potential of $U=0.75 \mathrm{~V}$. In these figures, the gray, blue, orange, red, and white balls represent $\mathrm{C}, \mathrm{N}, \mathrm{Fe}, \mathrm{O}$, and $\mathrm{H}$ atoms, respectively. 


\section{Conclusions}

In summary, for the first time, we demonstrated a viable PGM-free Fe-N-C cathode catalyst in acidic low-temperature fuel cells with performance and durability competitive with Pt nanoparticle catalysts. Through experiments and theoretical analysis, we systemically studied how the intrinsic activity and stability of $\mathrm{FeN}_{4}$ active sites in the catalyst can be tailored by regulating the catalyst's local carbon structure. In particular, we discovered that a solid-state $\mathrm{Fe}_{2} \mathrm{O}_{3}$ precursor has advantages over traditional $\mathrm{Fe}^{3+}$ ions for synthesizing atomically-dispersed $\mathrm{Fe}-\mathrm{N}-\mathrm{C}$ catalysts due to the increased site density and suppression of Fe cluster formation during thermal activation. Furthermore, we monitored the dynamic transformation of $\mathrm{Fe}_{2} \mathrm{O}_{3}$ into $\mathrm{FeN}_{4}$ sites, in which $\mathrm{Fe}_{2} \mathrm{O}_{3}$ nanoparticles are gradually decomposed and released into atomic Fe sites to coordinate with surrounding nitrogen ligands. In addition, we found that an $\mathrm{NH}_{4} \mathrm{Cl}$ treatment is critical for improving $\mathrm{FeN}_{4}$ site's intrinsic activity. In-situ decomposed $\mathrm{NH}_{3}$ and $\mathrm{HCl}$ could create local carbon defects and remove residual Fe aggregates in catalysts. The best-performing catalyst treated with $\mathrm{NH}_{4} \mathrm{Cl}$ treatment (i.e., Fe-N-C-AC) shows record high ORR activity in aqueous acids and solid-state electrolyte-based MEAs. The measured half-wave potential, $E_{1 / 2}$ was as high as 0.915 V vs. RHE (at $0.6 \mathrm{mg}_{\mathrm{cat}} \mathrm{cm}^{-2}$ ), and the ORR kinetic current density and mass activity at $0.9 \mathrm{~V}$ are $6.3 \mathrm{~mA} \mathrm{~cm}^{-2} 10 \mathrm{mAcm}_{\mathrm{cat}^{-1}}$ in $\mathrm{RDE}$ tests with $\mathrm{O}_{2}$-saturated $0.5 \mathrm{M} \mathrm{H}_{2} \mathrm{SO}_{4}$ electrolytes. The corresponding mass activity in an MEA at $0.9 \mathrm{~V}$ (IR corrected) under $\mathrm{H}_{2}-\mathrm{O}_{2}$ exceeds $44 \mathrm{~mA} \mathrm{~cm}^{-2}$ (U.S. DOE 2025 target). Under practical $\mathrm{H}_{2}$-air conditions, the MEA generated promising performance, $151 \mathrm{~mA} \mathrm{~cm}^{-2}$ at $0.8 \mathrm{~V}$ and a peak power density of $601 \mathrm{~mW} \mathrm{~cm}^{-2}$. However, the $\mathrm{NH}_{4} \mathrm{Cl}$-treated catalyst still suffered significant performance loss.

To overcome the grand stability challenge of Fe-N-C catalysts, we discovered an effective CVD strategy, for the first time, to deposit nitrogen-doped carbon on the $\mathrm{NH}_{4} \mathrm{Cl}$-treated catalyst 
and modify the local carbon structure to a more stable but still active $\mathrm{FeN}_{4} \mathrm{C}_{10}$, as modelled by DFT. Direct evidence for deposition of nitrogen-doped carbon during the CVD process was provided by unique identical-location-scanning transmission electron microscopy experiments, where up to $1 \mathrm{~nm}$ of graphitic carbon was observed to be deposited on the surface of the catalyst, forming a shell-like structure. The CVD-treated catalyst had dramatically improved stability, only losing $30 \mathrm{mV}(5.1 \%)$ at a current density of $0.8 \mathrm{~A} \mathrm{~cm}^{-2}$ after 30, 000 voltage cycles under $\mathrm{H}_{2}$-air conditions. The compelling stability enhancement was further verified by a long-term steady-state fuel cell life test ( $>300$ hours) at a practical voltage of $0.67 \mathrm{~V}$. Despite the reduced initial ORR activity and MEA performance of the CVD-treated catalyst, its EOL performance is superior to the initially highly active Fe-N-C-AC catalyst and comparable even to a commercial Pt/C catalyst.

Therefore, besides the promising mass activity and performance in fuel cells, the extraordinary stability improvement presented here represents a breakthrough in developing FeN-C catalysts viable for replacing Pt cathodes, whould would address the cost barrier of current PEMFCs and realize their widespread implementation.

\section{Acknowledgment}

We acknowledge the support from the U.S. Department of Energy (DOE), Energy Efficiency and Renewable Energy, Fuel Cell Technologies Office. Electron microscopy was conducted at the Center for Nanophase Materials Sciences, which is a DOE Office of Science User Facility. The Talos F200X S/TEM tool provided by US DOE, Office of Nuclear Energy, Fuel Cycle R\&D Program and the Nuclear Science User Facilities. XAS measurements were performed at beamlines 9-BM and 10-BM (MRCAT) at the Advanced Photon Source, a User Facility operated for Argonne National Laboratory. The operation of MRCAT is supported both by DOE and the MRCAT member institutions. This work was in part authored by Argonne National Laboratory, 
which is operated for the US DOE by the University of Chicago Argonne LLC under contract no. DE-AC02-06CH11357. G. Wu also thanks to the Research and Education in eNergy, Environment, and Water (RENEW) program at the University at Buffalo, SUNY and National Science Foundation (CBET1604392, 1804326) for partial support.

\section{Competing interests}

G. Wu. and S. Liu have filed a provisional patent application: US Provisional 63/068,937 filed 8/21/2020. The $\mathrm{Fe}_{2} \mathrm{O}_{3}$ precursor, the $\mathrm{NH}_{4} \mathrm{Cl}$ treatment, and the CVD process are covered by this patent application. The remaining authors declare no competing interests.

\section{References}

1. X. X. Wang, M. T. Swihart, G. Wu, Achievements, challenges and perspectives on cathode catalysts in proton exchange membrane fuel cells for transportation. Nat. Catal. 2, 578-589 (2019).

2. E. L. Miller et al., US Department of Energy hydrogen and fuel cell technologies perspectives. MRS Bulletin 45, 57-64 (2020).

3. W. Wang, Q. Jia, S. Mukerjee, S. Chen, Recent Insights into the Oxygen-Reduction Electrocatalysis of Fe/N/C Materials. ACS Catal. 9, 10126-10141 (2019).

4. U. Martinez et al., Progress in the Development of Fe-Based PGM-Free Electrocatalysts for the Oxygen Reduction Reaction. Adv. Mater., e1806545 (2019).

5. H. Zhang et al., Single Atomic Iron Catalysts for Oxygen Reduction in Acidic Media: Particle Size Control and Thermal Activation. J. Am. Chem. Soc. 139, 14143-14149 (2017).

6. Y. He, S. Liu, C. Priest, Q. Shi, G. Wu, Atomically dispersed metal-nitrogen-carbon catalysts for fuel cells: advances in catalyst design, electrode performance, and durability improvement. Chem. Soc. Rev. 49, 3484-3524 (2020). 
7. H. T. Chung et al., Direct atomic-level insight into the active sites of a high-performance PGM-free ORR catalyst. Science 357, 479-484 (2017).

8. A. Zitolo et al., Identification of catalytic sites for oxygen reduction in iron- and nitrogendoped graphene materials. Nat. Mater. 14, 937-942 (2015).

9. J. Li et al., Thermally Driven Structure and Performance Evolution of Atomically Dispersed $\mathrm{FeN}_{4}$ Sites for Oxygen Reduction. Angew. Chem. Int. Ed. 58, 18971-18980 (2019).

10. R. Jiang et al., Edge-Site Engineering of Atomically Dispersed Fe-N 4 by Selective C-N Bond Cleavage for Enhanced Oxygen Reduction Reaction Activities. J. Am. Chem. Soc. 140, 11594-11598 (2018).

11. Y. Chen et al., Isolated Single Iron Atoms Anchored on N-Doped Porous Carbon as an Efficient Electrocatalyst for the Oxygen Reduction Reaction. Angew. Chem. Int. Ed. 56, 69376941 (2017).

12. G. Wu, K. L. More, C. M. Johnston, P. Zelenay, High-Performance Electrocatalysts for Oxygen Reduction Derived from Polyaniline, Iron, and Cobalt. Science 332, $443-447$ (2011).

13. E. Proietti et al., Iron-based cathode catalyst with enhanced power density in polymer electrolyte membrane fuel cells. Nat. Commun. 2, 416 (2011).

14. X. Wang et al., Directly converting Fe-doped metal-organic frameworks into highly active and stable Fe-N-C catalysts for oxygen reduction in acid. Nano Energy 25, 110-119 (2016).

15. H. Zhang et al., High-performance fuel cell cathodes exclusively containing atomically dispersed iron active sites. Energy Environ. Sci. 12, 2548-2558 (2019).

16. J. Wang et al., Design of N-Coordinated Dual-Metal Sites: A Stable and Active Pt-Free Catalyst for Acidic Oxygen Reduction Reaction. J. Am. Chem. Soc. 139, 17281-17284 (2017). 
17. M. Liu et al., Atomically dispersed metal catalysts for the oxygen reduction reaction: synthesis, characterization, reaction mechanisms and electrochemical energy applications. Energy Environ. Sci. 12, 2890-2923 (2019).

18. J. Li et al., Evolution Pathway from Iron Compounds to Fe1(II)-N4 Sites through GasPhase Iron during Pyrolysis. J. Am. Chem. Soc. 142, 1417-1423 (2020).

19. Y. Zhu et al., Engineering Local Coordination Environments of Atomically Dispersed and Heteroatom-Coordinated Single Metal Site Electrocatalysts for Clean Energy-Conversion. Angew. Chem. Int. Ed. 10, 1902844 (2020).

20. K. Liu, G. Wu, G. Wang, Role of Local Carbon Structure Surrounding FeN4 Sites in Boosting the Catalytic Activity for Oxygen Reduction. J. Phys. Chem. C 121, 11319-11324 (2017).

21. K. Mao, L. Yang, X. Wang, Q. Wu, Z. Hu, Identifying Iron-Nitrogen/Carbon Active Structures for Oxygen Reduction Reaction under the Effect of Electrode Potential. J. Phys. Chem. Lett. 11, 2896-2901 (2020).

22. X. Wang et al., Edge-Rich Fe- $\mathrm{N}_{4}$ Active Sites in Defective Carbon for Oxygen Reduction Catalysis. Advanced Materials 32, 2000966 (2020).

23. Y. Mun et al., Versatile Strategy for Tuning ORR Activity of a Single Fe-N4 Site by Controlling Electron-Withdrawing/Donating Properties of a Carbon Plane. J. Am. Chem. Soc. 141, 6254-6262 (2019).

24. N. Ramaswamy, U. Tylus, Q. Jia, S. Mukerjee, Activity descriptor identification for oxygen reduction on nonprecious electrocatalysts: linking surface science to coordination chemistry. J. Am. Chem. Soc. 135, 15443-15449 (2013). 
25. Y. Shao, J. P. Dodelet, G. Wu, P. Zelenay, PGM-Free Cathode Catalysts for PEM Fuel Cells: A Mini-Review on Stability Challenges. Adv. Mater. 31, e1807615 (2019).

26. H. Singh, S. Q. Zhuang, B. Ingis, B. B. Nunna, E. S. Lee, Carbon-based catalysts for oxygen reduction reaction: A review on degradation mechanisms. Carbon 151, 160-174 (2019).

27. Z. Qiao et al., 3D porous graphitic nanocarbon for enhancing the performance and durability of Pt catalysts: a balance between graphitization and hierarchical porosity. Energy Environ. Sci. 12, 2830-2841 (2019).

28. N. Macauley et al., Carbon Corrosion in PEM Fuel Cells and the Development of Accelerated Stress Tests. J. Electrochem. Soc. 165, F3148-F3160 (2018).

29. N. Giordano et al., Relationship between physicochemical properties and electrooxidation behaviour of carbon materials. Electrochim. Acta 36, 1931-1935 (1991).

30. M. Lefèvre, E. Proietti, F. Jaouen, J.-P. Dodelet, Iron-Based Catalysts with Improved Oxygen Reduction Activity in Polymer Electrolyte Fuel Cells. Science 324, 71-74 (2009).

31. X. Fu et al., Tailoring $\mathrm{FeN}_{4}$ Sites with Edge Enrichment for Boosted Oxygen Reduction Performance in Proton Exchange Membrane Fuel Cell. Carbon 9, 201706758 (2019).

32. C. Zhu et al., Sugar Blowing-Induced Porous Cobalt Phosphide/Nitrogen-Doped Carbon Nanostructures with Enhanced Electrochemical Oxidation Performance toward Water and Other Small Molecules. Small 13, 1700796 (2017).

33. D. Malko, A. Kucernak, T. Lopes, In situ electrochemical quantification of active sites in Fe-N/C non-precious metal catalysts. Nat. Commun. 7, 13285 (2016).

34. S. Liu, Q. Shi, G. Wu, Solving the activity-stability trade-off riddle. Nat. Catal. 4, 6-7 (2021). 
35. M. Lefèvre, J.-P. Dodelet, Fe-based catalysts for the reduction of oxygen in polymer electrolyte membrane fuel cell conditions: determination of the amount of peroxide released during electroreduction and its influence on the stability of the catalysts. Electrochim. Acta 48, 2749-2760 (2003).

36. V. Goellner, V. Armel, A. Zitolo, E. Fonda, F. Jaouen, Degradation by Hydrogen Peroxide of Metal-Nitrogen-Carbon Catalysts for Oxygen Reduction. J. Electrochem. Soc. 162, H403-H414 (2015).

37. T. Mineva et al., Understanding Active Sites in Pyrolyzed Fe-N-C Catalysts for Fuel Cell Cathodes by Bridging Density Functional Theory Calculations and 57Fe Mössbauer Spectroscopy. ACS Catal. 9, 9359-9371 (2019).

38. J. Li et al., Identification of durable and non-durable $\mathrm{FeN} x$ sites in $\mathrm{Fe}-\mathrm{N}-\mathrm{C}$ materials for proton exchange membrane fuel cells. Nat. Catal. 4, 10-19 (2021).

39. S. K. Babu, R. W. Atkinson III, A. B. Papandrew, S. Litster, Vertically Oriented Polymer Electrolyte Nanofiber Catalyst Support for Thin Film Proton-Exchange Membrane Fuel Cell Electrodes. ChemElectroChem 2, 1752-1759 (2015).

40. X. Wan et al., Fe-N-C electrocatalyst with dense active sites and efficient mass transport for high-performance proton exchange membrane fuel cells. Nat. Catal. 2, 259-268 (2019).

41. J. Tian et al., Optimized synthesis of Fe/N/C cathode catalysts for PEM fuel cells: a matter of iron-ligand coordination strength. Angew. Chem. Int. Ed. 52, 6867-6870 (2013).

42. S. Liu et al., Chemical Vapor Deposition for Atomically Dispersed and Nitrogen Coordinated Single Metal Site Catalysts. Angew. Chem. Int. Ed. 59, 21698-21705. (2020).

43. S. T. Thompson et al., ElectroCat: DOE's approach to PGM-free catalyst and electrode R\&D. Solid State Ionics 319, 68-76 (2018). 
44. R. Chenitz et al., A specific demetalation of Fe-N 4 catalytic sites in the micropores of $\mathrm{NC} \_\mathrm{Ar}+\mathrm{NH}_{3}$ is at the origin of the initial activity loss of the highly active $\mathrm{Fe} / \mathrm{N} / \mathrm{C}$ catalyst used for the reduction of oxygen in PEM fuel cells. Energy \& Environmental Science 11, 365382 (2018).

45. J. T. Gostick et al., PoreSpy: A python toolkit for quantitative analysis of porous media images. J. Open Source Software 4, 1296 (2019).

46. X. Yuan, H. Wang, J. Colin Sun, J. Zhang, AC impedance technique in PEM fuel cell diagnosis-A review. Int. J. Hydrogen Energy 32, 4365-4380 (2007).

47. I. Pivac, D. Bezmalinović, F. Barbir, Catalyst degradation diagnostics of proton exchange membrane fuel cells using electrochemical impedance spectroscopy. Int. J. Hydrogen Energy 43, 13512-13520 (2018).

48. Y.-C. Lin, P.-Y. Teng, P.-W. Chiu, K. Suenaga, Exploring the Single Atom Spin State by Electron Spectroscopy. Phys Rev. Lett. 115, 206803 (2015).

49. M. Primbs et al., Establishing reactivity descriptors for platinum group metal (PGM)-free Fe-N-C catalysts for PEM fuel cells. Energy Environ. Sci., (2020).

50. M. Wang, L. Árnadóttir, Z. J. Xu, Z. Feng, In situ X-ray absorption spectroscopy studies of nanoscale electrocatalysts. Nano-Micro Lett. 11, 1-18 (2019).

51. R. D. Leapman, P. L. Fejes, J. Silcox, Orientation dependence of core edges from anisotropic materials determined by inelastic scattering of fast electrons. Phys. Rev. B 28, 2361-2373 (1983).

52. M. Bosman, M. Watanabe, D. T. L. Alexander, V. J. Keast, Mapping chemical and bonding information using multivariate analysis of electron energy-loss spectrum images. Ultramicroscopy 106, 1024-1032 (2006). 
53. J. K. Nørskov et al., Origin of the overpotential for oxygen reduction at a fuel-cell cathode. J. Phys. Chem. B 108, 17886-17892 (2004).

54. C. H. Choi et al., Stability of Fe-N-C Catalysts in Acidic Medium Studied by Operando Spectroscopy. Angew. Chem. Int. Ed. 54, 12753-12757 (2015). 
Supporting Information for

\section{Durable and High-Power Iron-Based Cathodes in Competition with Platinum for Proton- Exchange Membrane Fuel Cells}

Shengwen $\mathrm{Liu}^{1+}$, Chenzhao Li ${ }^{2+, 3}$, Michael J. Zachman ${ }^{4+}$, Haoran $\mathrm{Yu}^{4}$ Yachao Zeng ${ }^{1}$, Boyang Li, ${ }^{5}$ Maoyu Wang ${ }^{6}$, Jonathan Braaten ${ }^{7}$, Jiawei Liu ${ }^{7}$, Harry M. Meyer III ${ }^{8}$, Marcos Lucero ${ }^{5}$, A. Jeremy Kropf $^{9}$, Qing Gong ${ }^{2}$, Qiurong Shi ${ }^{1}$, Zhenxing Feng ${ }^{6}$, Guofeng Wang ${ }^{5}$, Deborah J. Myers ${ }^{9}$ Jian $\mathrm{Xie}^{2, *}$, David A. Cullen ${ }^{4, *}$, Shawn Litster, ${ }^{7, *}$ and Gang $\mathrm{Wu}^{1, *}$

${ }^{1}$ Department of Chemical and Biological Engineering, University at Buffalo, The State University of New York, Buffalo, New York 14260, USA. Email: gangwu@buffalo.edu

${ }^{2}$ Department of Mechanical Engineering, Purdue School of Engineering and Technology, Indiana University-Purdue University, Indianapolis, Indiana 46202, USA. Email: jianxie@iupui.edu

${ }^{3}$ School of Mechanical Engineering, Purdue University, West Lafayette, Indiana 47906, USA

${ }^{4}$ Center for Nanophase Materials Sciences, Oak Ridge National Laboratory, Oak Ridge, TN 37831, USA. Email: cullenda@ornl.gov

${ }^{5}$ Department of Mechanical Engineering and Materials Science, University of Pittsburgh, Pittsburgh, PA, 15261 USA

${ }^{6}$ School of Chemical Biological, and Environmental Engineering Oregon State University Corvallis, OR 97331, USA

${ }^{7}$ Department of Mechanical Engineering, Carnegie Mellon University, Pittsburgh, PA, 15213

USA. Email: $\underline{\text { litster@andrew.cmu.edu }}$

${ }^{8}$ Chemical Sciences Division, Oak Ridge National Laboratory, Oak Ridge, TN 37831, USA

${ }^{9}$ Chemical Sciences and Engineering Division, Argonne National Laboratory, Lemont, IL 60439, United States.

+ These authors contributed equally

This PDF file includes:

Experimental details

Figures S1 to S52

Tables S1 to S17

References 

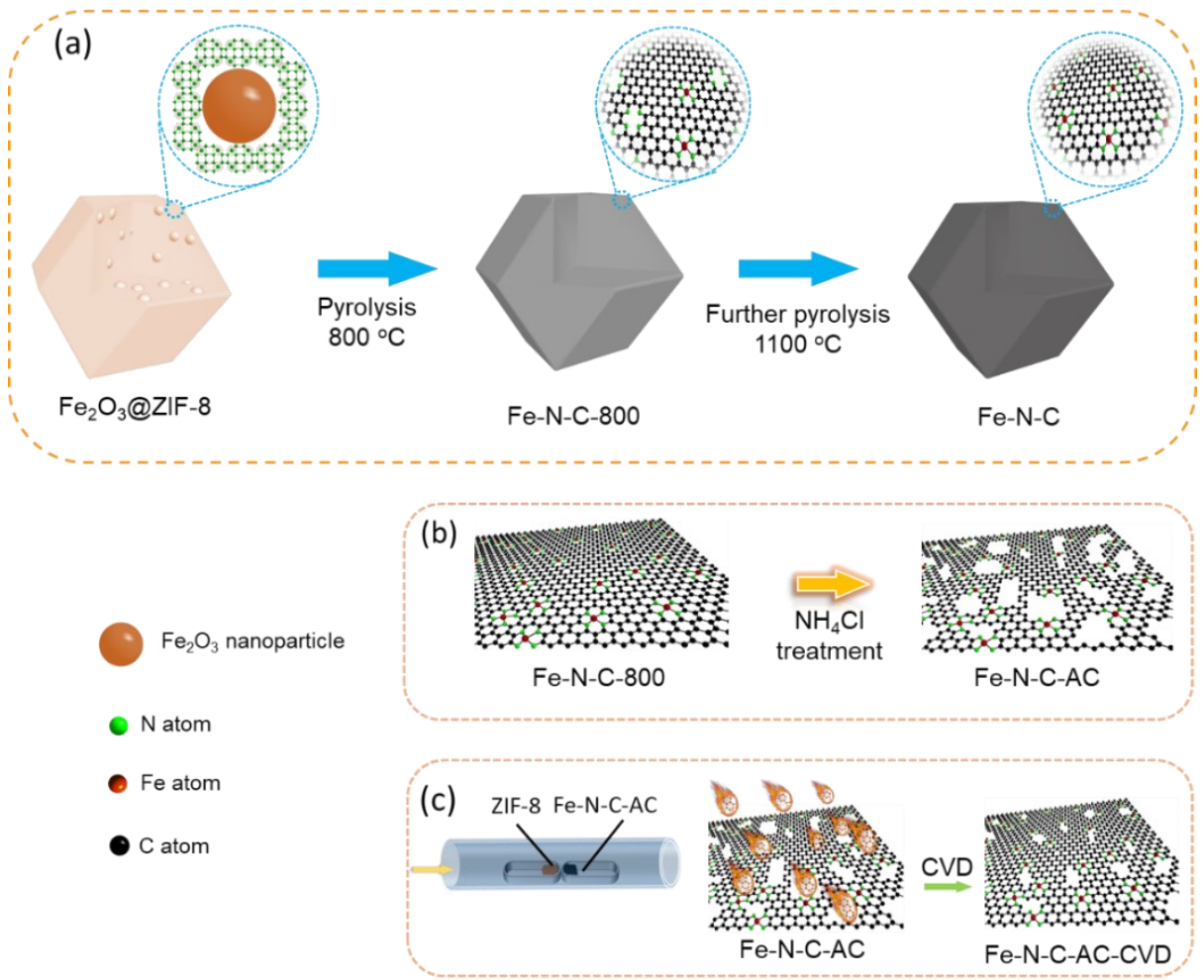

Figure S1. (a) Schematic of synthesis of Fe-N-C catalyst. Engineering of carbon structure of Fe$\mathrm{N}-\mathrm{C}$ catalyst to fabricate (b) Fe-N-C-AC through $\mathrm{NH}_{4} \mathrm{Cl}$ treatment and (c) Fe-N-C-AC-CVD catalyst by CVD method.
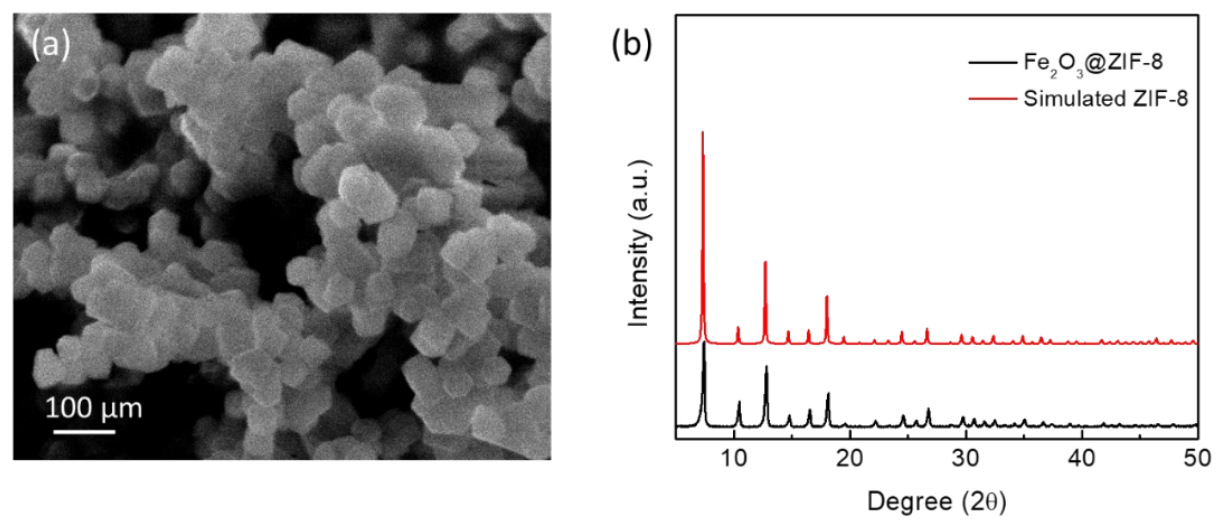

Figure S2. (a) SEM image and (b) XRD pattern of $\mathrm{Fe}_{2} \mathrm{O}_{3} @ Z I F-8$ composite. 

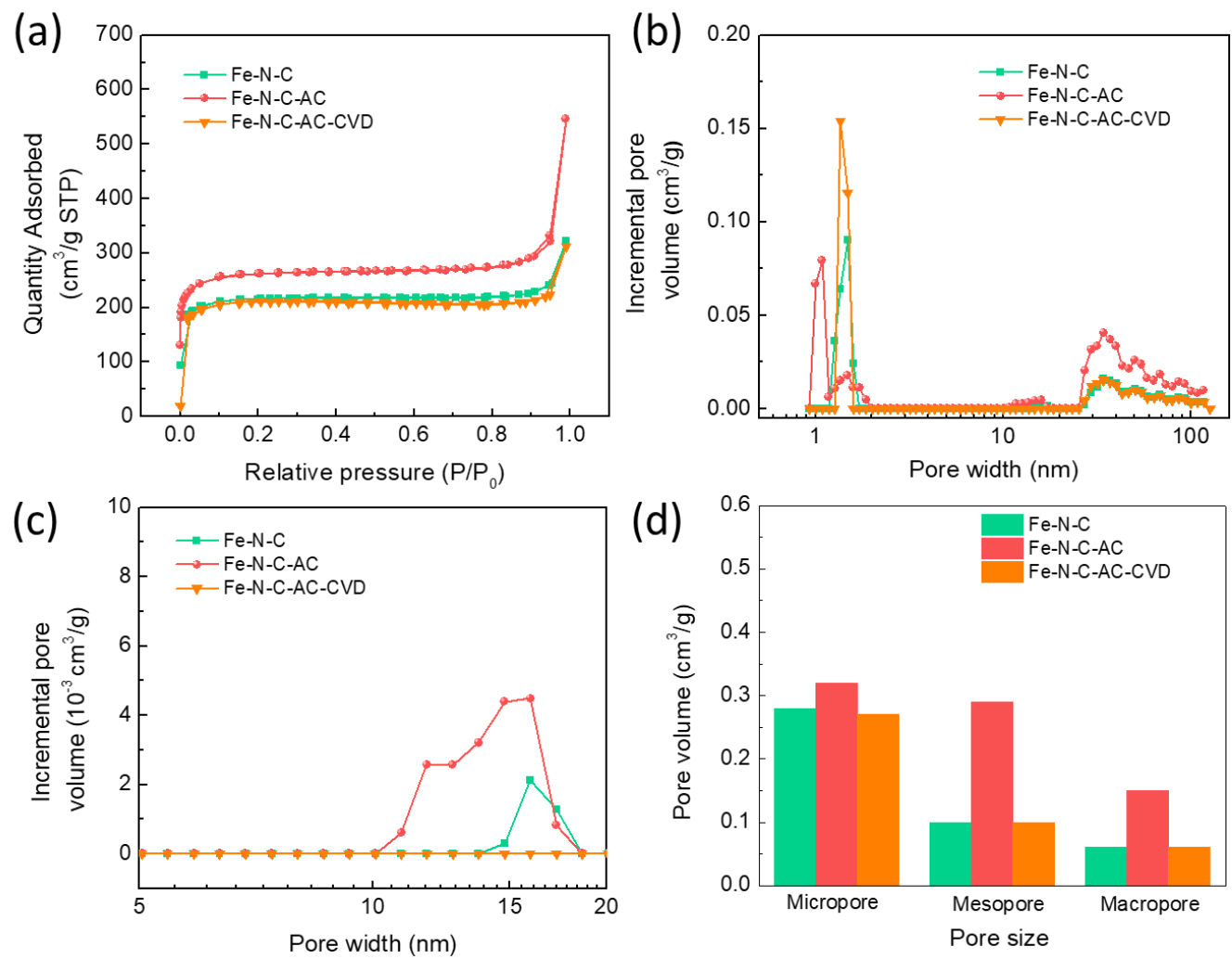

Figure S3. (a) $\mathrm{N}_{2}$ adsorption/desorption and (b, c) pore distribution plots of Fe-N-C, Fe-N-C-AC and Fe-N-C-AC-CVD catalysts, (d) comparison in porosity for the three catalysts. The result shows the $\mathrm{NH}_{4} \mathrm{Cl}$ treatment has the capability of producing abundant carbon defects in Fe-N-C catalysts.

Table S1. Pore distributions and specific surface areas of Fe-N-C, Fe-N-C-AC, and Fe-N-C-ACCVD catalysts.

\begin{tabular}{ccccccccc}
\hline \multirow{2}{*}{ Sample } & \multicolumn{2}{c}{$\mathrm{V}_{\text {micro }}$} & \multicolumn{2}{c}{$\mathrm{V}_{\text {meso }}$} & \multicolumn{2}{c}{$\mathrm{V}_{\text {macro }}$} & $\mathrm{V}_{\text {total }}$ & $\mathrm{S}_{\text {BET }}$ \\
\cline { 2 - 9 } & $\mathrm{cm}^{3} \mathrm{mg}^{-1}$ & $\%$ & $\mathrm{~cm}^{3} \mathrm{mg}^{-1}$ & $\%$ & $\mathrm{~cm}^{3} \mathrm{mg}^{-1}$ & $\%$ & $\mathrm{~cm}^{3} \mathrm{mg}^{-1}$ & $\mathrm{~m}^{2} \mathrm{~g}^{-1}$ \\
\hline Fe-N-C & 0.28 & 63.64 & 0.10 & 22.73 & 0.06 & 13.64 & 0.44 & 684.2 \\
Fe-N-C-AC & 0.32 & 42.11 & 0.29 & 38.16 & 0.15 & 19.74 & 0.76 & 809.1 \\
$\begin{array}{c}\text { Fe-N-C-AC- } \\
\text { CVD }\end{array}$ & 0.27 & 62.79 & 0.10 & 23.26 & 0.06 & 13.95 & 0.43 & 668.6 \\
\hline
\end{tabular}

According to the ICP-OES analysis, the Fe-N-C-AC catalyst has a slightly decreased Fe content compared to the Fe-N-C catalyst without $\mathrm{NH}_{4} \mathrm{Cl}$ treatment. Thus, it is very likely that gaseous $\mathrm{HCl}$ reacts with $\mathrm{Fe}$ aggregates and form $\mathrm{FeCl}_{3}$. Because of its low boiling point, a small portion of $\mathrm{FeCl}_{3}$ would escape from the catalyst, leading to a slightly reduced $\mathrm{Fe}$ content in the $\mathrm{Fe}$ - 
$\mathrm{N}-\mathrm{C}$-AC catalyst (after $\mathrm{NH}_{4} \mathrm{Cl}$ treatment). Reduced $\mathrm{Zn}$ content was also observed in the N-C-AC and $\mathrm{Fe}-\mathrm{N}-\mathrm{C}-\mathrm{AC}$ catalysts, indicating $\mathrm{HCl}$ capable of etching $\mathrm{Zn}$ species.

Table S2. Zn and Fe contents in catalysts determined by ICP-OES (wt.\%)

\begin{tabular}{cccccc}
\hline Samples & Elements & $\begin{array}{c}\text { Content } 1 \\
\text { (wt. \%) }\end{array}$ & $\begin{array}{c}\text { Content 2 } \\
\text { (wt. \%) }\end{array}$ & $\begin{array}{c}\text { Content 3 } \\
\text { (wt. \%) }\end{array}$ & $\begin{array}{c}\text { Average } \\
\text { (wt. \%) }\end{array}$ \\
\hline \multirow{2}{*}{ Fe-N-C } & Fe & 1.91 & 1.88 & 1.87 & 1.89 \\
& $\mathrm{Zn}$ & 0.09 & 0.089 & 0.09 & 0.090 \\
\hline Fe-N-C-AC & $\mathrm{Fe}$ & 1.76 & 1.75 & 1.75 & 1.75 \\
\hline Fe-N-C-AC- & $\mathrm{Zn}$ & 0.055 & 0.054 & 0.054 & 0.054 \\
CVD & $\mathrm{Zn}$ & 0.050 & 0.049 & 0.049 & 0.049 \\
\hline N-C & $\mathrm{Zn}$ & 0.77 & 0.77 & 0.76 & 0.77 \\
N-C-AC & $\mathrm{Zn}$ & 0.5802 & 0.58 & 0.58 & 0.58 \\
\hline
\end{tabular}

${ }^{\mathrm{a}}$ Nitrogen-doped carbon (N-C) derived from direct pyrolysis of ZIF-8 at $1100{ }^{\circ} \mathrm{C}$ for one hour under Ar flow.

${ }^{\mathrm{b}}$ Similar to Fe-N-C-AC synthesis process, N-C-800 obtained from pyrolysis of $300 \mathrm{mg}$ ZIF-8 at $800{ }^{\circ} \mathrm{C}$ for one hour under Ar flow, then $100 \mathrm{mg} \mathrm{N}-\mathrm{C}-800$ mixed with $300 \mathrm{mg} \mathrm{NH} 4 \mathrm{Cl}$ to take the second pyrolysis at $1100^{\circ} \mathrm{C}$ under Ar flow for one hour to obtain N-C-AC.
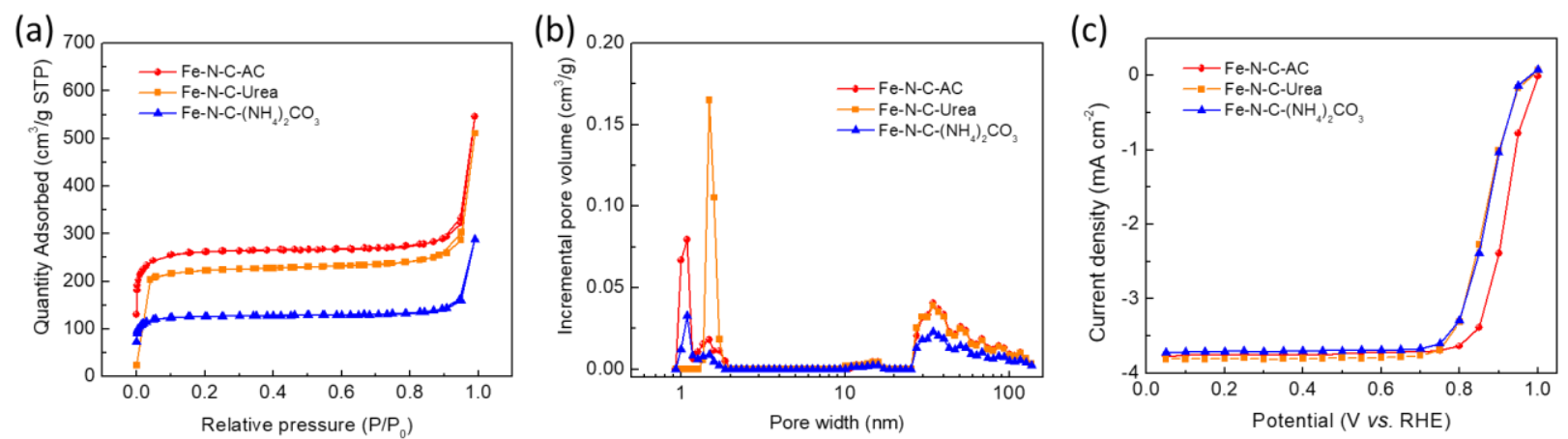

Figure S4. (a) $\mathrm{N}_{2}$ adsorption/desorption and (b) pore distribution plots of Fe-N-C-AC, Fe-N-CUrea, and Fe-N-C-( $\left.\mathrm{NH}_{4}\right)_{2} \mathrm{CO}_{3}$ catalysts. (c) Steady-state ORR polarization plots of Fe-N-C-AC, $\mathrm{Fe}-\mathrm{N}-\mathrm{C}-\mathrm{Urea}$, and Fe-N-C-(NH$)_{2} \mathrm{CO}_{3}$ catalysts in $\mathrm{O}_{2}$-saturated $0.5 \mathrm{M} \mathrm{H}_{2} \mathrm{SO}_{4}$. 
Table S3. Pore distributions and specific surface areas of Fe-N-C-AC, Fe-N-C-Urea, and Fe-N$\mathrm{C}-\left(\mathrm{NH}_{4}\right)_{2} \mathrm{CO}_{3}$ catalysts.

\begin{tabular}{cccccccccc}
\hline \multirow{2}{*}{ Sample } & \multicolumn{2}{c}{$V_{\text {micro }}$} & \multicolumn{2}{c}{$V_{\text {meso }}$} & \multicolumn{2}{c}{$V_{\text {macro }}$} & $V_{\text {total }}$ & $S_{\text {BET }}$ \\
\cline { 2 - 9 } & $\mathrm{cm}^{3} \mathrm{mg}^{-1}$ & $\%$ & $\mathrm{~cm}^{3} \mathrm{mg}^{-1}$ & $\%$ & $\mathrm{~cm}^{3} \mathrm{mg}^{-1}$ & $\%$ & $\mathrm{~cm}^{3} \mathrm{mg}^{-1}$ & $\mathrm{~m}^{2} \mathrm{~g}^{-1}$ \\
\hline Fe-N-C-AC & 0.32 & 42.11 & 0.29 & 38.16 & 0.15 & 19.74 & 0.76 & 809.1 \\
Fe-N-C-Urea & 0.29 & 40.28 & 0.29 & 40.28 & 0.14 & 19.44 & 0.72 & 706.3 \\
Fe-N-C- & 0.15 & 37.5 & 0.17 & 42.5 & 0.08 & 20 & 0.40 & 408.2 \\
$(\mathrm{NH})_{2} \mathrm{CO}_{3}$ & & & & & & & &
\end{tabular}

FeNC-800 was treated with urea, $\left(\mathrm{NH}_{4}\right)_{2} \mathrm{CO}_{3}$, and $\mathrm{NH}_{4} \mathrm{Cl}$, respectively, to further investigate the role of $\mathrm{HCl}$ during the $\mathrm{NH}_{4} \mathrm{Cl}$ treatment process. BET-specific surface areas and ORR activities of the derived Fe-N-C-AC, Fe-N-C-Urea, and Fe-N-C-( $\left.\mathrm{NH}_{4}\right)_{2} \mathrm{CO}_{3}$ catalysts were recorded. Compared to Fe-N-C-Urea and Fe-N-C- $\left(\mathrm{NH}_{4}\right)_{2} \mathrm{CO}_{3}$ catalysts, the Fe-N-C-AC catalyst has a higher specific surface area indicating a portion of carbon atoms etched by gaseous $\mathrm{HCl}$. Moreover, $\mathrm{Fe}-$ $\mathrm{N}-\mathrm{C}-\mathrm{AC}$ catalyst indeed shows improved ORR activity, suggesting that the gaseous $\mathrm{HCl}$ and $\mathrm{NH} 3$ contribute to its ORR activity improvement.

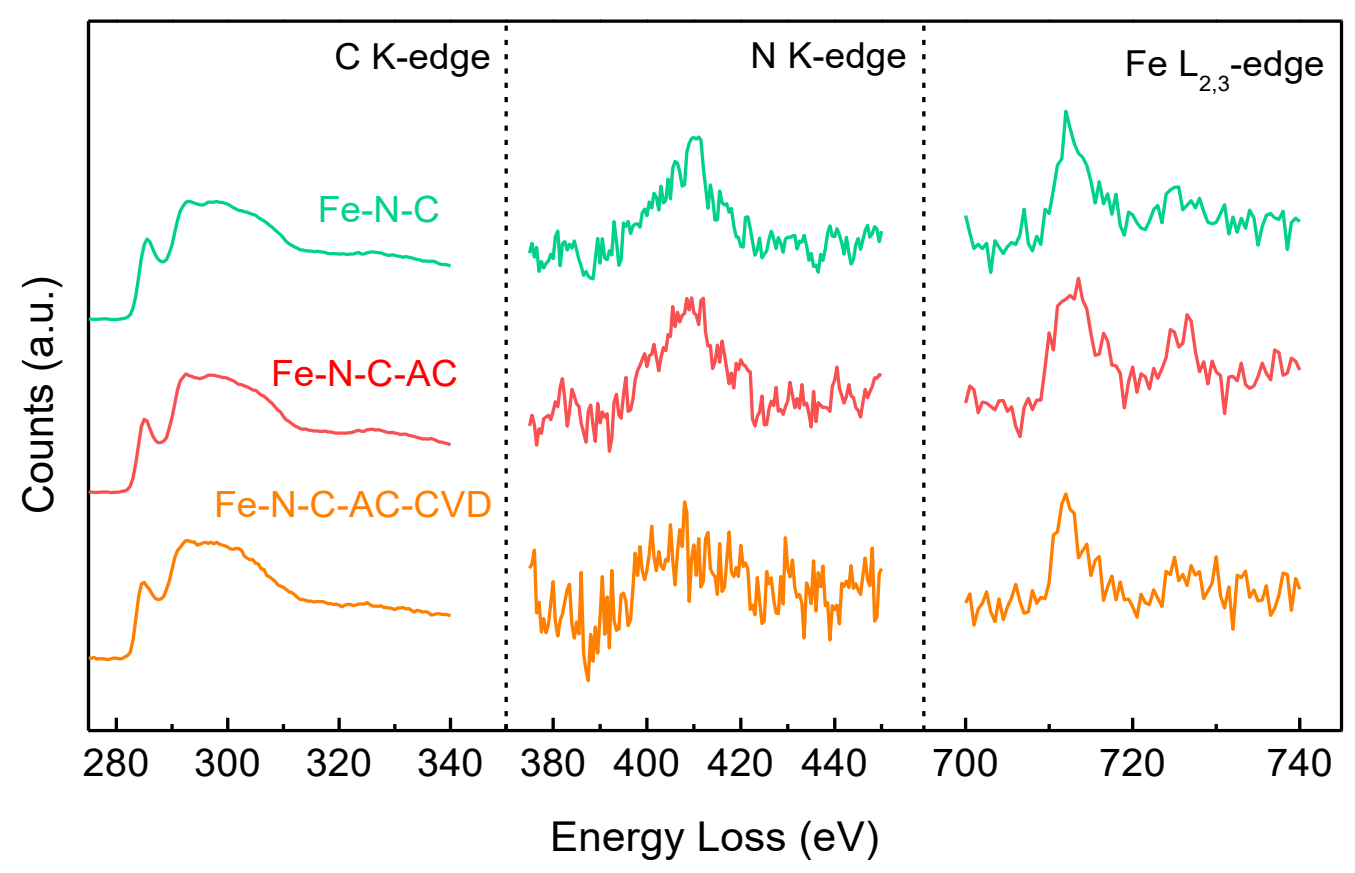

Figure S5. Average EEL point spectra from multiple individual atomic Fe sites, such as those circled in Fig. 1b, providing evidence for Fe-N coordination in the catalysts. 
Table S4. Surface compositions of three typical Fe-N-C, Fe-N-C-AC, and Fe-N-C-AC-CVD catalysts by using XPS.

\begin{tabular}{lcccccc}
\hline \multirow{2}{*}{ Sample } & \multicolumn{5}{c}{ Surface composition } \\
\cline { 2 - 7 } & C(at.\%) & O(at.\%) & N(at.\%) & Fe(at.\%) & Zn(at.\%) & D-parameter \\
\hline Fe-N-C_a & 88.1 & 8.2 & 3.1 & 0.14 & 0.07 & $17.78 \mathrm{eV}$ \\
Fe-N-C_b & 87.8 & 8.7 & 2.9 & 0.11 & 0.07 & $16.60 \mathrm{eV}$ \\
Fe-N-C_c & 87.8 & 8.5 & 3.1 & 0.10 & 0.07 & $17.37 \mathrm{eV}$ \\
Average & $\mathbf{8 8 . 3}$ & $\mathbf{8 . 5}$ & $\mathbf{3 . 0}$ & $\mathbf{0 . 1 2}$ & $\mathbf{0 . 0 7}$ & $\mathbf{1 7 . 2 5} \mathbf{~ e V}$ \\
\hline Fe-N-C-AC_a & 89.1 & 8.1 & 2.3 & 0.10 & 0.01 & $17.53 \mathrm{eV}$ \\
Fe-N-C-AC_b & 88.9 & 8.2 & 2.4 & 0.10 & 0.01 & $16.34 \mathrm{eV}$ \\
Fe-N-C-AC_c & 89.1 & 8.1 & 2.4 & 0.07 & 0.01 & $18.33 \mathrm{eV}$ \\
Average & $\mathbf{8 9 . 4}$ & $\mathbf{8 . 1}$ & $\mathbf{2 . 4}$ & $\mathbf{0 . 0 9}$ & $\mathbf{0 . 0 1}$ & $\mathbf{1 7 . 4 0} \mathbf{e V}$ \\
\hline Fe-N-C-AC-CVD_a & 88.9 & 7.8 & 2.6 & 0.14 & 0.01 & $18.59 \mathrm{eV}$ \\
Fe-N-C-AC-CVD_b & 88.7 & 7.9 & 2.7 & 0.13 & 0.01 & $19.07 \mathrm{eV}$ \\
Fe-N-C-AC-CVD_c & 88.6 & 8.6 & 2.2 & 0.10 & 0.01 & $17.69 \mathrm{eV}$ \\
Average & $\mathbf{8 9 . 2}$ & $\mathbf{8 . 1}$ & $\mathbf{2 . 5}$ & $\mathbf{0 . 1 2}$ & $\mathbf{0 . 0 1}$ & $\mathbf{1 8 . 4 5} \mathbf{~ e V}$ \\
\hline
\end{tabular}

Table S5. Elemental quantification of three typical Fe-N-C, Fe-N-C-AC, and Fe-N-C-AC-CVD catalysts by STEM-EDS.

\begin{tabular}{lccccc}
\hline Sample & $\mathrm{C}($ at.\%) & $\mathrm{N}($ at.\%) & $\mathrm{O}($ at.\%) & $\mathrm{Fe}($ at.\%) & $\mathrm{Zn}($ at.\%) \\
\hline Fe-N-C & 95.86 & 2.06 & 1.87 & 0.12 & 0.09 \\
Fe-N-C-AC & 94.73 & 3.37 & 1.83 & 0.06 & 0.01 \\
Fe-N-C-AC-CVD & 96.24 & 2.00 & 1.61 & 0.15 & 0.01 \\
\hline
\end{tabular}


(a)

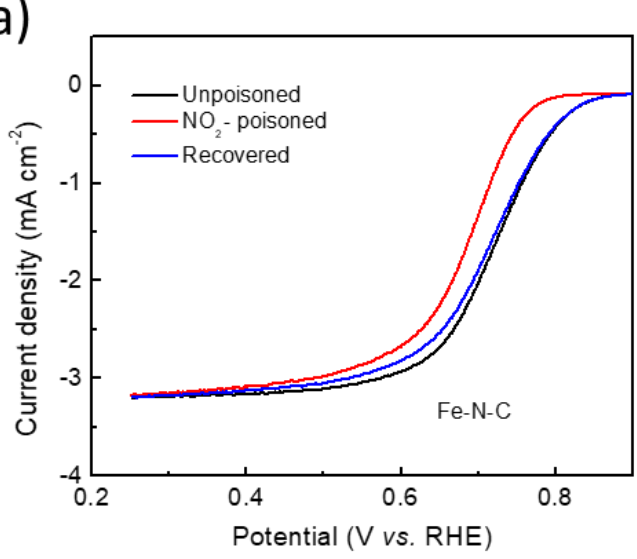

(c)

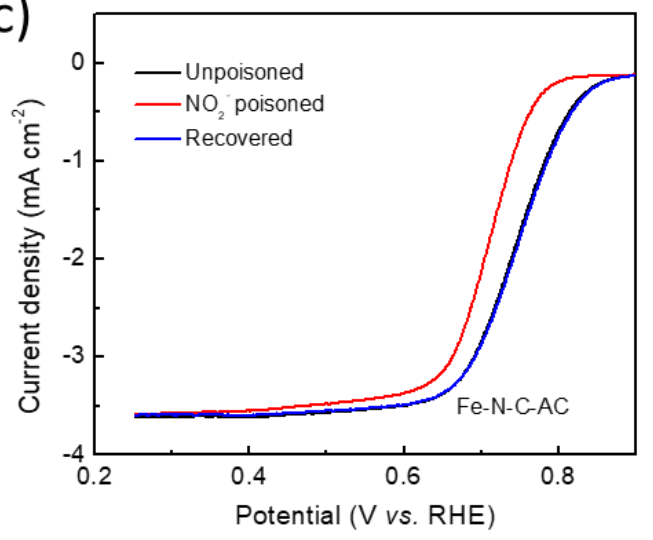

(e)

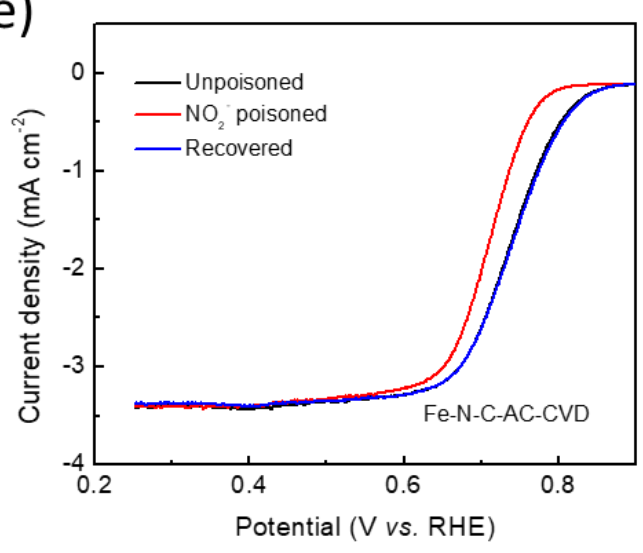

(b)

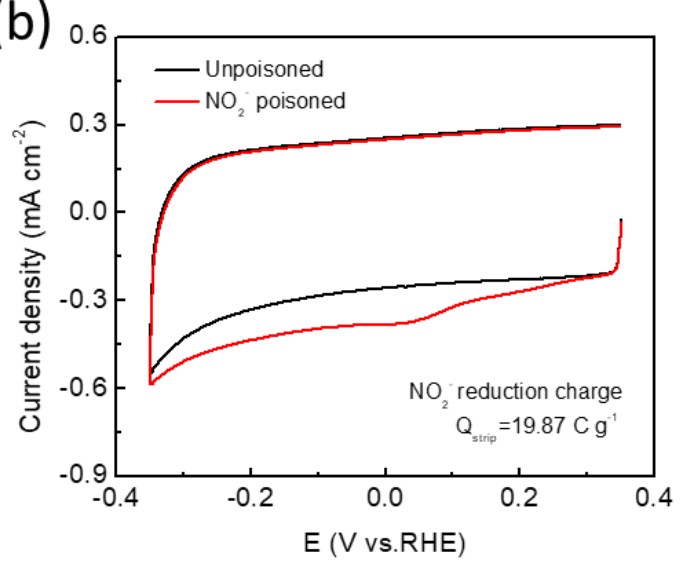

(d)

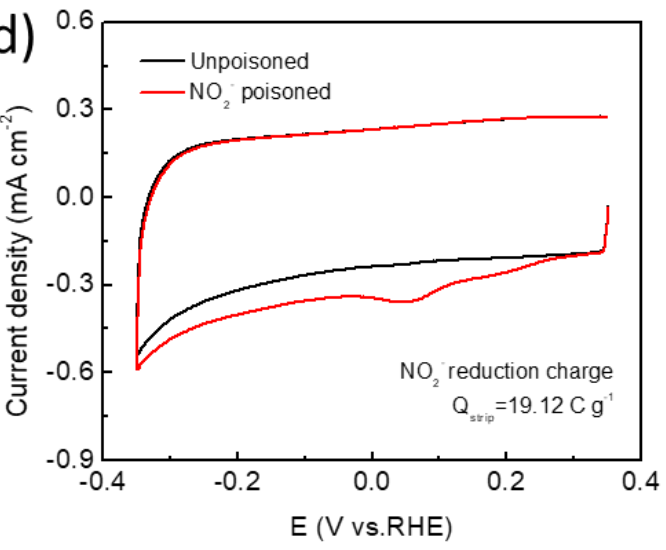

(f)

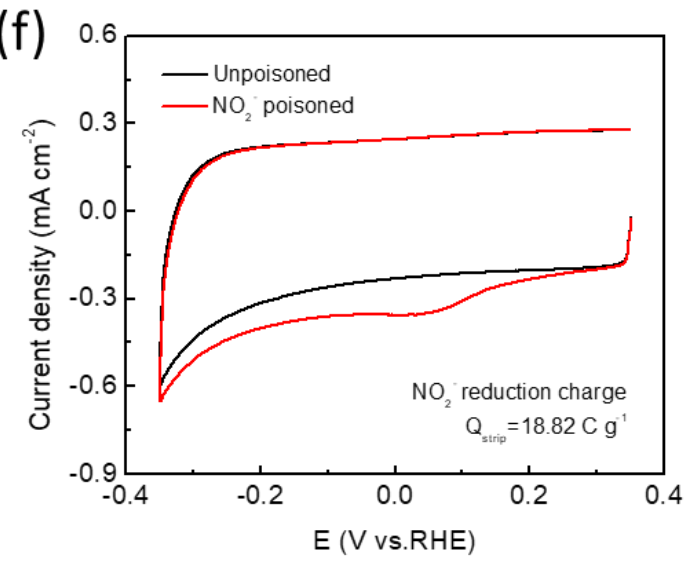

Figure S6. Determination of $\mathrm{FeN}_{4}$ site densities of Fe-N-C, Fe-N-C-AC, and Fe-N-C-AC-CVD catalysts through reversible nitrite poisoning. Left column, LSV curves before, during, and after nitrite adsorption in a $0.5 \mathrm{M}$ acetate buffer at $\mathrm{pH} 5.2$ for (a) Fe-N-C, (c) Fe-N-C-AC, and (e) Fe$\mathrm{N}-\mathrm{C}-\mathrm{AC}-\mathrm{CVD}$ catalysts. Right column, $\mathrm{CV}$ curves before and during nitrite adsorption in the nitrite reductive stripping region for (b) Fe-N-C, (d) Fe-N-C-AC, and (f) Fe-N-C-AC-CVD catalysts. Catalyst loading, $0.27 \mathrm{mg} \mathrm{cm}^{-2}$. 

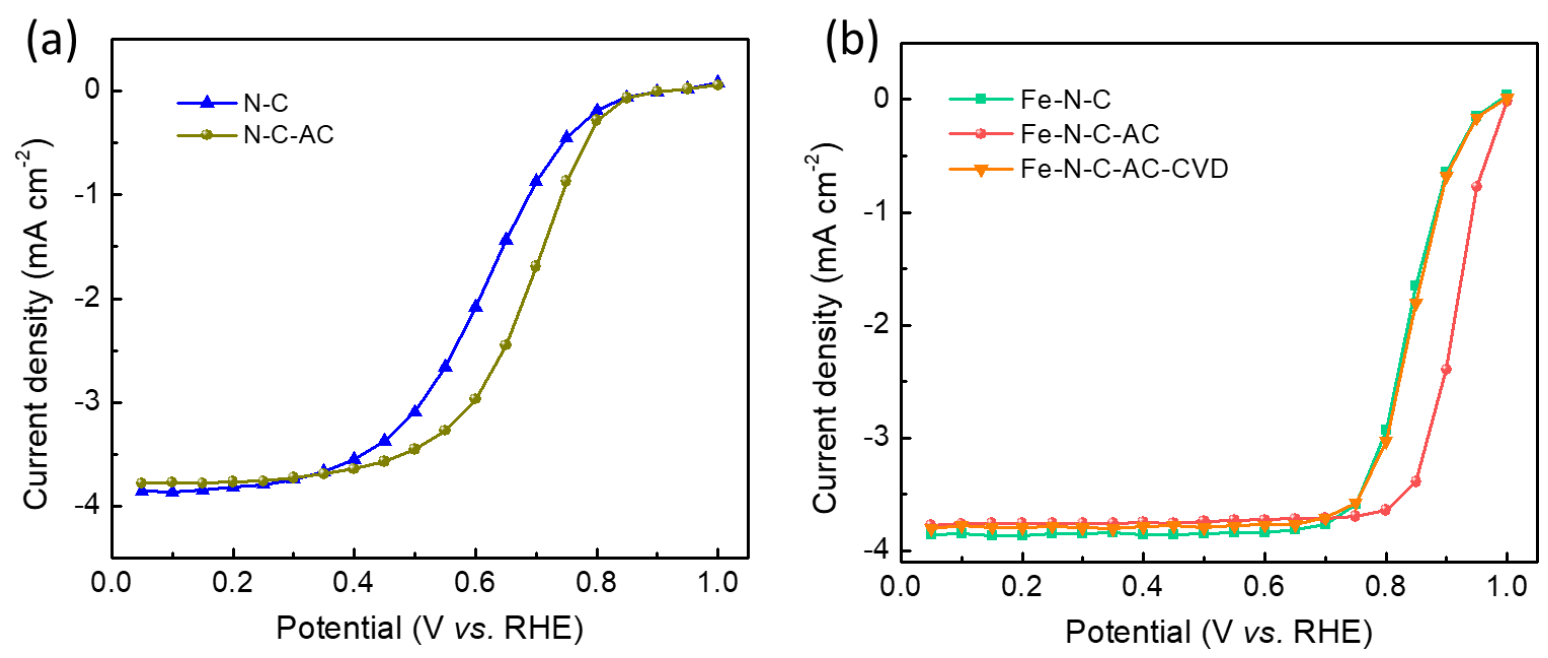

Figure S7. Steady-state ORR polarization plots of (a) N-C, N-C-AC, and (b) Fe-N-C, Fe-N-C-AC, $\mathrm{Fe}-\mathrm{N}-\mathrm{C}$-AC-CVD catalysts were tested in $\mathrm{O}_{2}$-saturated $0.5 \mathrm{M} \mathrm{H}_{2} \mathrm{SO}_{4}$. Low ORR activities of N-C and N-C-AC catalyst shows neglectable ORR activity of atomically dispersed $\mathrm{Zn}$ atoms in nitrogen-doped carbon. Compared to three Fe-based catalysts, the $\mathrm{N}-\mathrm{C}$ catalyst directly pyrolyzed from ZIF-8 presented a relatively high $\mathrm{Zn}$ content (Table S2). However, its low ORR activity $\left(\mathrm{E}_{1 / 2}=0.61 \mathrm{~V}\right)$ in acidic media is the same as nitrogen-doped carbon $(16,17)$, indicating neglectable ORR activity of $\mathrm{Zn}$ species. Furthermore, we carried out the $\mathrm{NH}_{4} \mathrm{Cl}$ treatment for the $\mathrm{Zn}$-rich N-C sample (i.e., N-C-AC catalyst). Its Zn content was significantly reduced but exhibited increased ORR activity. This control experiment pointed out that $\mathrm{Zn}$ species don't directly act as active sites and its impact on the ORR is adverse. On the contrary, highly active Fe-N-C catalysts often contain extremely low $\mathrm{Zn}$ content. Especially, After $\mathrm{NH}_{4} \mathrm{Cl}$ treatment, Fe-N-C-AC catalyst with further reduced $\mathrm{Zn}$ content generated superior ORR activity $\left(\mathrm{E}_{1 / 2}=0.915 \mathrm{~V}\right)$. Besides, our DFT studies also predict that the possible $\mathrm{ZnN}_{4}$ sites are not capable of adsorbing $\mathrm{O}_{2}$ and breaking its $\mathrm{O}-\mathrm{O}$ bond for desirable 4electron pathway. The significantly improved ORR activity observed with the Fe$\mathrm{N}-\mathrm{C}$-AC catalyst after $\mathrm{NH}_{4} \mathrm{Cl}$ treatment is not due to $\mathrm{Zn}$ species. In turn, reducing $\mathrm{Zn}$ content in catalysts would provide more defects and $\mathrm{N}$ dopants to stabilize increased single Fe active sites. 
Table S6. Summary of previously reported Fe-N-C catalysts.

\begin{tabular}{|c|c|c|c|c|c|c|}
\hline \multirow[b]{2}{*}{ Catalyst } & \multirow[b]{2}{*}{$\begin{array}{c}\text { Pyrolysi } \\
\text { s } \\
\text { temperat } \\
\text { ure } \\
\left({ }^{\circ} \mathrm{C}\right)\end{array}$} & \multirow[b]{2}{*}{$\begin{array}{c}\text { Half- } \\
\text { wave } \\
\text { potential } \\
\text { /V vs. } \\
\text { (RHE) }\end{array}$} & \multirow[b]{2}{*}{$\begin{array}{l}\text { Electrolyte } \\
\text { disk rotation } \\
\text { rate/rpm }\end{array}$} & \multicolumn{2}{|c|}{ Fuel cell performance } & \multirow[b]{2}{*}{ Ref. } \\
\hline & & & & $\begin{array}{c}\text { Current } \\
\text { density } \\
@ 0.9 \mathrm{~V} \\
/ \mathrm{mA} \mathrm{H}_{2}-\mathrm{O}_{2}\end{array}$ & $\begin{array}{c}\text { Current } \\
\text { density } \\
@ 0.8 \mathrm{~V} \\
/ \mathrm{mA} \mathrm{H}_{2}- \\
\text { air }\end{array}$ & \\
\hline Fe-N-C-AC & $\begin{array}{c}800 / 110 \\
0\end{array}$ & 0.915 & $\begin{array}{c}0.5 \mathrm{M} \mathrm{H}_{2} \mathrm{SO}_{4} \\
900\end{array}$ & 42.6 & 151 & $\begin{array}{l}\text { This } \\
\text { work }\end{array}$ \\
\hline $\begin{array}{c}0.17 \mathrm{CVD} / \mathrm{Fe}-\mathrm{N}- \\
\mathrm{C}-k a t\end{array}$ & 1000 & 0.835 & $\begin{array}{c}0.5 \mathrm{M} \mathrm{H}_{2} \mathrm{SO}_{4} \\
900\end{array}$ & 27 & 105 & (18) \\
\hline $\begin{array}{c}(\mathrm{CM}+\mathrm{PANI}) \\
\mathrm{Fe}-\mathrm{C}\end{array}$ & 900 & 0.80 & $\begin{array}{c}0.5 \mathrm{M} \mathrm{H}_{2} \mathrm{SO}_{4} \\
900\end{array}$ & 16 & 75 & (19) \\
\hline $\mathrm{Zn}(\mathrm{eIm})_{2} \mathrm{TPIP}$ & 900 & 0.78 & $\begin{array}{c}0.1 \mathrm{M} \mathrm{HClO}_{4} \\
1600\end{array}$ & - & - & $(20)$ \\
\hline $\begin{array}{c}\text { Fe-PAN-EN } \\
\text { hydrogel }\end{array}$ & 900 & 0.83 & $\begin{array}{c}0.5 \mathrm{M} \mathrm{H}_{2} \mathrm{SO}_{4} \\
900\end{array}$ & - & - & (16) \\
\hline $1.5 \mathrm{Fe}-\mathrm{ZIF}$ & 1100 & 0.88 & $\begin{array}{c}0.5 \mathrm{M} \mathrm{H}_{2} \mathrm{SO}_{4} \\
900\end{array}$ & 18 & 68 & $(21)$ \\
\hline $\begin{array}{c}\mathrm{TPI} @ \mathrm{Z} 8\left(\mathrm{SiO}_{2}\right)- \\
650-\mathrm{C}\end{array}$ & $\begin{array}{c}650 / 100 \\
0\end{array}$ & 0.823 & $\begin{array}{c}0.5 \mathrm{M} \mathrm{H}_{2} \mathrm{SO}_{4} \\
1600\end{array}$ & 22 & 105 & $(22)$ \\
\hline $\mathrm{Fe} / \mathrm{TPTZ} / \mathrm{ZIF}-8$ & - & - & - & 4 & 96 & (23) \\
\hline $\begin{array}{c}\text { ZIF-NC-0.5Fe- } \\
700\end{array}$ & $\begin{array}{c}1100 / 70 \\
0\end{array}$ & 0.84 & $\begin{array}{c}0.5 \mathrm{M} \mathrm{H}_{2} \mathrm{SO}_{4} \\
900\end{array}$ & 30 & 78 & $(24)$ \\
\hline $\mathrm{FeN}_{\mathrm{x}} / \mathrm{Gp}$ & 900 & 0.80 & $\begin{array}{c}0.5 \mathrm{M} \mathrm{H}_{2} \mathrm{SO}_{4} \\
900\end{array}$ & 13 & 70 & $(25)$ \\
\hline $\mathrm{FeCl}_{2}-\mathrm{NC}-1000$ & 1000 & 0.80 & $\begin{array}{c}0.1 \mathrm{M} \mathrm{HClO}_{4} \\
1600\end{array}$ & 15 & 37 & $(26)$ \\
\hline
\end{tabular}




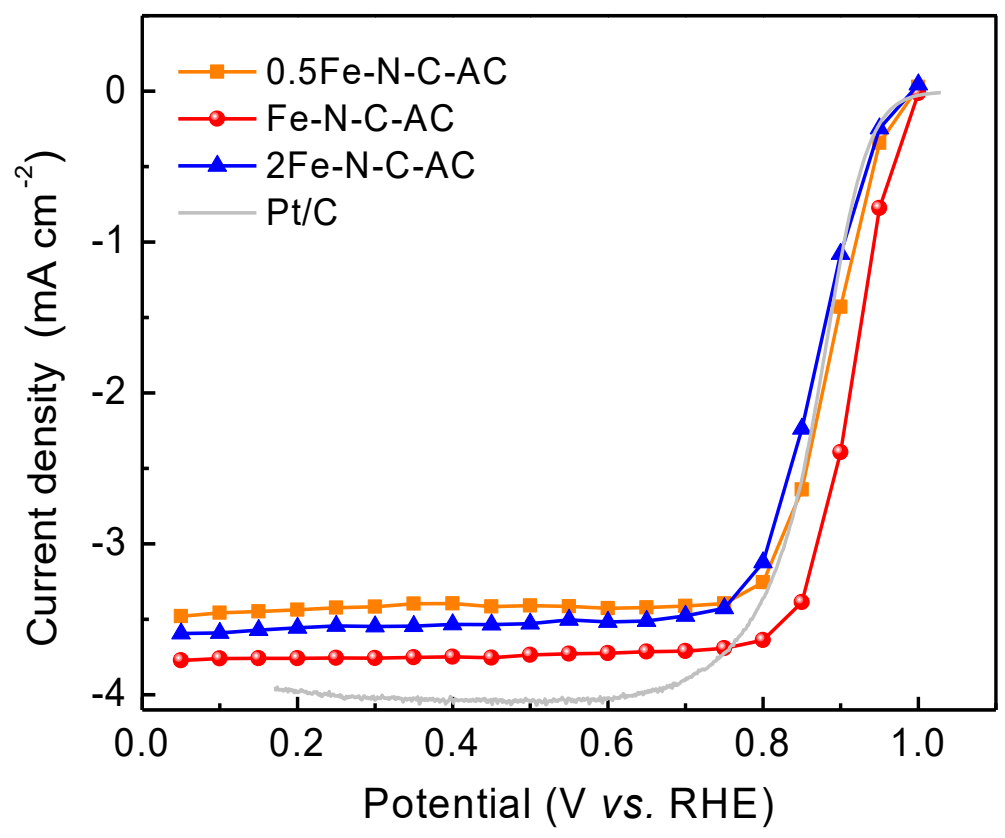

Figure S8. Steady-state ORR polarization plots of $0.5 \mathrm{Fe}-\mathrm{N}-\mathrm{C}-\mathrm{AC}, \mathrm{Fe}-\mathrm{N}-\mathrm{C}-\mathrm{AC}, 2 \mathrm{Fe}-\mathrm{N}-\mathrm{C}-\mathrm{AC}$, and $\mathrm{Pt} / \mathrm{C}\left(60 \mu \mathrm{g}_{\mathrm{Pt}} \mathrm{cm}^{-2}\right)$ catalysts in $\mathrm{O}_{2}$-saturated $0.5 \mathrm{M} \mathrm{H}_{2} \mathrm{SO}_{4} .0 .5 \mathrm{Fe}-\mathrm{N}-\mathrm{C}-\mathrm{AC}, \mathrm{Fe}-\mathrm{N}-\mathrm{C}-\mathrm{AC}$, and $2 \mathrm{Fe}-$ $\mathrm{N}-\mathrm{C}$-AC catalysts were prepared from $\mathrm{Fe}_{2} \mathrm{O}_{3} @ \mathrm{ZIF}-8$ precursor with $\mathrm{Fe}_{2} \mathrm{O}_{3}$ content from 5, 10, and $20 \mathrm{mg}$, respectively.
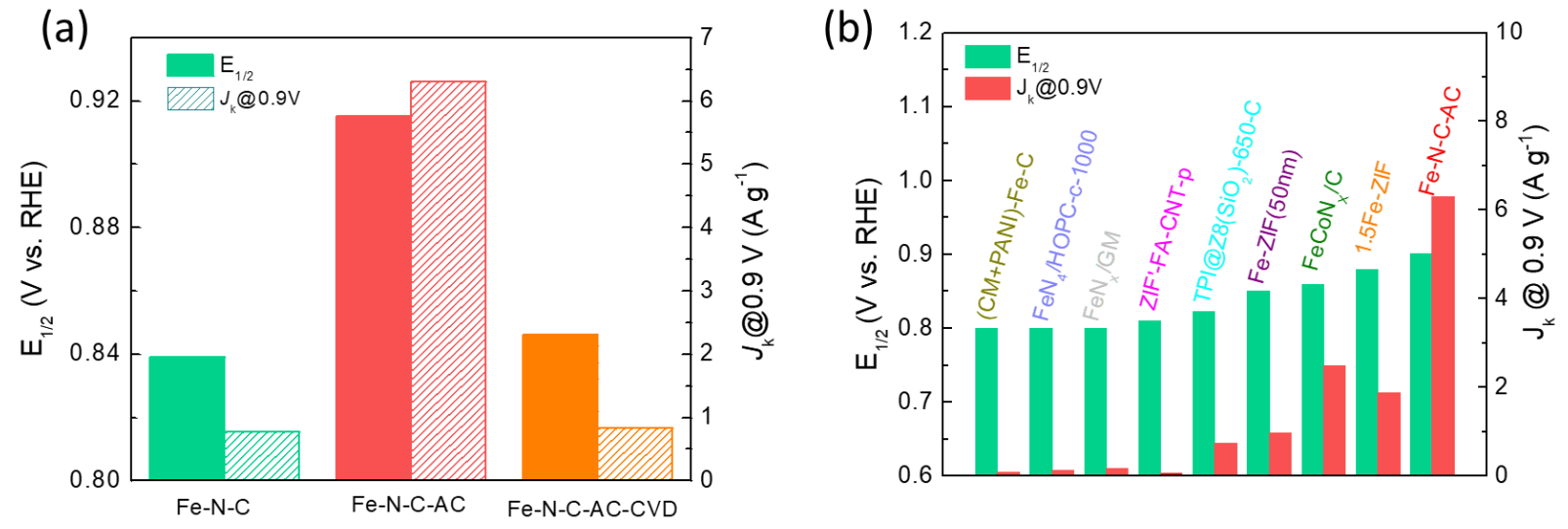

Figure S9. (a) Comparison of the $\mathrm{E}_{1 / 2}$ and kinetic current densities at $0.9 \mathrm{~V} v$. RHE of Fe-N-C, Fe-N-C-AC, and Fe-N-C-AC-CVD catalysts. (b) Comparison of kinetic current densities at $0.9 \mathrm{~V}$ vs. RHE of Fe-N-C-AC catalyst and the reported (CM+PANI)-Fe-C,(19) FeN $4 / \mathrm{HOPC}-\mathrm{c}-1000,(27)$ $\mathrm{FeN}_{x} / \mathrm{GM},(25)$ ZIF'-FA-CNT-p,(28) TPI@Z8SiO $2-650-\mathrm{C},(22) \mathrm{Fe}-\mathrm{ZIF}(50 \mathrm{~nm}),(29) \mathrm{FeCoN}_{x} / \mathrm{C}(30)$ and $1.5 \mathrm{Fe}-\mathrm{ZIF}(21)$ catalysts. 

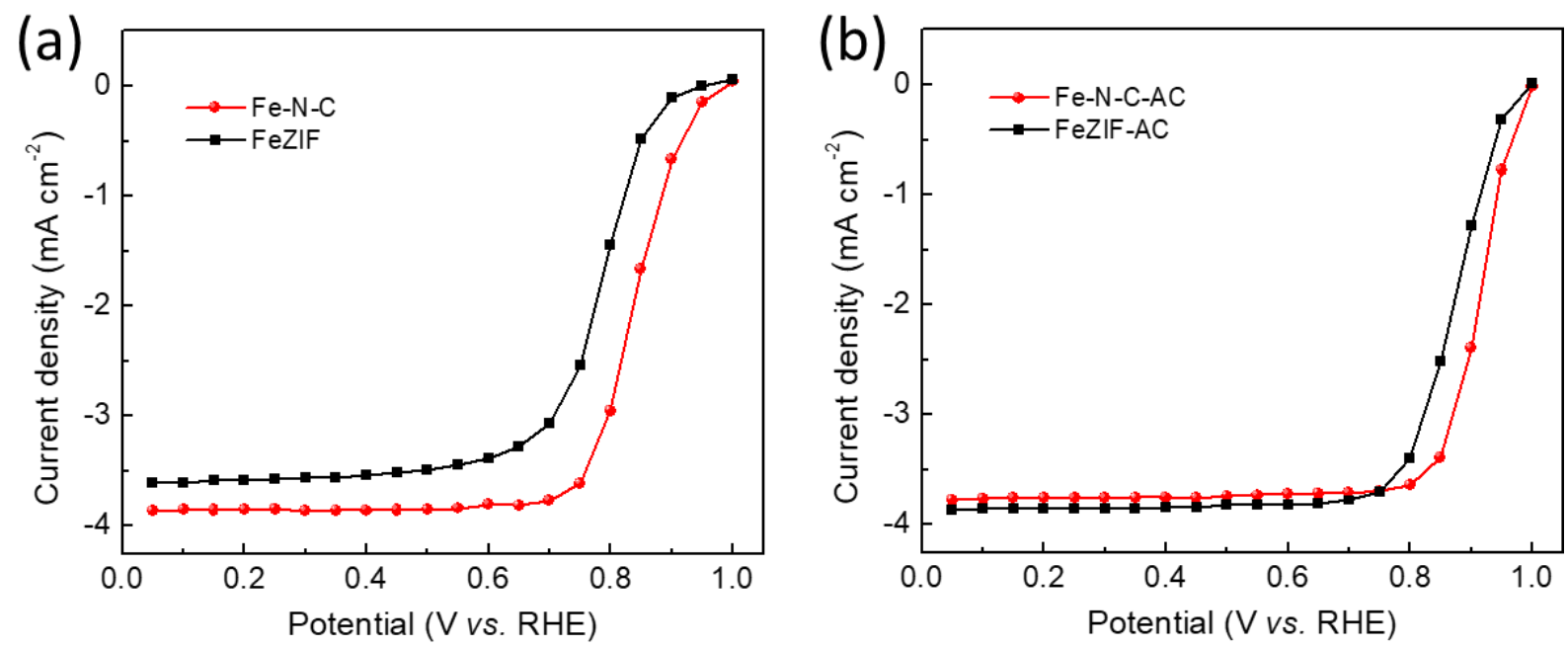

Figure S10. (a-b) Steady-state ORR polarization plots of Fe-N-C and Fe-N-C-AC catalysts prepared from $\mathrm{Fe}_{2} \mathrm{O}_{3}$ as an iron source, while FeZIF and FeZIF-AC catalysts fabricated from $\mathrm{Fe}^{3+}$ as an iron source. FeZIF was fabricated by the first pyrolysis of the Fe doped ZIF-8 (21) at $800{ }^{\circ} \mathrm{C}$ for one hour and the second pyrolysis at $1100{ }^{\circ} \mathrm{C}$ for another one hour under Ar gas. For the synthesis of FeZIF-AC, Fe-doped ZIF-8 precursors were first pyrolyzed at $800{ }^{\circ} \mathrm{C}$ for one hour under $\mathrm{Ar}$ gas to obtain FeZIF-800, then $100 \mathrm{mg}$ FeZIF-800 was ground with $300 \mathrm{mg} \mathrm{NH} \mathrm{NH}_{4}$ powder, after the second pyrolysis process at $1100{ }^{\circ} \mathrm{C}$ under Ar flow for $1 \mathrm{~h}$, the FeZIF-AC catalyst was obtained.

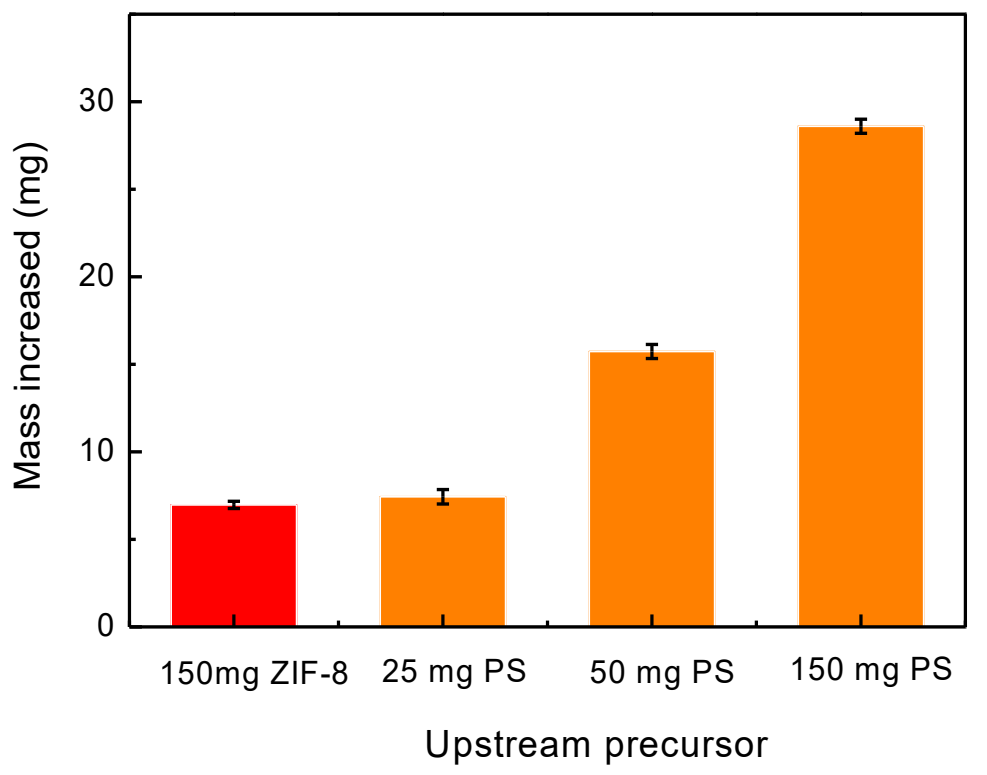

Figure S11. Mass variation of Fe-N-C-AC-CVD catalysts after CVD process. $150 \mathrm{mg}$ ZIF-8, 25, 50 , and $150 \mathrm{mg}$ PS represents $150 \mathrm{mg}$ ZIF-8, 25, 50, and $150 \mathrm{mg}$ polystyrene used as upstream precursor for the CVD process, respectively. 

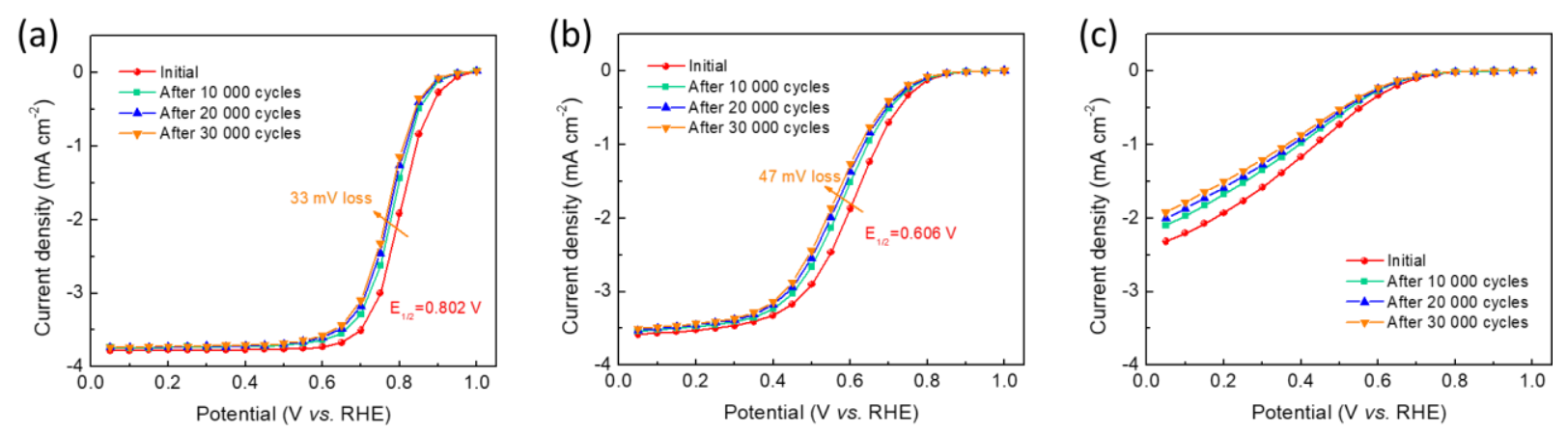

Figure S12. Stability accelerated stress test (AST) by cycling the potential (0.6-1.0 V, 30000 cycles) in $\mathrm{O}_{2}$-saturated $0.5 \mathrm{M} \mathrm{H}_{2} \mathrm{SO}_{4}$ for (a) Fe-N-C-AC-CVD(25PS), (b) Fe-N-C-AC-CVD(50PS), and (c) Fe-N-C-AC-CVD(150PS) catalysts. The ORR activities and stabilities of Fe-N-C-AC$\mathrm{CVD}(\mathrm{ZIF})$ and Fe-N-C-AC-CVD(PS) were examined to try to explore the effect of the presence of $\mathrm{N}$ atoms in the healed carbon structure of Fe-N-C-AC-CVD. We find that $150 \mathrm{mg} \mathrm{ZIF}-8$ and 25 mg PS precursors lead to the formed Fe-N-C-AC-CVD(150ZIF) and Fe-N-C-AC-CVD(25PS) catalysts with comparable mass (Table S7). Compared to Fe-N-C-AC catalyst without CVD process exhibits $124 \mathrm{mV}$ loss in half-wave potential ( $\left.\mathrm{E}_{1 / 2}\right)$ after 30000 AST cycles (Fig.1c), only $17 \mathrm{mV}$ and $33 \mathrm{mV}$ loss in $\mathrm{E}_{1 / 2}$ for Fe-N-C-AC-CVD(150ZIF) (Fig. 1c, i.e. Fe-N-C-AC-CVD catalyst) and Fe-N-C-AC-CVD(25PS), respectively, suggesting deposition of carbon atoms onto $\mathrm{Fe}-\mathrm{N}-\mathrm{C}-\mathrm{AC}$ catalyst able to enhance its stability. However, without $\mathrm{N}$ atoms deposition onto the Fe-N-C-AC-CVD(25PS), its low initial ORR activity indicating the presence of $\mathrm{N}$ atoms, is beneficial for improving its initial and final ORR activities during the AST. 
Table S7. Mass variation of Fe-N-C-AC-CVD catalysts during the CVD process.

\begin{tabular}{c|c|c|c|c|c}
\hline \multirow{2}{*}{ Samples } & \multicolumn{5}{|c}{ Mass variation (mg) } \\
\cline { 2 - 6 } & Pyrolysis 1 & Pyrolysis 2 & Pyrolysis 3 & Average & $\begin{array}{c}\text { Net mass } \\
\text { increased }\end{array}$ \\
\hline $\begin{array}{c}\text { Fe-N-C-AC- } \\
1100-1 h^{\text {a }}\end{array}$ & -3.2 & -4.8 & -3.1 & -3.70 & $\mathbf{- 3 . 7 0}$ \\
\hline $\begin{array}{c}\text { Fe-N-C-AC-CVD } \\
(150 Z \text { ZIF-8) }\end{array}$ & 3.1 & 3.5 & 3.2 & 3.27 & $\mathbf{6 . 9 7}$ \\
\hline $\begin{array}{c}\text { Fe-N-C-AC-CVD } \\
(25 P S)^{c}\end{array}$ & 4.2 & 3.4 & 3.6 & 3.73 & $\mathbf{7 . 4 3}$ \\
\hline $\begin{array}{c}\text { Fe-N-C-AC-CVD } \\
(50 P S)^{c}\end{array}$ & 11.6 & 12.4 & 12.1 & 12.00 & $\mathbf{1 5 . 7 3}$ \\
\hline $\begin{array}{c}\text { Fe-N-C-AC-CVD } \\
(150 P S)^{c}\end{array}$ & 24.5 & 25.3 & 24.9 & 24.90 & $\mathbf{2 8 . 6 0}$ \\
\hline
\end{tabular}

${ }^{a} \mathrm{Fe}-\mathrm{N}-\mathrm{C}-\mathrm{AC}-1100-1 \mathrm{~h}$ catalyst represents the further treatment of Fe-N-C-AC catalyst for $1 \mathrm{~h}$ at $1100{ }^{\circ} \mathrm{C}$ without any deposition.

${ }^{\mathrm{b}} 150 \mathrm{mg}$ ZIF-8 represents $150 \mathrm{mg}$ ZIF-8 used as the upstream precursor for the CVD process. c $25,50,150 \mathrm{mg}$ PS represents 25, 50, $150 \mathrm{mg}$ polystyrene used as the upstream precursor for the CVD process, respectively.

Increased mass was both observed after the CVD of the Fe-N-C-AC catalyst by separately using ZIF-8 and PS as upstream precursors, suggesting successful deposition of carbon atoms onto the Fe-N-C-AC catalysts. 


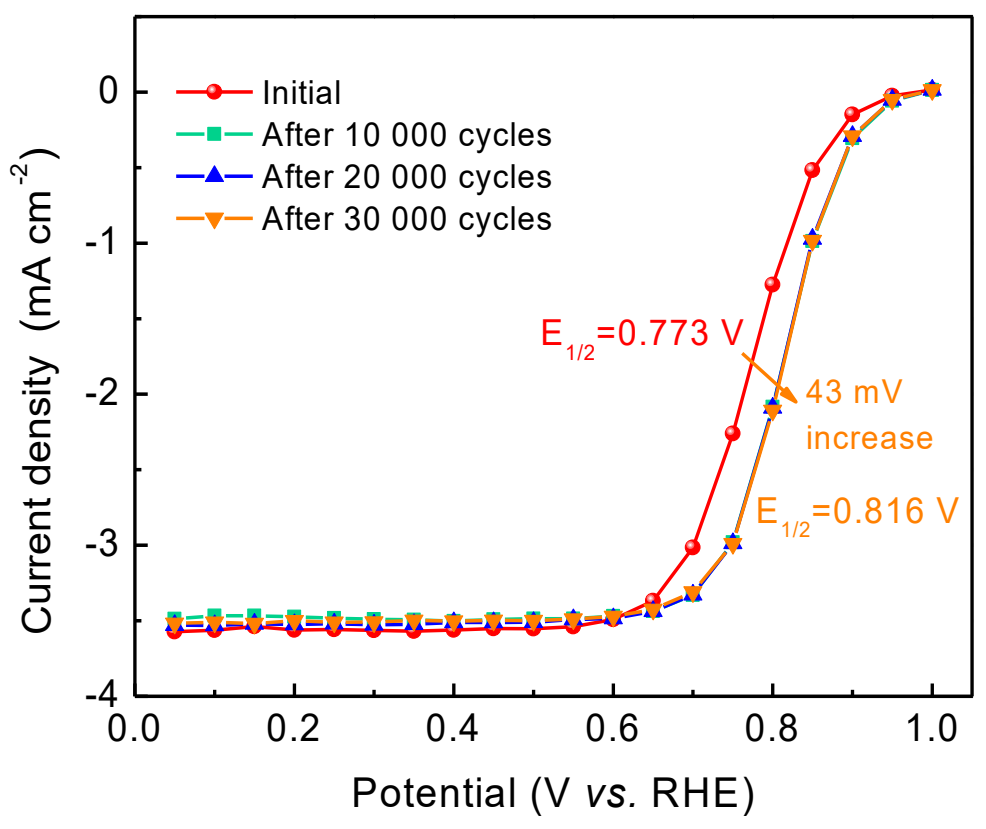

Figure S13. Stability AST cycling the potential (0.6-1.0 V) in $\mathrm{O}_{2}$-saturated $0.5 \mathrm{M} \mathrm{H}_{2} \mathrm{SO}_{4}$ for FeN-C-CVD catalyst, steady-state ORR polarization plots were recorded at intervals of 0, 10000,20 000 and 30000 cycles. Same as Fe-N-C-AC-CVD catalyst synthesis, $50 \mathrm{mg}$ Fe-N-C catalyst, and $150 \mathrm{mg}$ ZIF-8 were separately placed on a high-temperature alumina combustion boat located at the down-stream and up-stream direction in a tube furnace, respectively. Heated tube furnace to $1100{ }^{\circ} \mathrm{C}$ under the Ar's stream, after one-hour chemical vapor deposition, the Fe-N-C-CVD catalyst was prepared.

(a)

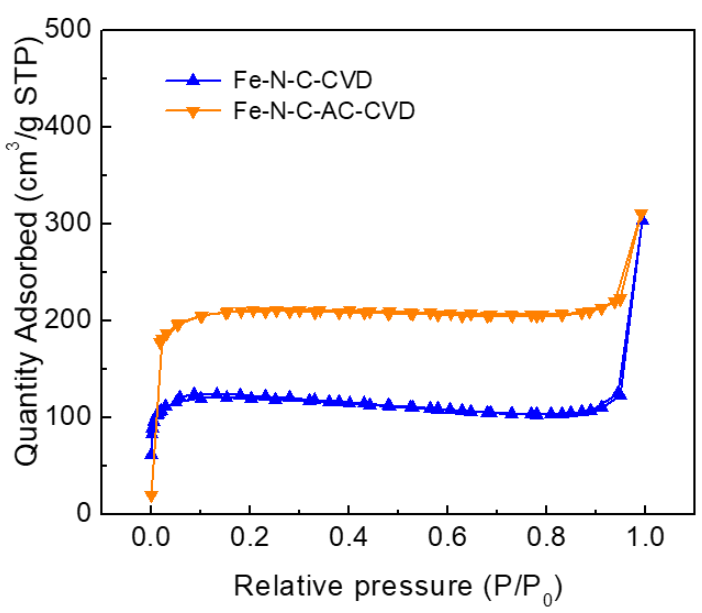

(b)

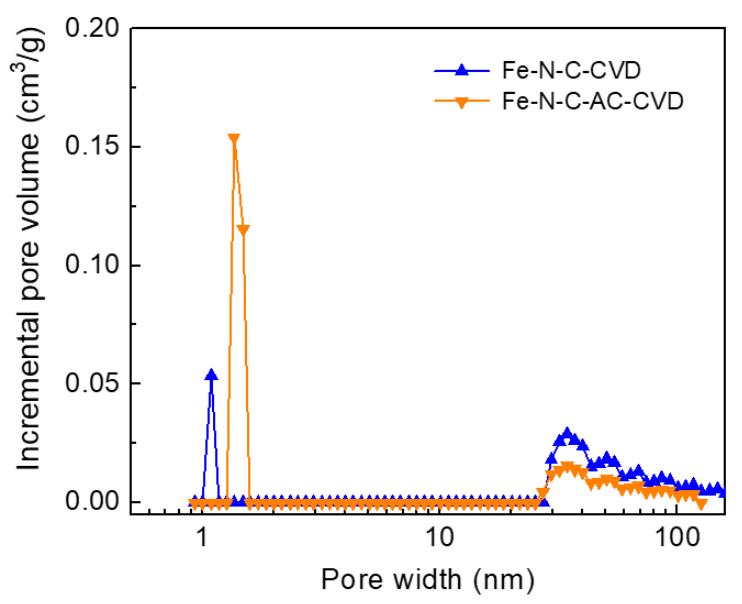

Figure S14. (a) $\mathrm{N}_{2}$ adsorption/desorption and (b) pore distribution plots of Fe-N-C-CVD and FeN-C-AC-CVD catalysts. 


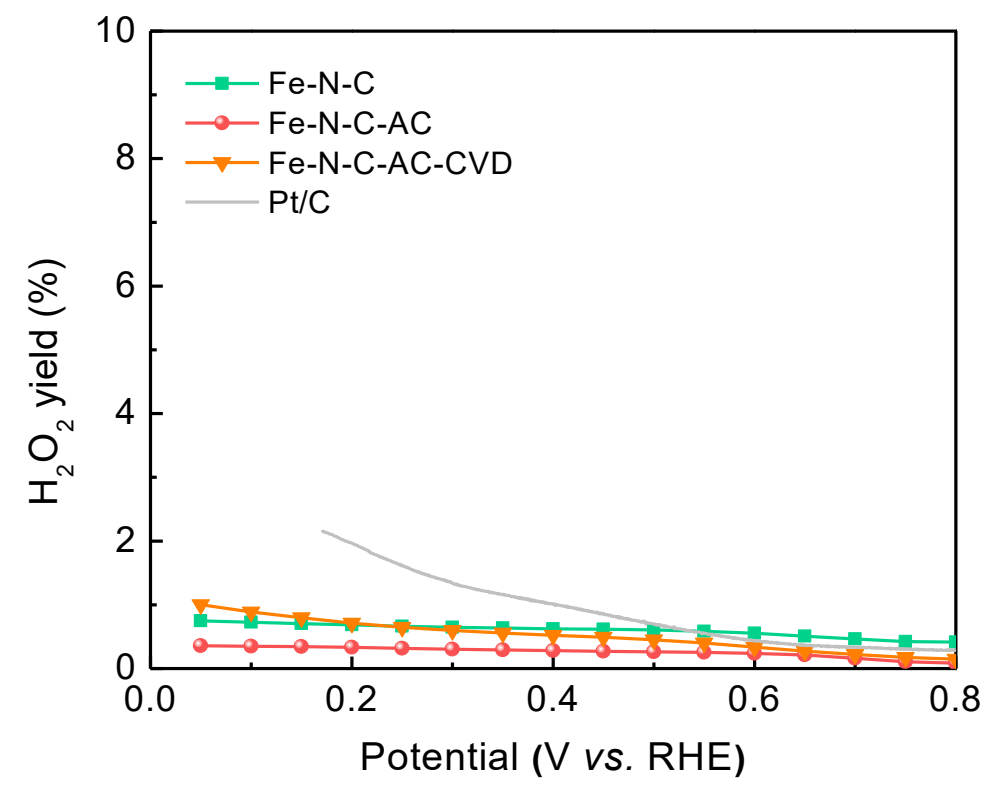

Figure S15. $\mathrm{H}_{2} \mathrm{O}_{2}$ yields of Fe-N-C, Fe-N-C-AC, Fe-N-C-AC-CVD, and commercial Pt/C catalysts were tested in $0.5 \mathrm{M} \mathrm{H}_{2} \mathrm{SO}_{4}$.
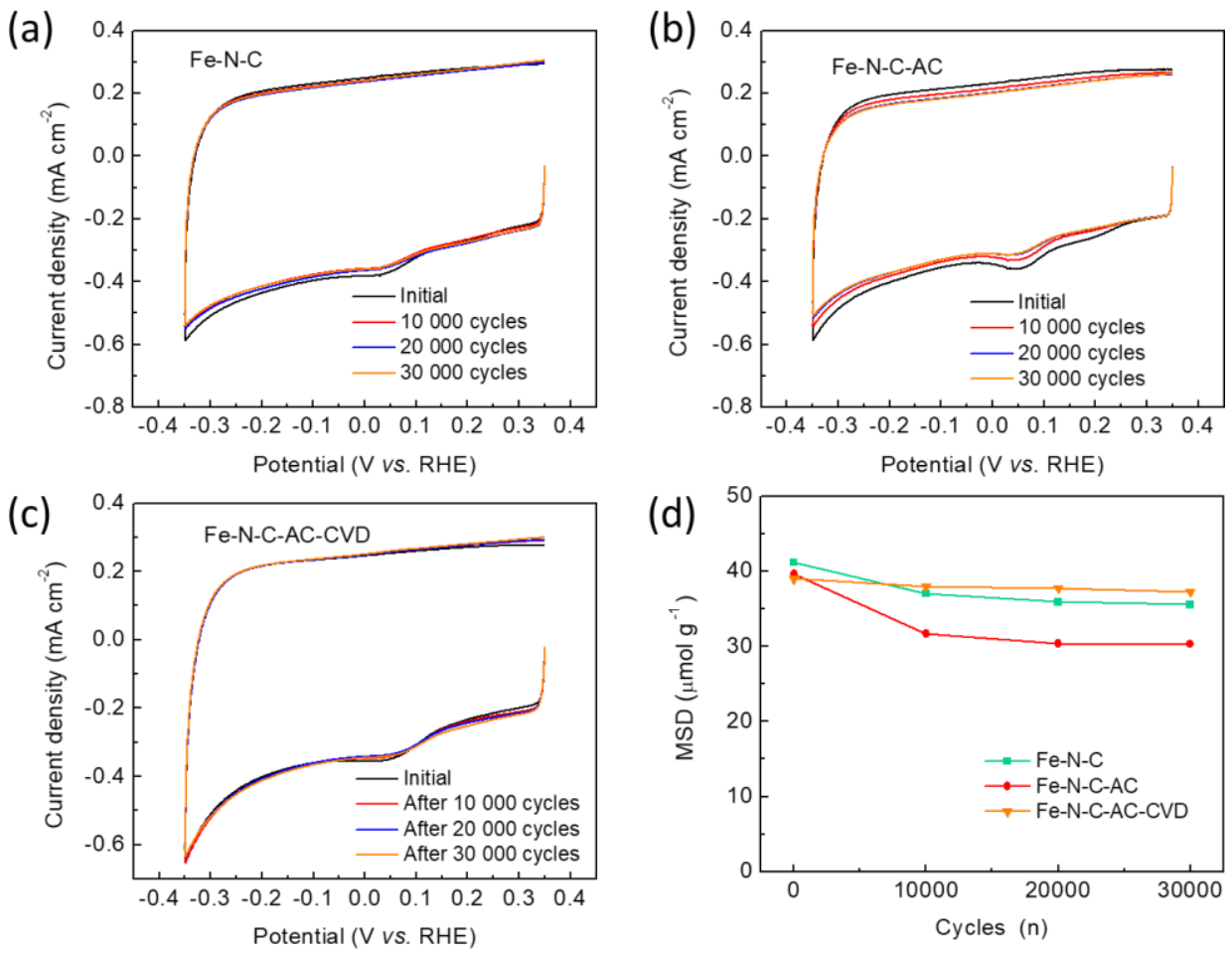

Figure S16. CV curves of nitrite adsorption in the nitrite reductive stripping region of (a) Fe-N-C (b) Fe-N-C-AC, and (c) Fe-N-C-AC-CVD catalysts were recorded at intervals of 0, 10 000, 20 000, and 30000 cycles during their stability AST tests. (d) Comparison of degradation in $\mathrm{FeN}_{4}$ gravimetric site density (MSD) of Fe-N-C, Fe-N-C-AC, and Fe-N-C-AC-CVD catalysts through reversible nitrite poisoning. 

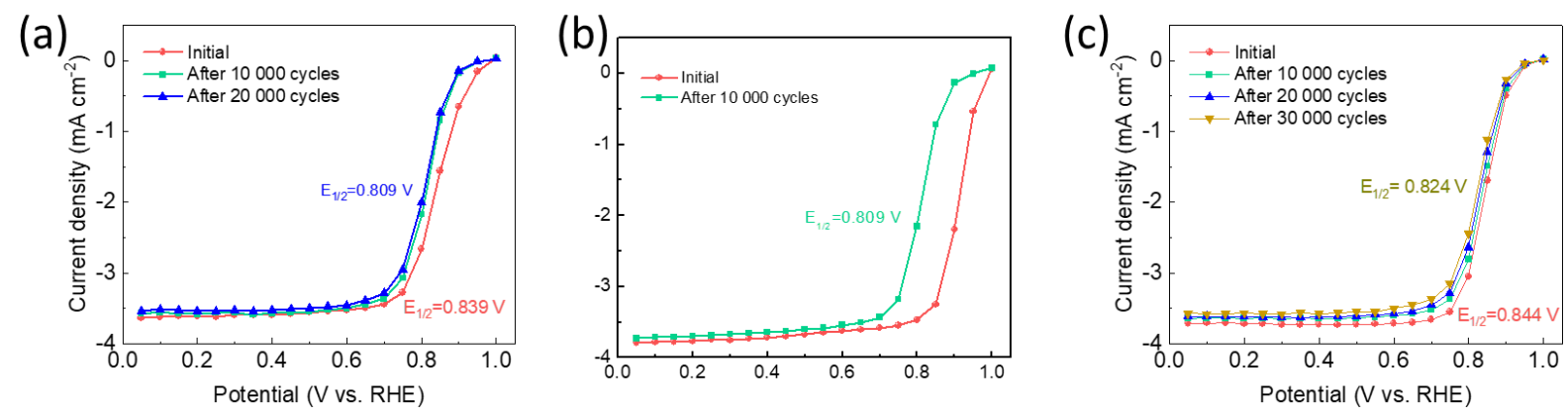

Figure S17. Stability AST by cycling the potential $(0.6-1.0 \mathrm{~V})$ in $\mathrm{O}_{2}$-saturated $0.5 \mathrm{M} \mathrm{H}_{2} \mathrm{SO}_{4}$, steady-state ORR polarization plots were recorded at intervals of 0,10000 , and 20000 cycles for (a) Fe-N-C catalyst; 0 and 10000 cycles for (b) Fe-N-C-AC; 0, 10 000, 20 000, 30000 cycles for Fe-N-C-AC-CVD catalyst. Compared to the Fe-N-C, Fe-N-C-AC, and Fe-N-C-AC-CVD catalysts tested in the $\mathrm{O}_{2}$-saturated $0.5 \mathrm{M} \mathrm{H}_{2} \mathrm{SO}_{4}$ solution, similar $\mathrm{E}_{1 / 2}$ loss in ORR activities tested in the $\mathrm{N}_{2}$-saturated $0.5 \mathrm{M} \mathrm{H}_{2} \mathrm{SO}_{4}$ solution illustrates the demetallation of $\mathrm{FeN}_{4}$ active sites is the cause contributing to the degradation of the catalysts.

(a)

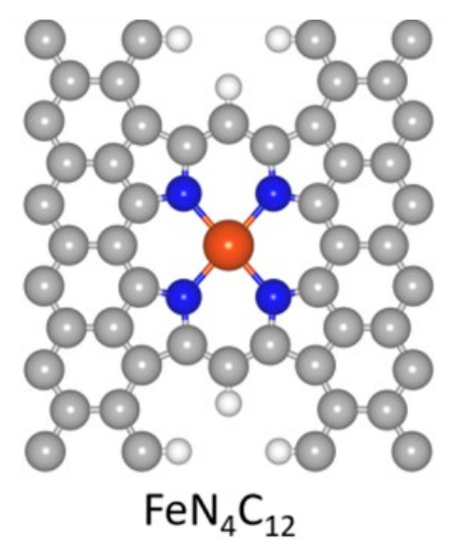

(b)

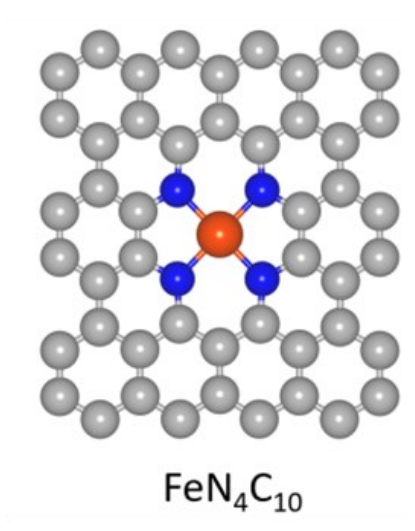

Figure S18. The possible sites $\mathrm{S} 1\left(\mathrm{FeN}_{4} \mathrm{C}_{12}\right)$ and $\mathrm{S} 2\left(\mathrm{FeN}_{4} \mathrm{C}_{10}\right)$ in $\mathrm{Fe}-\mathrm{N}-\mathrm{C}$ catalysts. 

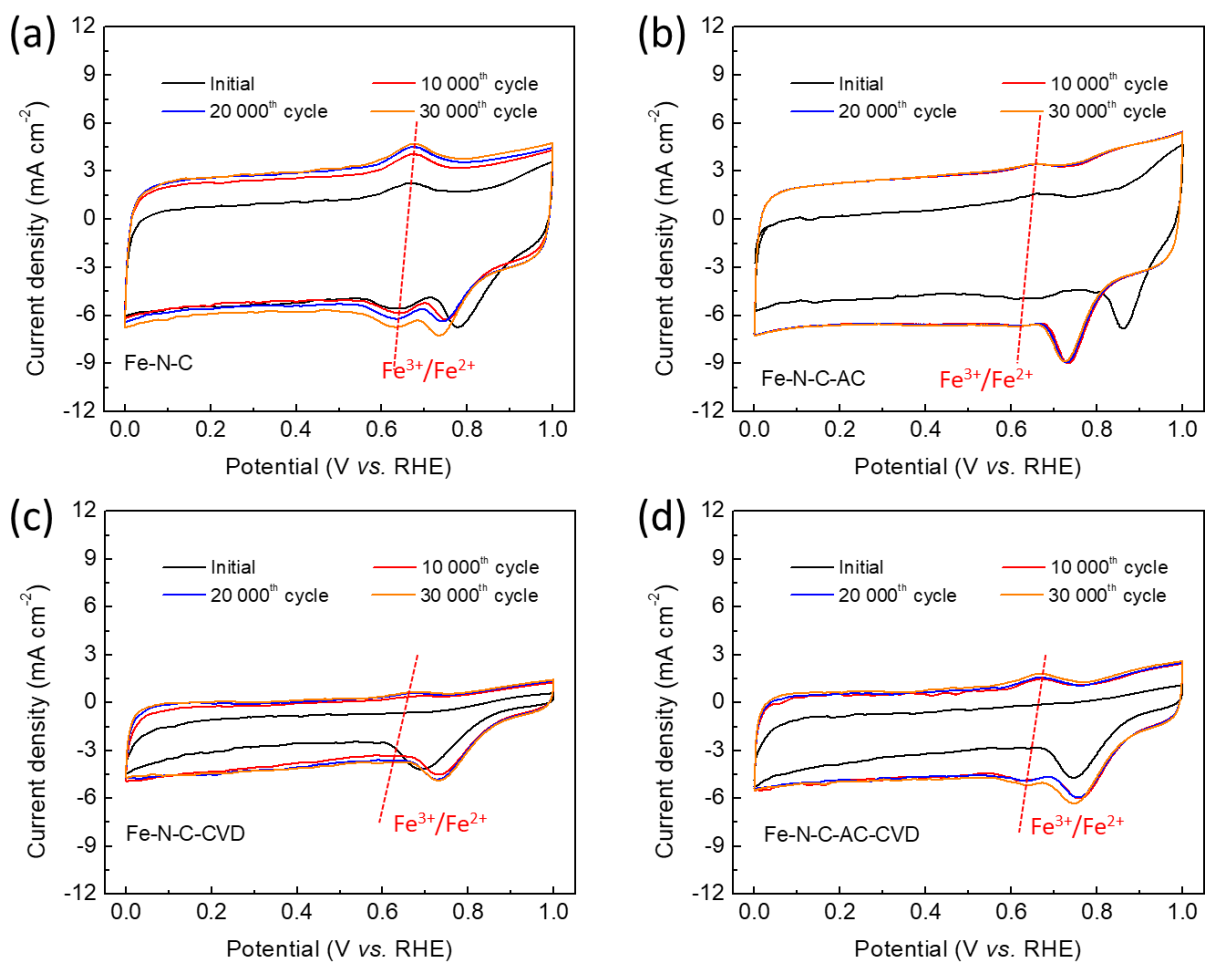

Figure S19. (a-d) Cyclic voltammograms $(C V S)$ of the Fe-N-C, Fe-N-C-AC, Fe-N-C-CVD, and Fe-N-C-AC-CVD collected during AST in $\mathrm{O}_{2}$-saturated $0.5 \mathrm{M} \mathrm{H}_{2} \mathrm{SO}_{4}$ electrolyte at room temperature with a scan rate of $20 \mathrm{mV} \mathrm{s}^{-1}$. High-spin $\mathrm{FeN}_{4} \mathrm{C}_{12}$ moiety (denoted as $\mathrm{S} 1$ ) and a lowor intermediate-spin $\mathrm{FeN}_{4} \mathrm{C}_{10}$ moiety (denoted as $\mathrm{S} 2$ ) existing in the Fe-N-C catalysts was demonstrated by Jaouen and co-workers, ${ }^{(31)}$ the former is more intrinsically active for the ORR with reduced activation energy to break $\mathrm{O}-\mathrm{O}$ bonds, therefore favoring reaction kinetics and reversibly switching from high-spin $\mathrm{Fe}(\mathrm{III}) \mathrm{N}_{4} \mathrm{C}_{12}$ structure with axial oxygen adsorbates to highspin $\mathrm{Fe}(\mathrm{II}) \mathrm{N}_{4} \mathrm{C}_{12}$ species without axial oxygen ligand. While $\mathrm{S} 2$ with no redox transition independent of $\mathrm{O}_{2}$ presence and the electronic state is potential-independent, being ferrous low- or medium-spin $\mathrm{FeN}_{4} \mathrm{C}_{10}$ structures. (1) The redox peaks of $\mathrm{Fe}^{2+} / \mathrm{Fe}^{3+}$ between 0.6-0.7 $\mathrm{V}$ are related to $\mathrm{S} 1$ sites, widespread in Fe-N-C and Fe-N-C-AC catalysts throughout the AST test. However, the intensity of redox peaks of $\mathrm{Fe}^{2+} / \mathrm{Fe}^{3+}$ in Fe-N-C-CVD and Fe-N-C-AC-CVD catalysts were gradually increased during the AST test, arising from more and more $\mathrm{S} 1$ sites exposure to electrolyte following electrochemical carbon oxidation, as expected, which is testified by the increased electrochemical double layer capacitor of the catalysts. (2) Compared to Fe-N-C catalyst, weaker redox peaks of $\mathrm{Fe}^{2+} / \mathrm{Fe}^{3+}$ of $\mathrm{Fe}-\mathrm{N}-\mathrm{C}-\mathrm{AC}$ catalyst indicating its lower active site density, while exhibits unprecedented ORR activity, may originate from unexplored active sites with superior ORR activity. (3) After CVD deposition, neglectable redox peaks of $\mathrm{Fe}^{2+} / \mathrm{Fe}^{3+}$ observed in the Fe-N-C-AC-CVD catalyst, its promising ORR activity $\left(\mathrm{E}_{1 / 2}=0.846 \mathrm{~V}\right)$ should come from more stable S2 sites, suggesting active site transition occurred during the CVD deposition. Fe-NC-CVD catalyst with higher stability but less activity ( $43 \mathrm{mV}$ increases in $\mathrm{E}_{1 / 2}$ after 30000 cycle AST test, as shown in Figure S14) may be due to more S2 sites generated in the CVD process, validated from weaker redox peaks of $\mathrm{Fe}^{2+} / \mathrm{Fe}^{3+}$ than that of $\mathrm{Fe}-\mathrm{N}-\mathrm{C}-\mathrm{AC}-\mathrm{CVD}$ catalyst after 10 000, 20 000, 30000 cycle AST. 


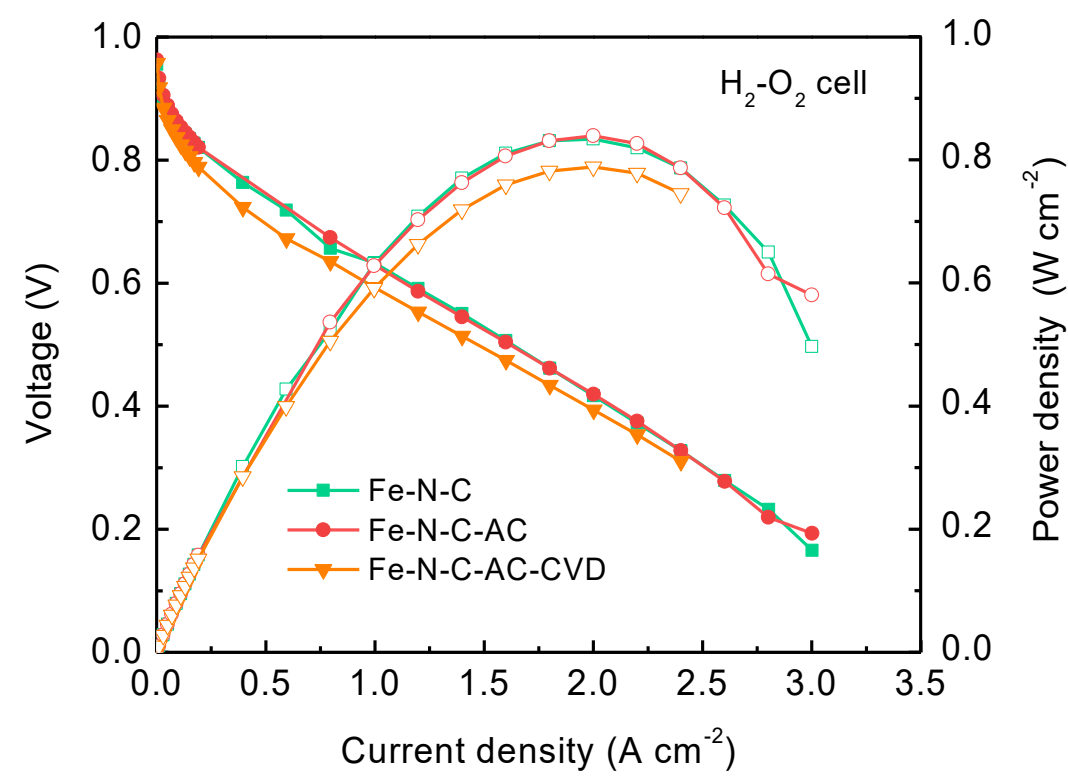

Figure S20. (a) $\mathrm{H}_{2}-\mathrm{O}_{2}$ fuel cell I-V polarization (solid symbols and lines) and power density (hollow symbols and lines) plots recorded under $150 \mathrm{kPa}_{\mathrm{abs}}$ pressure anodic and cathodic of Fe-N$\mathrm{C}$, Fe-N-C-AC, and Fe-N-C-AC-CVD catalysts at the flow rates of $\mathrm{O}_{2} 500$ standard cubic centimeter per minute ( $\mathrm{sccm}$ ) and $\mathrm{H}_{2} 300 \mathrm{sccm}$.

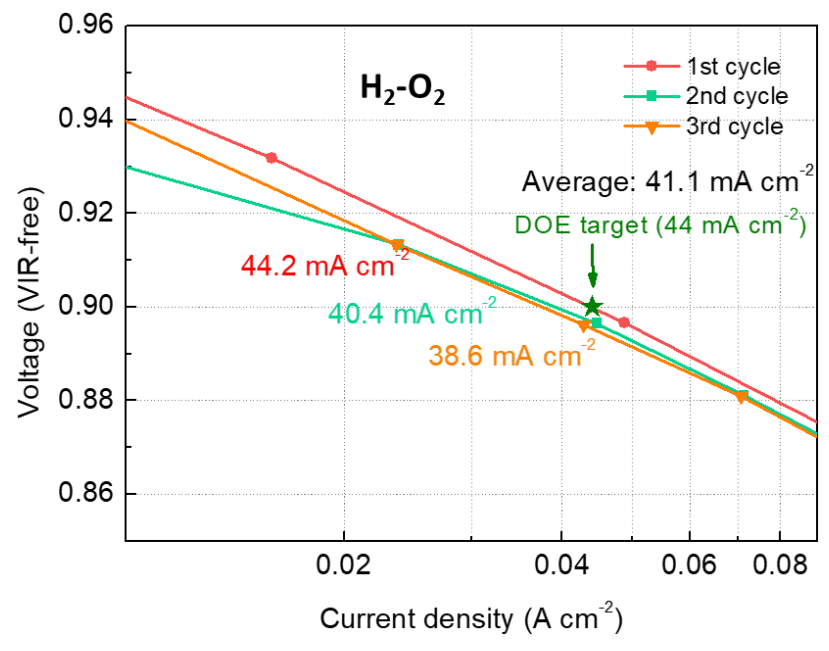

Figure S21. $\mathrm{H}_{2}-\mathrm{O}_{2}$ fuel cell performance of Fe-N-C-AC catalyst measured at in a differential cell by averaging the first three polarization curves, as proposed in PGM-free catalyst test protocols by DOE. Anode: $0.2 \mathrm{mg}_{\mathrm{Pt}} \mathrm{cm}^{-2} \mathrm{Pt} / \mathrm{C} \mathrm{H}_{2}, 700 \mathrm{sccm}, 150 \mathrm{kPa}_{\mathrm{abs}}$ pressure; Cathode: $c a .6 .00 \mathrm{mg} \mathrm{cm}$, Fe-N-C-AC, ionomer (25 wt. \%, Aquivion D-79-25BS), $1700 \mathrm{sccm}, 150 \mathrm{kPa}_{\mathrm{abs}}$ pressure; Membrane: Nafion ${ }^{\mathrm{TM}} 212$; Cell: $5 \mathrm{~cm}^{2}$. Test conditions: $80^{\circ} \mathrm{C}$; $0.96 \mathrm{~V}$ to $0.88 \mathrm{~V}$ in $20 \mathrm{mV}$ steps; $0.88 \mathrm{~V}$ to $0.72 \mathrm{~V}$ in $40 \mathrm{mV}$ steps; $45 \mathrm{~s} / \mathrm{step}$. 

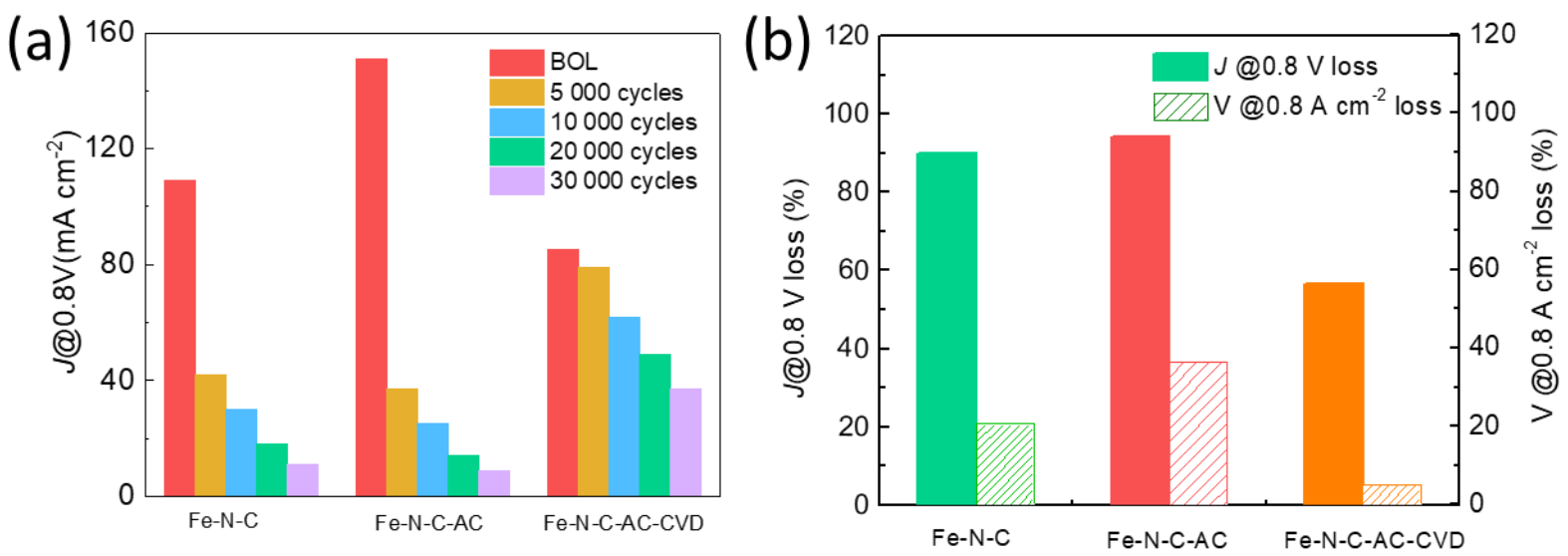

Figure S22. (a) Comparison of current density loss at $0.8 \mathrm{~V}$ in $\mathrm{H}_{2}$-air cell. (b) Comparison of the percentage of current density loss at $0.8 \mathrm{~V}$ and the percentage of voltage loss at $0.8 \mathrm{~A} \mathrm{~cm}^{-2}$ in $\mathrm{H}_{2}$ air cell after 30000 cycle stability tests.

Table S8. Comparison in current density loss at $0.8 \mathrm{~V}$ and peak power density loss in $\mathrm{H}_{2}$-air cell for the Fe-N-C, Fe-N-C-AC, and Fe-N-C-AC-CVD cathodes.

\begin{tabular}{|c|c|c|c|c|c|c|c|c|c|}
\hline \multirow[b]{2}{*}{ Cycles } & \multicolumn{3}{|c|}{$\mathrm{Fe}-\mathrm{N}-\mathrm{C}$} & \multicolumn{3}{|c|}{$\mathrm{Fe}-\mathrm{N}-\mathrm{C}-\mathrm{AC}$} & \multicolumn{3}{|c|}{$\mathrm{Fe}-\mathrm{N}-\mathrm{C}-\mathrm{AC}-\mathrm{CVD}$} \\
\hline & 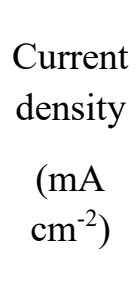 & $\begin{array}{l}\text { Voltage } \\
(\mathrm{V} @ \\
0.8 \mathrm{~A} \\
\left.\mathrm{~cm}^{-2}\right)\end{array}$ & $\begin{array}{l}\text { Peak } \\
\text { power } \\
\text { density } \\
(\mathrm{mW} \\
\left.\mathrm{cm}^{-2}\right)\end{array}$ & $\begin{array}{c}\text { Current } \\
\text { density } \\
(\mathrm{mA} \\
\left.\mathrm{cm}^{-2}\right)\end{array}$ & $\begin{array}{c}\text { Voltage } \\
(\mathrm{V} @ \\
0.8 \mathrm{~A} \\
\mathrm{~cm}^{-2} \text { ) }\end{array}$ & $\begin{array}{c}\text { Peak } \\
\text { power } \\
\text { density } \\
(\mathrm{mW} \\
\left.\mathrm{cm}^{-2}\right)\end{array}$ & $\begin{array}{c}\text { Current } \\
\text { density }\end{array}$ & $\begin{array}{c}\text { Voltage } \\
\text { (V@ } \\
0.8 \mathrm{~A} \\
\mathrm{~cm}^{-2} \text { ) }\end{array}$ & $\begin{array}{c}\text { Peak } \\
\text { power } \\
\text { density } \\
(\mathrm{mW} \\
\left.\mathrm{cm}^{-2}\right)\end{array}$ \\
\hline BOL & 109 & 0.58 & 500 & 151 & 0.63 & 601 & 85 & 0.58 & 535 \\
\hline 5000 & 42 & 0.49 & 425 & 37 & 0.52 & 440 & 79 & 0.57 & 557 \\
\hline 10000 & 30 & 0.51 & 450 & 25 & 0.49 & 408 & 62 & 0.57 & 575 \\
\hline 20000 & 18 & 0.50 & 430 & 14 & 0.44 & 368 & 49 & 0.56 & 535 \\
\hline 30000 & 11 & 0.46 & 390 & 9 & 0.40 & 327 & 37 & 0.55 & 514 \\
\hline
\end{tabular}




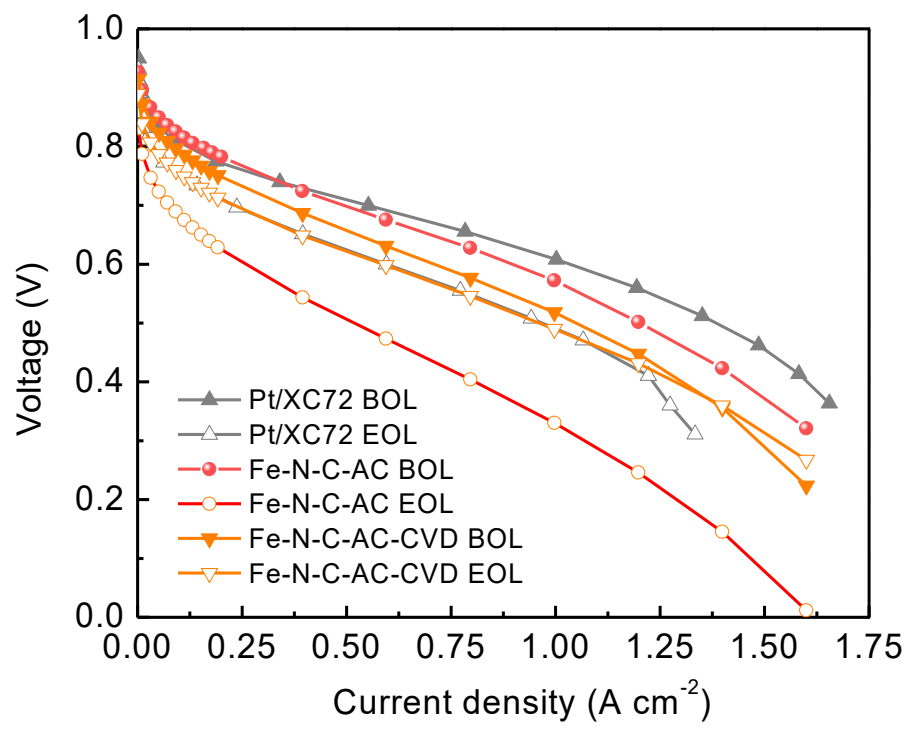

Figure S23. Comparison of $\mathrm{H}_{2}$-air fuel cell polarization plots of Fe-N-C-AC, Fe-N-C-AC-CVD, and commercial $\mathrm{Pt} / \mathrm{XC} 72$ catalyst cathodes recorded at BOL and EOL during the 30000 cycles AST under $150 \mathrm{kPa}_{\text {abs }}$ pressure anodic and cathodic at the flow rate of $\mathrm{O}_{2} 500 \mathrm{sccm}$ and $\mathrm{H}_{2} 300$ sccm, respectively. AST square-wave voltage cycles between 0.6 and OCV $(\sim 0.92 \mathrm{~V})$ under ambient pressure $\left(100 \mathrm{kPa}_{\text {abs }}\right)$ at the flow rates of air $400 \mathrm{sccm}$ and $\mathrm{H}_{2} 200 \mathrm{sccm}$. Fuel cell cathode: catalyst loading $4.0 \mathrm{mg} \mathrm{cm}^{2}$ for Fe-N-C-AC, Fe-N-C-AC-CVD and $0.1 \mathrm{mg} \mathrm{cm}^{-2} \mathrm{Pt}$ for Pt/XC72; $100 \% \mathrm{RH}: \mathrm{Pt} / \mathrm{C}, 0.20 \mathrm{mg}_{\mathrm{Pt}} \mathrm{cm}^{-2}, 100 \% \mathrm{RH} .$. Membrane: Nafion 212. Temperature: $80{ }^{\circ} \mathrm{C}$. MEA area: $5.0 \mathrm{~cm}^{2}$.

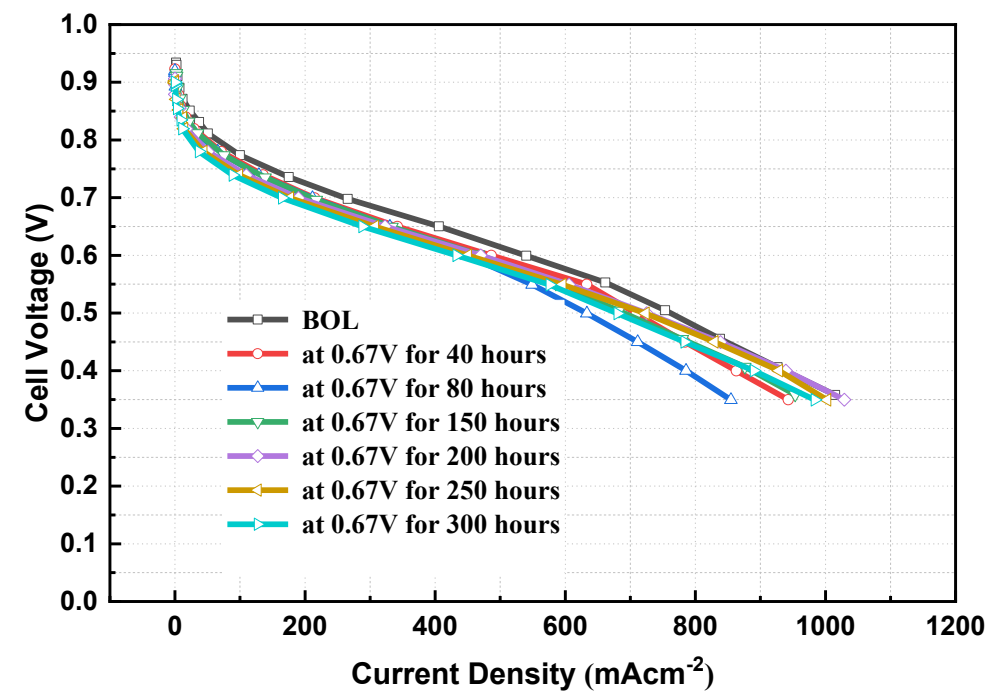

Figure S24. Fuel cell polarization plots recorded at different times during the 319-hour durability test at $0.67 \mathrm{~V}$ with flow rates of air $500 \mathrm{sccm}$ and $\mathrm{H}_{2} 300 \mathrm{sccm}$. Fuel cell cathode: catalyst loading $\sim 4.0 \mathrm{mg} \mathrm{cm}{ }^{-2} ; 100 \% \mathrm{RH} ; 150 \mathrm{kPa}_{\text {abs }}$ pressure. Anode: Pt/C, $0.20 \mathrm{mg}_{\mathrm{Pt}} \mathrm{cm}^{-2}, 100 \% \mathrm{RH} ; 150 \mathrm{kPa}_{\mathrm{abs}}$ pressure. Membrane: Nafion 212. Temperature: $80^{\circ} \mathrm{C}$. MEA area: $5.0 \mathrm{~cm}^{2}$. 

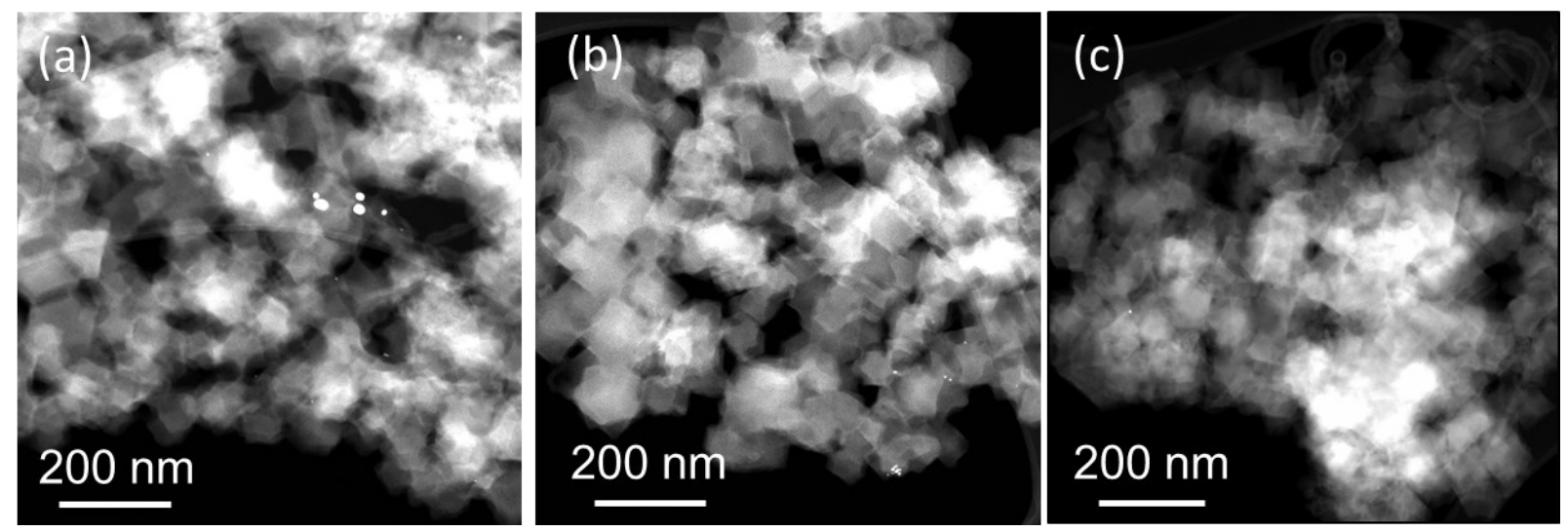

Figure S25. HAADF-STEM images of aged (a)Fe-N-C, (b) Fe-N-C-AC, and (c) Fe-N-C-ACCVD catalysts from correspondingly aged MEAs. Aged Fe-N-C-AC-CVD catalyst from aged Fe$\mathrm{N}-\mathrm{C}$-AC-CVD MEA after 60000 cycle AST in $\mathrm{H}_{2}$-air cell, the MEA damaged because of $\mathrm{H}_{2}$ cut off after 60000 cycles AST.

Table S9. Elemental quantification of three typical aged Fe-N-C, Fe-N-C-AC, and Fe-N-C-ACCVD MEAs by STEM-EDS.

\begin{tabular}{lccccc}
\hline Sample & C(at.\%) & N(at.\%) & O(at.\%) & Fe(at.\%) & Zn(at.\%) \\
\hline Aged Fe-N-C MEA & & & & & \\
Aged Fe-N-C-AC MEA & 95.02 & 2.39 & 2.51 & 0.04 & 0.04 \\
aAged Fe-N-C-AC-CVD MEA & 91.82 & 2.12 & 5.94 & 0.11 & 0.00
\end{tabular}

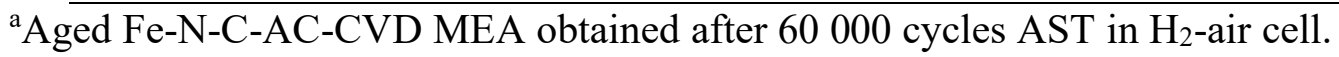

The resulting Nyquist impedance plots obtained at a current density of $0.8 \mathrm{~A} \mathrm{~cm}^{-2}$ for MEAs of Fe-N-C, Fe-N-C-AC, and Fe-N-C-AC-CVD catalysts during the AST are shown here, where the comparison is given at the BOL and after 30000 cycles. This feature is well-known, as below 0.2 $\mathrm{A} \mathrm{cm}^{2}$, the performance limitations are typically dominated by the charge transfer resistance (32). From the extracted parameter values summarized and compared in Fig. S26, it is observed that Fe$\mathrm{N}-\mathrm{C}$-AC $\left(0.2510 \Omega \mathrm{cm}^{2}\right)$ catalyst has the lowest charge transfer resistance at the beginning of the test than that of Fe-N-C-AC-CVD $\left(0.2695 \Omega \mathrm{cm}^{2}\right)$ and Fe-N-C $\left(0.2806 \Omega \mathrm{cm}^{2}\right)$ catalysts. This observation is well in line with their corresponding polarization curves (Fig. 2d-f). After undergoing degradation, where the charge transfer resistance for the three catalysts increased during the AST. As expected, the Fe-N-C-AC-CVD $\left(0.2755 \Omega \mathrm{cm}^{2}\right)$ catalyst has the lowest charge transfer resistance compared to the Fe-N-C $\left(0.5245 \Omega \mathrm{cm}^{2}\right)$ and Fe-N-C-AC $\left(0.3420 \Omega \mathrm{cm}^{2}\right)$ catalysts after 30000 cycles, thus indicating that the Fe-N-C-AC-CVD catalyst is more durable, possessing longer lifecycle under continuous operation. 

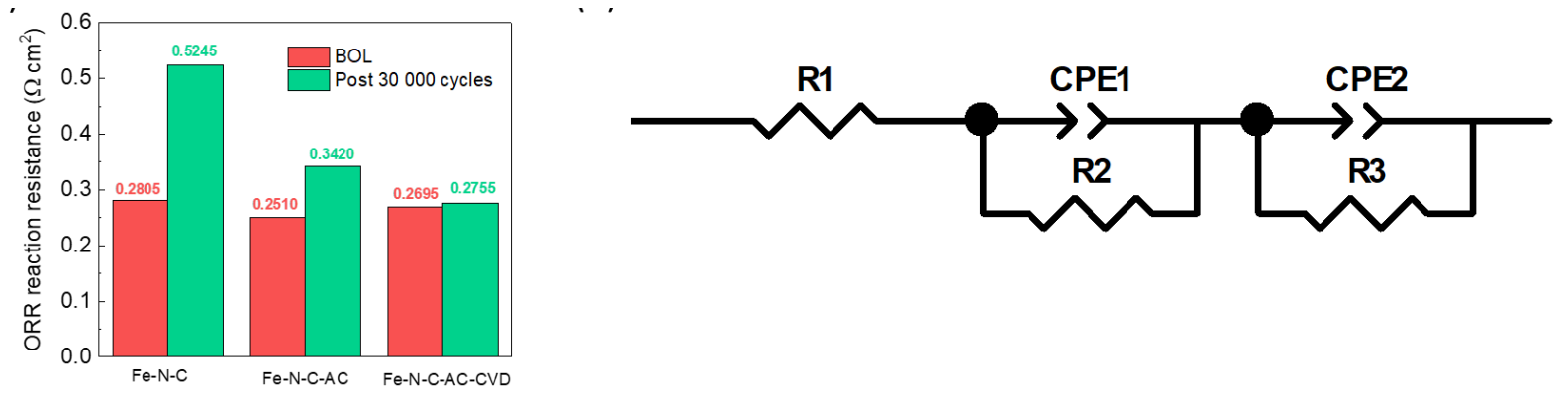

Figure S26. Comparison of the ORR reaction resistances in the fuel cells of these three catalysts simulated from EIS (left). Equivalent circuit mode used in impedance spectra of fuel cells (right). This equivalent circuit model of PEM fuel cell was developed to capture the processes that cause the low-frequency inductive loop in the impedance spectra to identify the main degradation behaviors.

The Fe-N-C, Fe-N-C-AC, and Fe-N-C-AC-CVD MEAs were tested in $\mathrm{H}_{2}-\mathrm{N}_{2}$ cells with identical AST protocol for $\mathrm{H}_{2}$-air cells. Current densities loss after AST in $\mathrm{H}_{2} / \mathrm{N}_{2}$ were compared for each MEA in Table S10. As shown in Fig. S27 and Table S10, before and after AST in $\mathrm{H}_{2} / \mathrm{N}_{2}$ cell, the Fe-N-C-AC MEA suffered the most significant performance loss, with $93 \mathrm{~mA} \mathrm{~cm}^{-2}$ current density loss at $0.8 \mathrm{~V}$ after 10000 cycles, whereas $125 \mathrm{~mA} \mathrm{~cm}^{-2}$ loss in $\mathrm{H}_{2} /$ air AST is observed, indicating most $\mathrm{FeN}_{4}$ sites loss is due to its chemically unstable $\mathrm{FeN}_{4}$ active site. In contrast, the Fe-N-C and Fe-N-C-AC-CVD MEAs delivered significantly lower current density loss both after $\mathrm{H}_{2} / \mathrm{N}_{2}$ and $\mathrm{H}_{2}$ /air ASTs. However, both MEAs had similar current density loss in $\mathrm{H}_{2}-\mathrm{N}_{2}$ and $\mathrm{H}_{2}$-air cells, further suggesting chemically unstable $\mathrm{FeN}_{4}$ active site more relatively important to $\mathrm{FeN}_{4}$ demetallation of three catalysts. More interestingly, compared to Fe-N-C-AC and Fe-N-C-ACCVD MEAs generated similar current density loss at $0.8 \mathrm{~V}$ after $\mathrm{H}_{2} / \mathrm{N}_{2}$ and $\mathrm{H}_{2} /$ air AST, Fe-N-CAC MEA lost more current densities in $\mathrm{H}_{2}$ /Air than $\mathrm{H}_{2} / \mathrm{N}_{2}$ ASTs, indicating its $\mathrm{FeN}_{4}$ site demetallation originates from both chemically unstable $\mathrm{FeN}_{4}$ active site in acid medium and electro-corrosion of the $\mathrm{FeN}_{4}$ carbon support. However, more stable Fe-N-C-AC and Fe-N-C-ACCVD catalysts with neglectable current density loss, indicating their $\mathrm{FeN}_{4}$ carbon support capable of resisting electro-corrosion, their $\mathrm{FeN}_{4}$ active site loss mainly results from chemically unstable $\mathrm{FeN}_{4}$ active site in acid medium. 

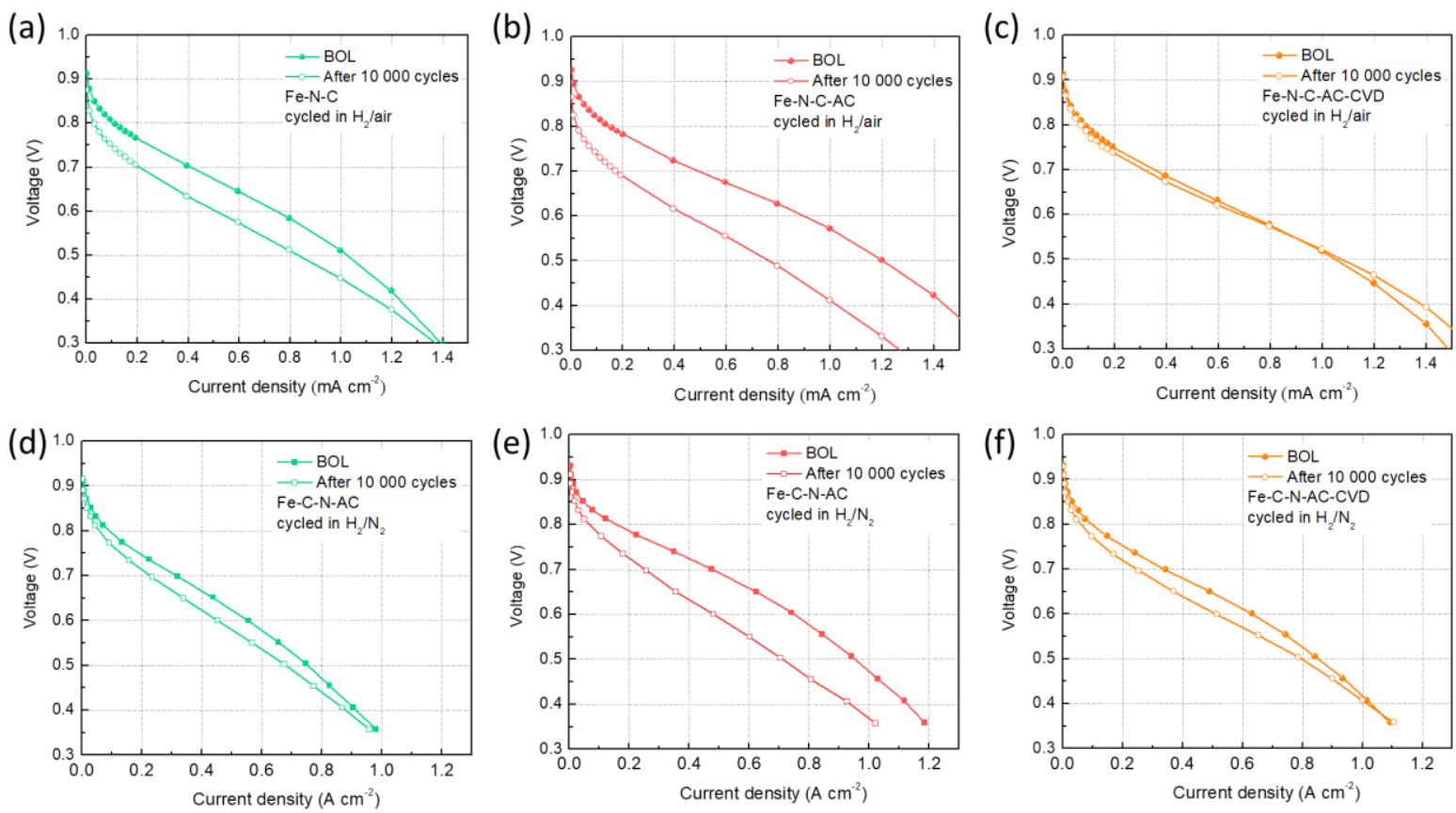

Figure S27. $\mathrm{H}_{2}$-air fuel cell polarization plots of (a, d) Fe-N-C, (b, e) Fe-N-C-AC, and (c, f) Fe$\mathrm{N}-\mathrm{C}-\mathrm{AC}-\mathrm{CVD}$ catalyst cathodes recorded before (BOL) and after 10000 cycles AST in $\mathrm{H}_{2} /$ air or $\mathrm{H}_{2} / \mathrm{N}_{2}$ cells at flow rates of air $/ \mathrm{N}_{2} 500 \mathrm{sccm}$ and $\mathrm{H}_{2} 300 \mathrm{sccm}$ under $150 \mathrm{kPa}_{\mathrm{abs}}$ pressure. AST square-wave voltage cycles in $\mathrm{H}_{2} /$ air or $\mathrm{H}_{2} / \mathrm{N}_{2}$ cells with potential between 0.6 and $0.92 \mathrm{~V}$ under ambient pressure $\left(100 \mathrm{kPa}_{\mathrm{abs}}\right)$ at flow rates of air $400 \mathrm{sccm}$ and $\mathrm{H}_{2} 200 \mathrm{sccm}$.

Table S10. Comparison in current density loss at $0.8 \mathrm{~V}$ in $\mathrm{H}_{2}$-air cell after 10000 cycles AST in $\mathrm{H}_{2} /$ air or $\mathrm{H}_{2} / \mathrm{N}_{2}$ for the Fe-N-C, Fe-N-C-AC, and Fe-N-C-AC-CVD cathodes.

\begin{tabular}{ccccccc}
\hline & \multicolumn{2}{c}{ Fe-N-C } & \multicolumn{2}{c}{ Fe-N-C-AC } & \multicolumn{2}{c}{ Fe-N-C-AC-CVD } \\
\cline { 2 - 7 } & $\begin{array}{c}\text { In } \mathrm{H}_{2-} \\
\text { Air }\end{array}$ & In $\mathrm{H}_{2}-\mathrm{N}_{2}$ & $\begin{array}{c}\text { In } \mathrm{H}_{2-} \\
\text { Air }\end{array}$ & In $\mathrm{H}_{2}-\mathrm{N}_{2}$ & In $\mathrm{H}_{2}$-Air & In $\mathrm{H}_{2}-\mathrm{N}_{2}$ \\
\hline $\begin{array}{c}\text { Current density loss @ } 0.8 \\
\text { V (mA cm }\end{array}$ c $\left.^{-2}\right)$ & 33 & 33 & 125 & 93 & 24 & 30 \\
\hline
\end{tabular}

As shown in this figure, the currents were normalized to geometric surface area and catalyst loadings. For both current densities, Fe-N-C-AC-CVD has the lowest value, indicating its high resistance to electrochemical oxidation; while $\mathrm{Fe}-\mathrm{N}-\mathrm{C}-\mathrm{AC}$ has the highest electrochemical oxidizing current density, manifesting its low resistance towards electrochemical corrosion; The transiting potentials from oxidative to reductive current increase in order of Fe-N-C-AC $<\mathrm{Fe}-\mathrm{N}$ $\mathrm{C}<\mathrm{Fe}-\mathrm{N}-\mathrm{C}-\mathrm{AC}-\mathrm{CVD}$, indicating the coverages of the vulnerable site in these three catalysts decreased in the order of Fe-N-C-AC $>$ Fe-N-C $>$ Fe-N-C-AC-CVD. Both oxidative current 
density and transiting potential revealed that CVD could greatly enhance durability by healing defects or increasing the graphitization degree.
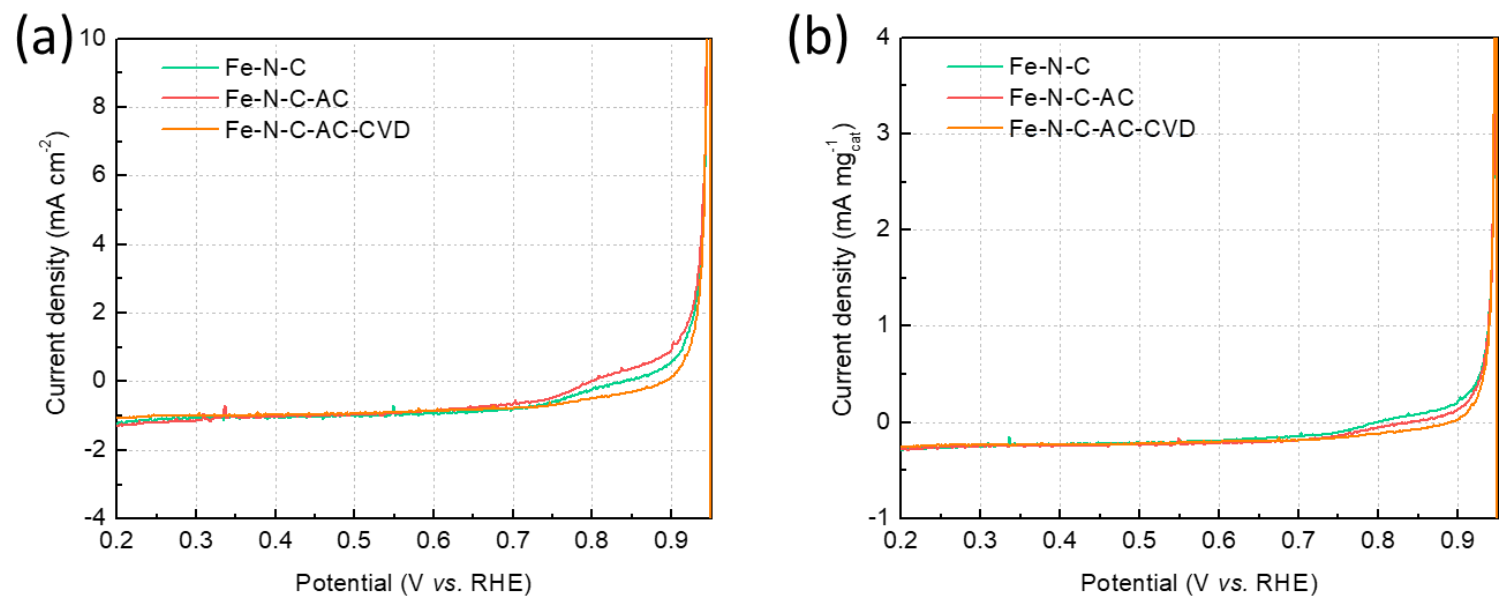

Figure S28. Background current densities for Fe-N-C, Fe-N-C-AC, and Fe-N-C-AC-CVD cathodes determined by linear sweep voltammetry (LSV) polarization curves test in the $\mathrm{H}_{2} / \mathrm{N}_{2}$ cell. Anode: $20 \% \mathrm{Pt} / \mathrm{C}, 0.2 \mathrm{mg}_{\mathrm{Pt}} \mathrm{cm}^{-2}$, Cathode: $4.3 \mathrm{mg} \mathrm{cm}^{-2} \mathrm{Fe}-\mathrm{N}-\mathrm{C}, 4.5 \mathrm{mg} \mathrm{cm}^{-2} \mathrm{Fe}-\mathrm{N}-\mathrm{C}-\mathrm{AC}, 4.2 \mathrm{mg}$ $\mathrm{cm}^{-2} \mathrm{Fe}-\mathrm{N}-\mathrm{C}-\mathrm{AC}-\mathrm{CVD}, \mathrm{I} / \mathrm{C}$ ratio $=0.8 ; \mathrm{H}_{2} / \mathrm{N}_{2}, 300 / 500 \mathrm{sccm}, 150 \mathrm{kPa}$ abs pressure, RH:100\%. Membrane: N212; Cell: $5.0 \mathrm{~cm}^{2}$. Test Protocols: Purge the cell for more than 2 hours with $\mathrm{N}_{2} / \mathrm{N}_{2}$ on anode/cathode at $80{ }^{\circ} \mathrm{C}$ with $100 \% \mathrm{RH}$ humidification; when the OCVs dropped below $0.2 \mathrm{~V}$, purge the cell with $\mathrm{H}_{2} / \mathrm{N}_{2}$ on anode/cathode for more than 30 minutes before LSV test. LSV curves were recorded from 0.96 to $0.2 \mathrm{~V}$ at $2 \mathrm{mV} \mathrm{s}^{-1}$. The test was repeated more than three times to obtain the overlapped curves. 

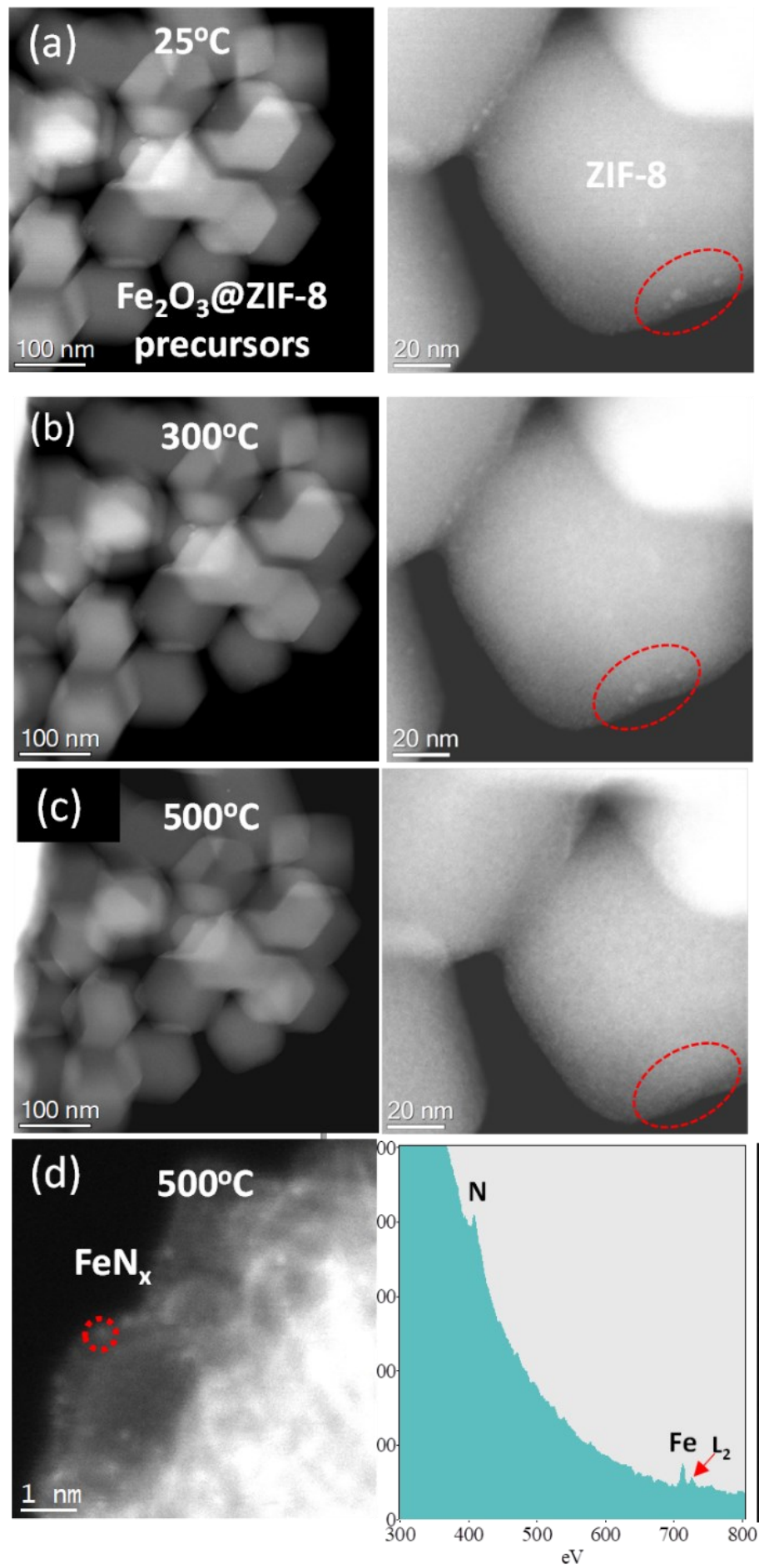

Figure S29. ADF-STEM images and corresponding EEL point spectra captured during in situ heating treatment of the $\mathrm{Fe}_{2} \mathrm{O}_{3} @ \mathrm{ZIF}-8$ precursor, showing $\mathrm{Fe}_{2} \mathrm{O}_{3}$ nanoparticles (red arrows) at (a) $25^{\circ} \mathrm{C}$ and (b) $300{ }^{\circ} \mathrm{C}$, followed by their decomposition at (c) $500{ }^{\circ} \mathrm{C}$. ADF-STEM images with corresponding EEL point spectra of single atoms at (d) $500{ }^{\circ} \mathrm{C}$. 

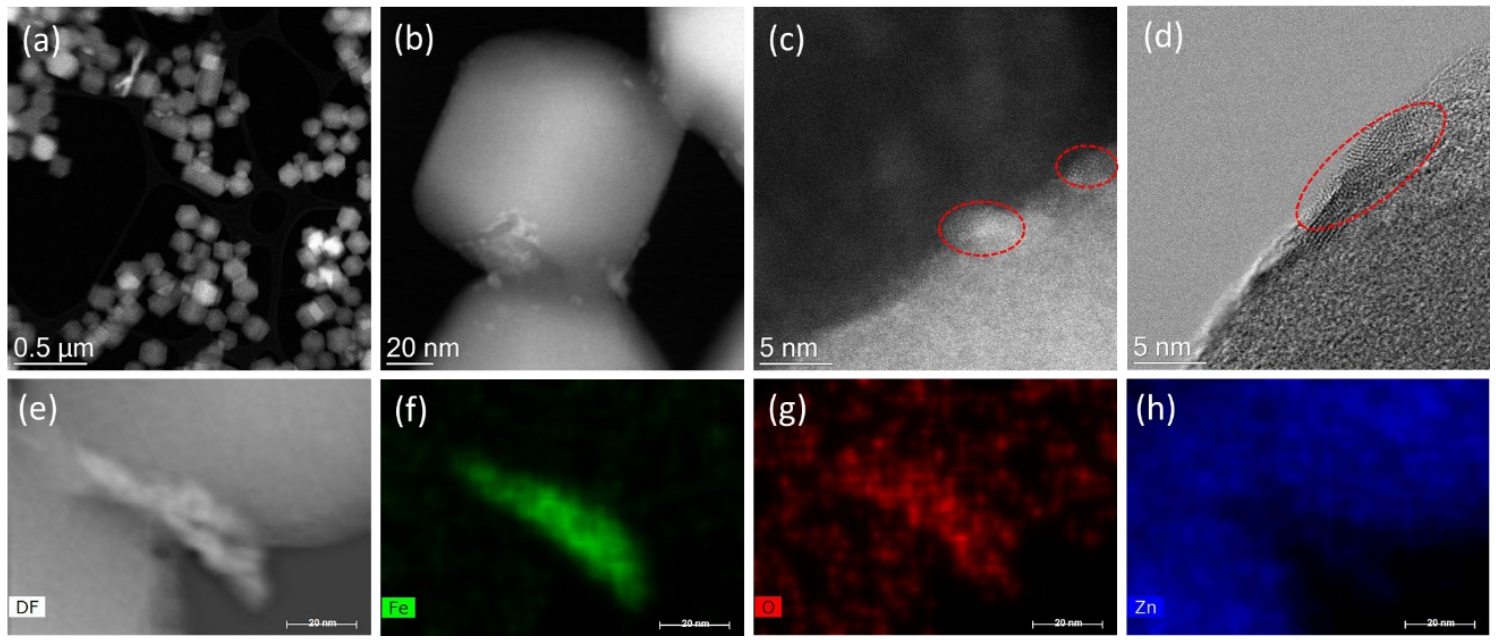

Figure S30. (a-e) ADF-STEM images of $\mathrm{Fe}_{2} \mathrm{O}_{3} @ Z$ ZIF-8 composites. $\mathrm{Fe}_{2} \mathrm{O}_{3}$ nanoparticles circled in red in (c, d). (f-h) EDS maps of Fe (f), O (g), and $\mathrm{Zn}(\mathrm{h})$ of the area in (e).

(a)

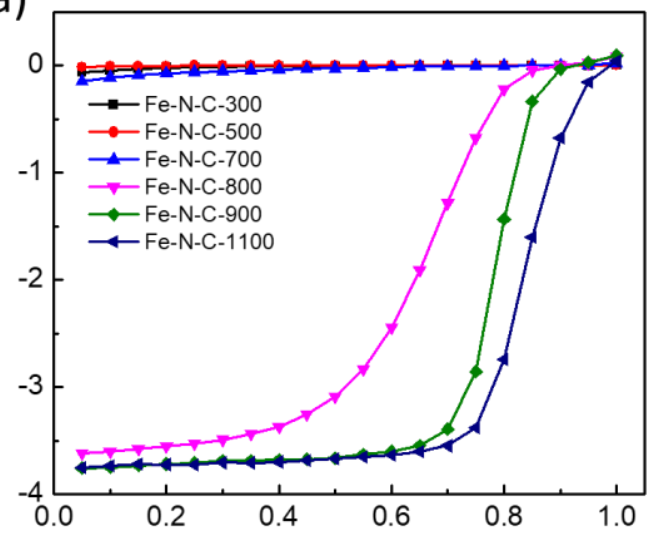

(b)

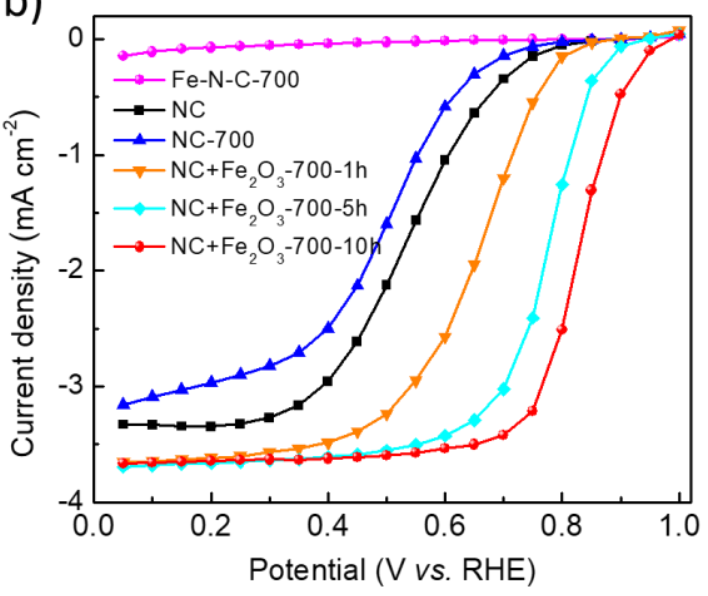

Figure S31. Steady-state ORR polarization plots of (a) Fe-N-C- $T$ catalysts pyrolyzed at different temperature ( $T=300,500,700,800,900$, and $\left.1100{ }^{\circ} \mathrm{C}\right)$, (b) comparison of Fe-N-C-700, nitrogendoped carbon (NC), and the catalysts derived from pyrolysis of the $\mathrm{NC} / \mathrm{Fe}_{2} \mathrm{O}_{3}$ composite at $700{ }^{\circ} \mathrm{C}$ for different duration. $\mathrm{NC} / \mathrm{Fe}_{2} \mathrm{O}_{3}$ composite prepared from physical mixing the $\mathrm{NC}$ and $\mathrm{Fe}_{2} \mathrm{O}_{3}$ nanoparticles. From the electrochemical analysis, we found that the $\mathrm{Fe}_{2} \mathrm{O}_{3} @ \mathrm{ZIF}-8$ composite pyrolyzed at $700{ }^{\circ} \mathrm{C}$ (Fe-N-C-700) without ORR activity, but pyrolysis of the $\mathrm{NC} / \mathrm{Fe}_{2} \mathrm{O}_{3}$ composite at $700{ }^{\circ} \mathrm{C}$ showing outstanding ORR activity. Combined with the in situ STEM observation of the evolution pathway of $\mathrm{Fe}_{2} \mathrm{O}_{3}$ converting into atomic $\mathrm{FeN}_{4}$ sites, the results illustrate the $\mathrm{FeN}_{4}$ sites have been generated at $700{ }^{\circ} \mathrm{C}$, but the low conductivity of the Fe-N-C-700 catalyst leads to its deficient ORR activity. 

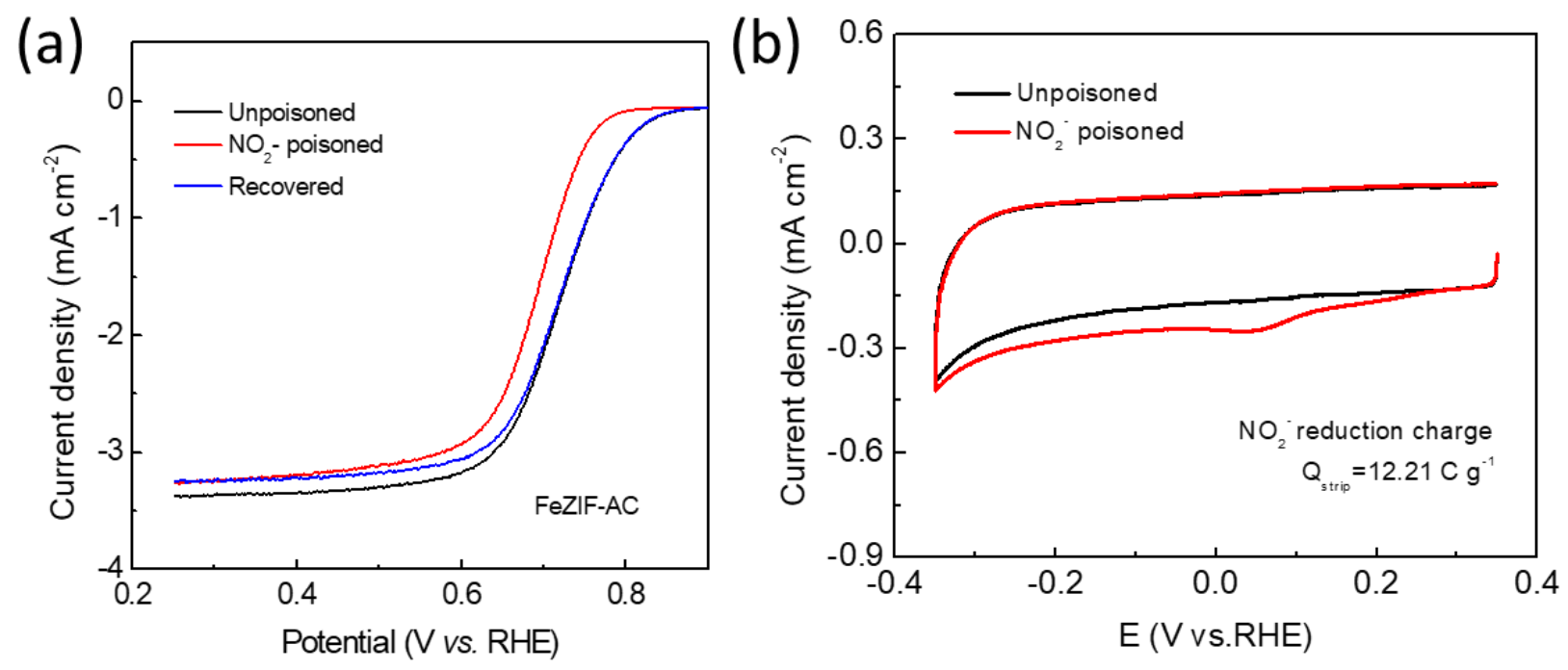

Figure S32. $\mathrm{FeN}_{4}$ site density of FeZIF-AC catalyst through reversible nitrite poisoning. (a) LSV curves before, during, and after nitrite adsorption in a $0.5 \mathrm{M}$ acetate buffer at $\mathrm{pH} 5.2$ for the FeZIF$\mathrm{AC}$ catalyst. (b) $\mathrm{CV}$ curves before and during nitrite adsorption in the nitrite reductive stripping region for the FeZIF-AC catalyst. Catalyst loading, $0.27 \mathrm{mg} \mathrm{cm}^{-2}$.

Table S11. Fitting parameters of the FePc standard (CN: coordination number; R: distance; $\sigma^{2}$ : mean-square disorder; $\mathrm{E}_{0}$ : energy shift). The single-digit numbers in parentheses are the last digit errors

\begin{tabular}{|c|c|c|c|c|c|}
\hline $\begin{array}{c}\text { Scattering } \\
\text { paths }\end{array}$ & $\mathrm{CN}$ & $\mathrm{R}(\AA)$ & $\mathrm{E}_{0}(\mathrm{eV})$ & $\sigma^{2}\left(\AA^{2}\right)$ & R-factor \\
\hline $\mathrm{Fe}-\mathrm{N}$ & 4 & $1.93(1)$ & \multirow{4}{*}{$-5(1)$} & $0.0078(9)$ & \multirow{4}{*}{0.018} \\
\hline $\mathrm{Fe}-\mathrm{C}$ & 8 & $2.96(1)$ & & $0.0078(1)$ & \\
\hline Fe-N-C & 16 & $3.13(2)$ & & $0.0040(6)$ & \\
\hline $\mathrm{Fe}-\mathrm{N}$ & 4 & $3.37(2)$ & & $0.0065(8)$ & \\
\hline
\end{tabular}




\begin{tabular}{|c|c|c|c|}
\hline Fe-N-N & 16 & $3.86(2)$ & $0.0008(7)$ \\
\hline Fe-N-N & 4 & $3.86(2)$ & $0.0008(7)$ \\
\hline $\mathrm{Fe}-\mathrm{C}$ & 6 & $4.19(2)$ & $0.0184(6)$ \\
\hline $\mathrm{Fe}-\mathrm{N}-\mathrm{C}$ & 12 & $4.22(2)$ & $0.0107(2)$ \\
\hline
\end{tabular}

Table S12. Fitting parameters of the Fe-N-C (CN: coordination number; R: distance; $\sigma^{2}$ : meansquare disorder; $\mathrm{E}_{0}$ : energy shift). The single-digit numbers in parentheses are the last digit errors. The numbers in parentheses for $\mathrm{CN}$ are the full errors.

\begin{tabular}{|c|c|c|c|c|c|}
\hline $\begin{array}{c}\text { Scattering } \\
\text { Paths }\end{array}$ & $\mathrm{CN}$ & $\mathrm{R}(\AA)$ & $\mathrm{E}_{0}(\mathrm{eV})$ & $\sigma^{2}\left(\AA^{2}\right)$ & $\mathrm{R}$-factor \\
\hline $\mathrm{Fe}-\mathrm{N}$ & $4.2(0.9)$ & $2.02(2)$ & \multirow{3}{*}{$0.5(1)$} & $0.0082(8)$ & \multirow{3}{*}{0.038} \\
\hline Fe-C & 9.1(1.7) & $3.04(7)$ & & $0.0197(6)$ & \\
\hline $\mathrm{Fe}-\mathrm{N}-\mathrm{C}$ & $18.2(3.5)$ & $3.26(7)$ & & $0.0132(9)$ & \\
\hline
\end{tabular}



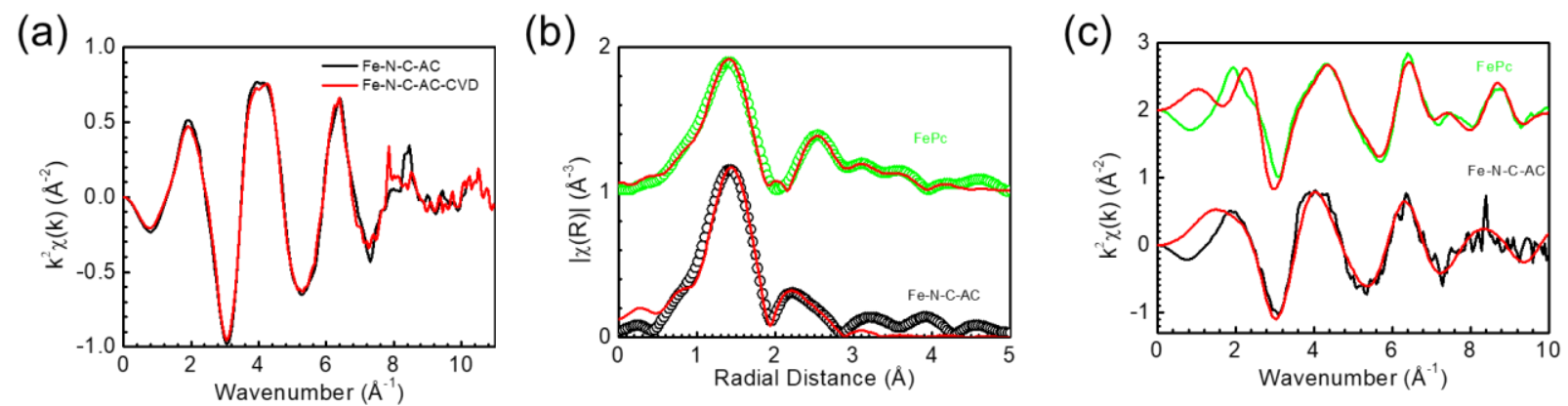

Figure S33. (a) k-space EXAFS spectra to compare catalyst with and without CVD process. Model-based fitting for EXAFS in (b) R-space and (c) k-space for FePc and Fe-N-C-AC catalyst.
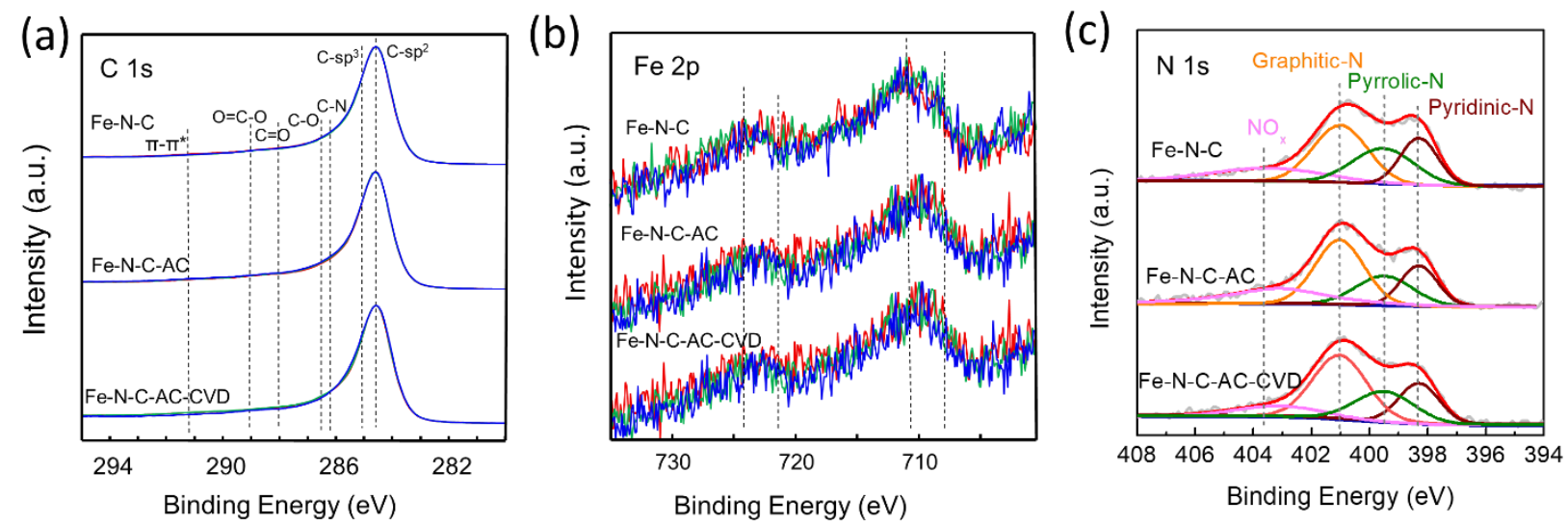

Figure S34. XPS analysis of (a) C 1s, (b) Fe 2p, and (c) N 1s for these three typical Fe-N-C, Fe$\mathrm{N}-\mathrm{C}-\mathrm{AC}$, and Fe-N-C-AC-CVD catalysts. 
Table S13. Surface compositions (at.\%) of three typical Fe-N-C, Fe-N-C-AC, and Fe-N-C-ACCVD catalysts by using XPS.

\begin{tabular}{|c|c|c|c|c|c|c|c|c|c|}
\hline \multirow[b]{2}{*}{ Name } & \multicolumn{3}{|c|}{ Fe-N-C } & \multicolumn{3}{|c|}{ Fe-N-C-AC } & \multicolumn{3}{|c|}{ Fe-N-C-AC-CVD } \\
\hline & Area 1 & Area2 & $\begin{array}{c}\text { Area } \\
3\end{array}$ & $\begin{array}{c}\text { Area } \\
1\end{array}$ & Area2 & $\begin{array}{c}\text { Area } \\
3\end{array}$ & $\begin{array}{c}\text { Area } \\
1\end{array}$ & Area2 & Area $3^{a}$ \\
\hline $\mathrm{C}-\mathrm{sp}^{2}$ & 58.60 & 54.94 & 57.5 & 63.13 & 63.91 & 62.40 & 63.44 & 64.96 & 52.06 \\
\hline C-sp $p^{3}$ & 22.07 & 25.42 & 23.16 & 19.73 & 18.72 & 20.51 & 18.27 & 15.93 & 28.54 \\
\hline $\mathrm{C}-\mathrm{N}$ & 2.55 & 2.55 & 2.44 & 2.01 & 2.03 & 1.98 & 2.16 & 2.35 & 2.41 \\
\hline $\mathrm{C}-\mathrm{O}$ & 0.64 & 0.64 & 0.61 & 0.57 & 0.58 & 0.57 & 1.13 & 1.23 & 1.26 \\
\hline $\mathrm{C}=\mathrm{O}$ & 2.98 & 2.98 & 2.85 & 2.68 & 2.71 & 2.65 & 3.07 & 3.34 & 3.43 \\
\hline $\mathrm{O}=\mathrm{C}-\mathrm{O}$ & 1.28 & 1.28 & 1.22 & 0.96 & 0.97 & 0.95 & 0.82 & 0.9 & 0.92 \\
\hline $\mathrm{O}=\mathrm{C}$ & 3.38 & 2.88 & 2.65 & 2.92 & 3.00 & 2.49 & 3.03 & 3.12 & 2.45 \\
\hline $\mathrm{O}=\mathrm{C}-\mathrm{O}$ & 2.13 & 2.27 & 2.28 & 2.58 & 2.59 & 2.49 & 1.49 & 1.43 & 2.24 \\
\hline $\mathrm{O}-\mathrm{Me}$ & 1.56 & 1.55 & 1.42 & 1.54 & 1.52 & 1.41 & 1.64 & 1.82 & 1.87 \\
\hline $\mathrm{O}-\mathrm{C}$ & 0.61 & 1.39 & 1.53 & 0.58 & 0.61 & 1.06 & 1.06 & 0.96 & 1.61 \\
\hline$-\mathrm{OH}$ & 0.47 & 0.56 & 0.66 & 0.48 & 0.51 & 0.62 & 0.62 & 0.6 & 0.41 \\
\hline N-pyridine & 0.53 & 0.44 & 0.60 & 0.63 & 0.65 & 0.58 & 0.33 & 0.40 & 0.32 \\
\hline $\begin{array}{c}\mathrm{N}- \\
\text { Graphitic }\end{array}$ & 1.14 & 0.99 & 0.96 & 0.87 & 0.90 & 0.96 & 1.16 & 1.21 & 0.95 \\
\hline N-Pyrrolic & 0.80 & 0.91 & 0.89 & 0.42 & 0.43 & 0.40 & 0.59 & 0.61 & 0.52 \\
\hline $\mathrm{O}-\mathrm{N}$ & 0.64 & 0.57 & 0.65 & 0.38 & 0.42 & 0.45 & 0.52 & 0.48 & 0.41 \\
\hline $\mathrm{Fe}-\mathrm{O}$ & 0.14 & 0.11 & 0.1 & 0.10 & 0.10 & 0.07 & 0.14 & 0.13 & 0.10 \\
\hline $\mathrm{Zn}-\mathrm{O}$ & 0.07 & 0.07 & 0.07 & 0.01 & 0.01 & 0.01 & 0.01 & 0.01 & 0.01 \\
\hline
\end{tabular}

${ }^{a}$ This area should be ignored due to out of margin of error. 


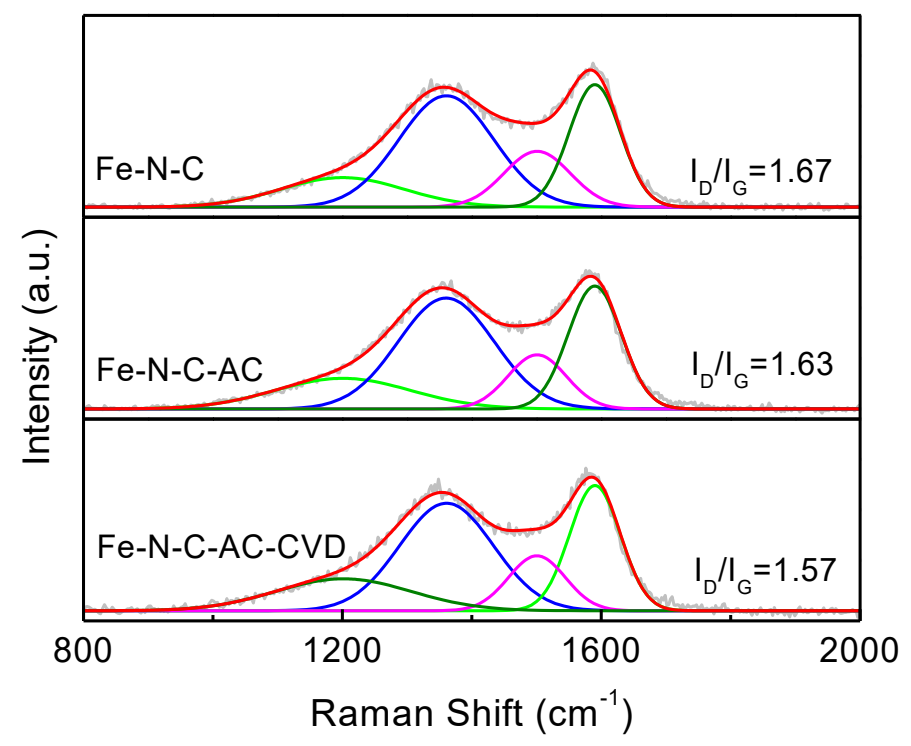

Figure S35. Raman spectra of Fe-N-C, Fe-N-C-AC, and Fe-N-C-AC-CVD catalysts.

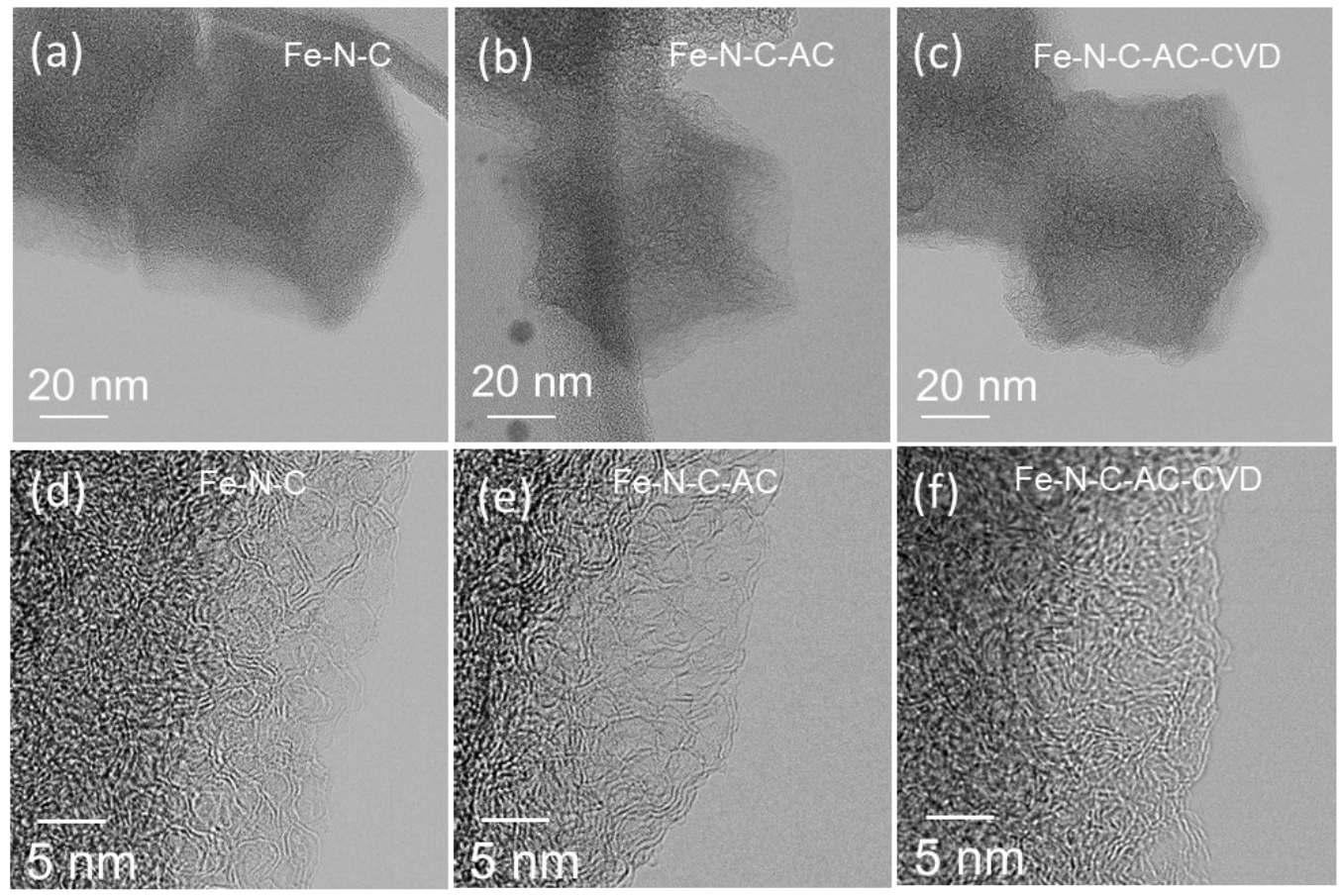

Figure S36. Bright-field STEM images of the Fe-N-C, Fe-N-C-AC, and Fe-N-C-AC-CVD catalysts. 


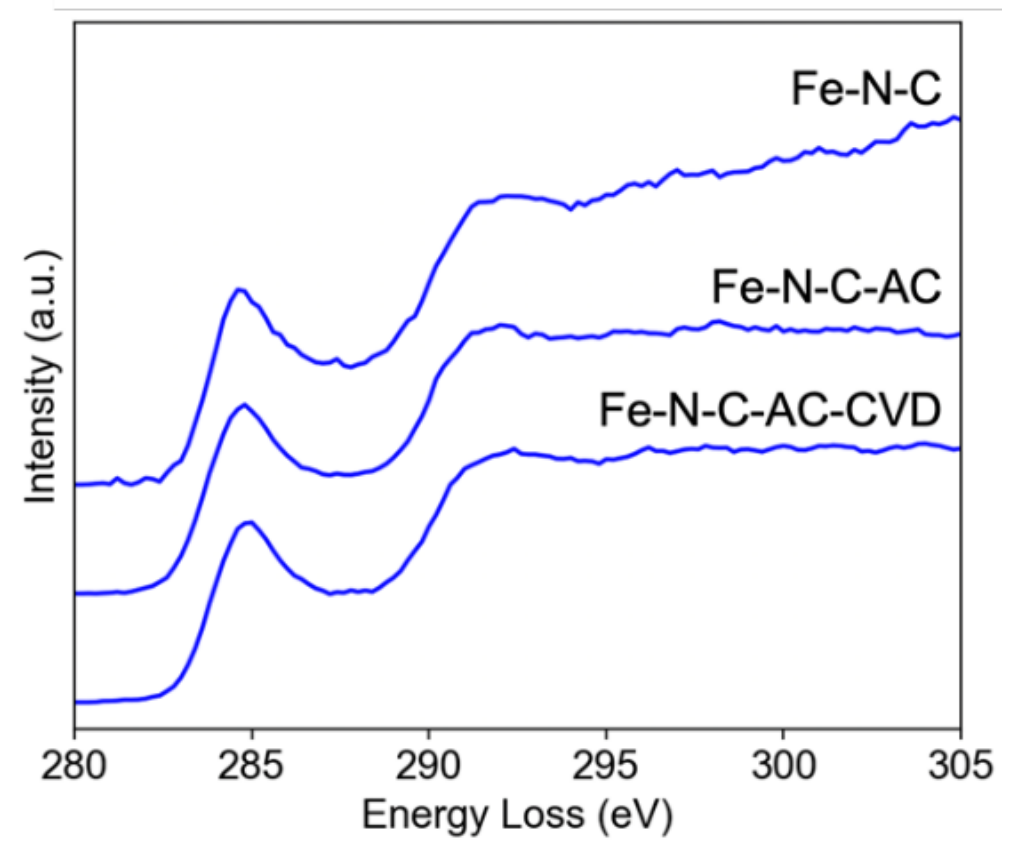

Figure S37. Third multivariate curve resolution (MCR) components are corresponding to the three catalysts concerning graphitic carbon signals from thicker regions.

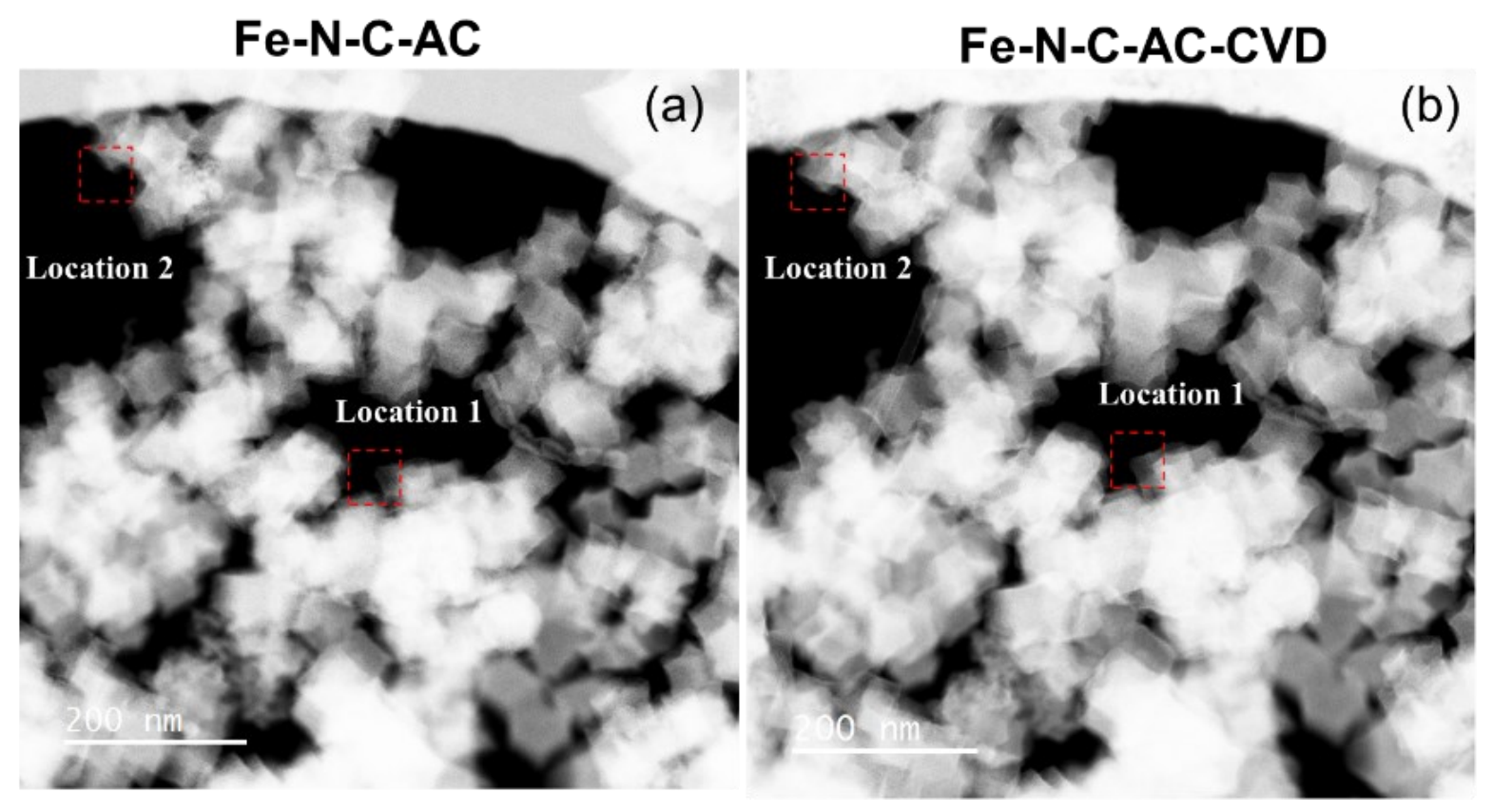

Figure S38. IL-STEM images of the Fe-N-C-AC catalyst before (a) and after (b) the CVD process, i.e., the Fe-N-C-AC-CVD catalyst. 


\section{Location 1}

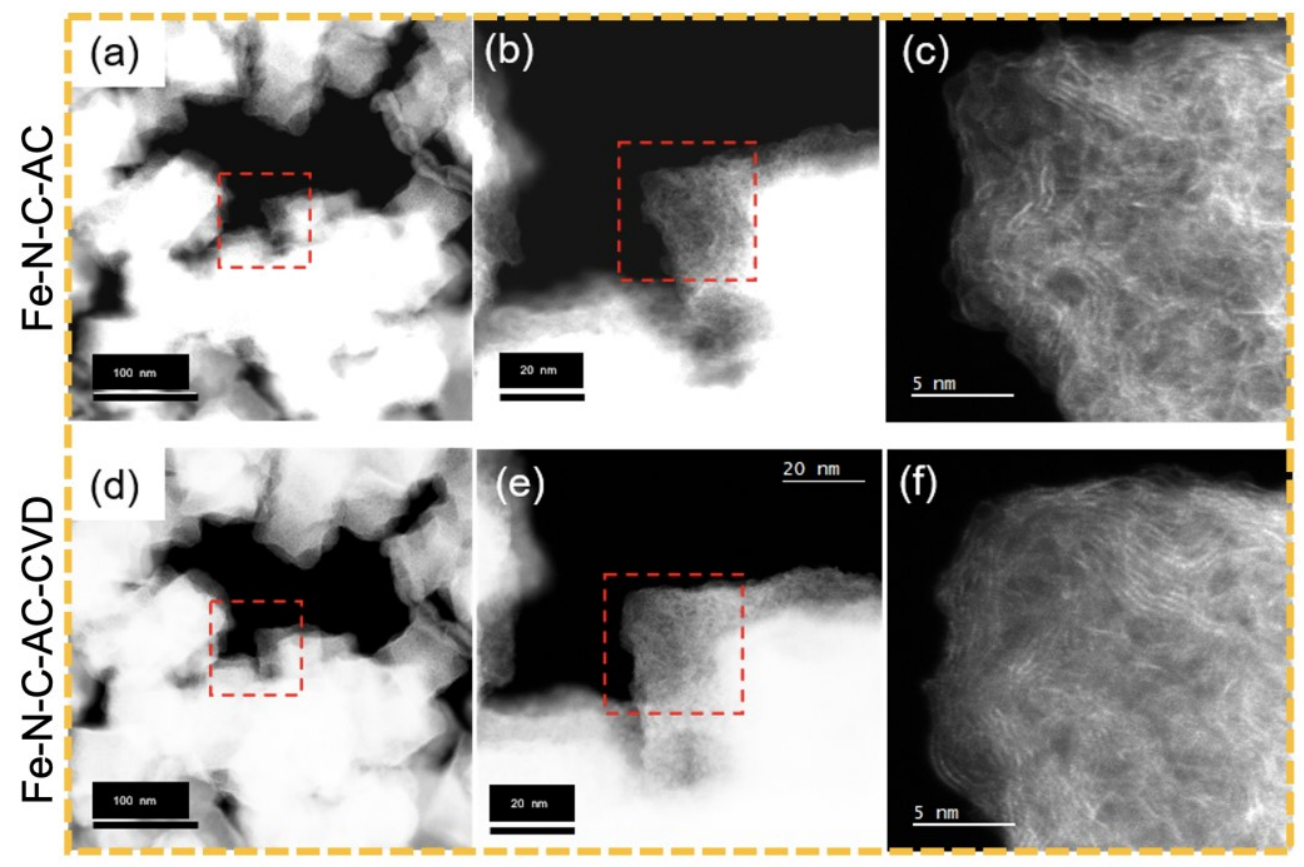

\section{Location 2}

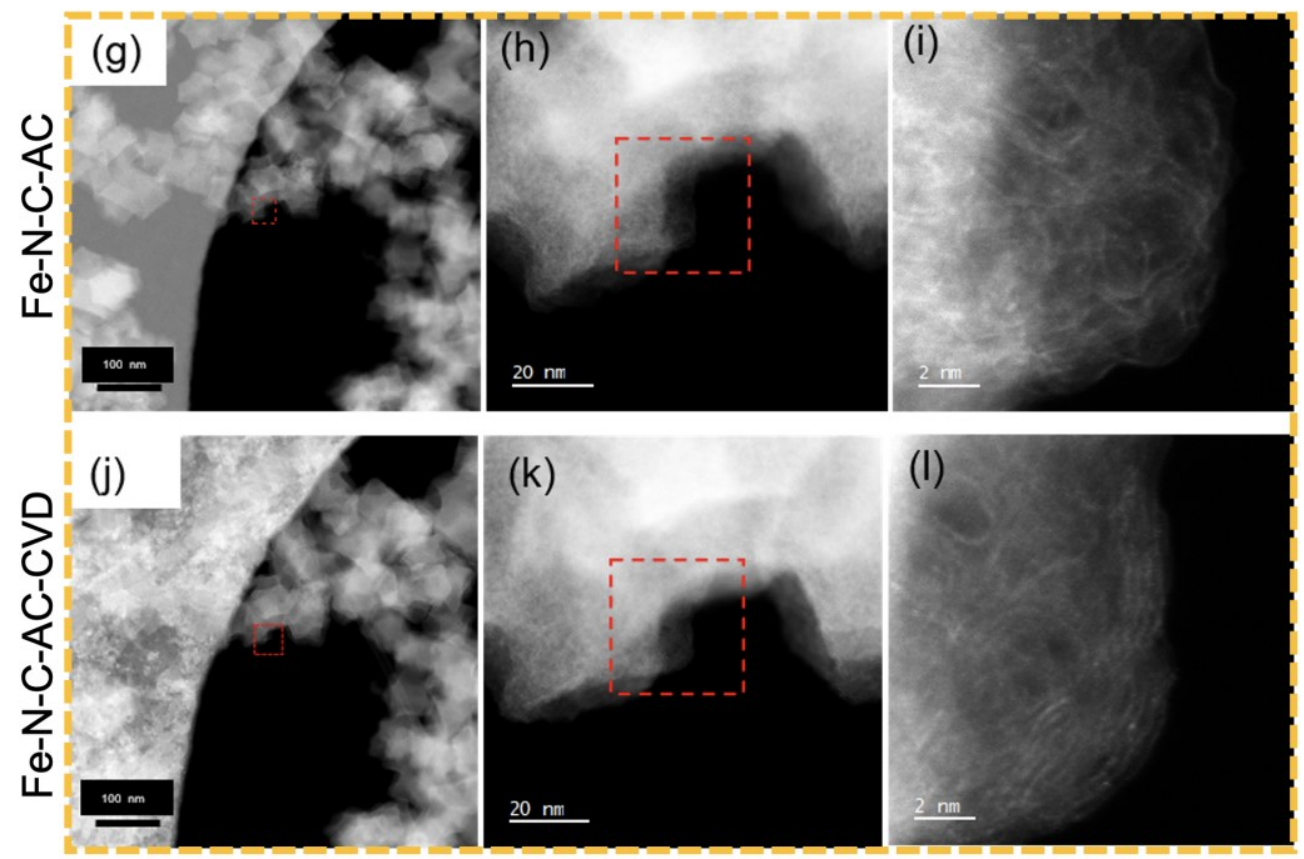

Figure S39. IL-STEM images for two locations on the Fe-N-C-AC catalyst before and after CVD. Location 1 of (a-c) Fe-N-C-AC and (d-f) Fe-N-C-AC-CVD catalysts, location 2 of (g-i) Fe-N-C$\mathrm{AC}$ and (j-1) Fe-N-C-AC-CVD catalysts. 
Note that the changes observed in the IL-STEM experiments likely represent an extreme case, since the surfaces examined were fully exposed to the gas stream during the CVD process. In a powder bed, a large proportion of the catalyst material would not be directly exposed to the gas stream in this manner, and degrees of coating and any potential defect healing would likely vary for particles in different locations within the bed, with a lower average deposition than observed in the IL-STEM experiments. This work therefore suggests that even minute changes to the sample surface structure can significantly alter the performance and durability of the catalyst.

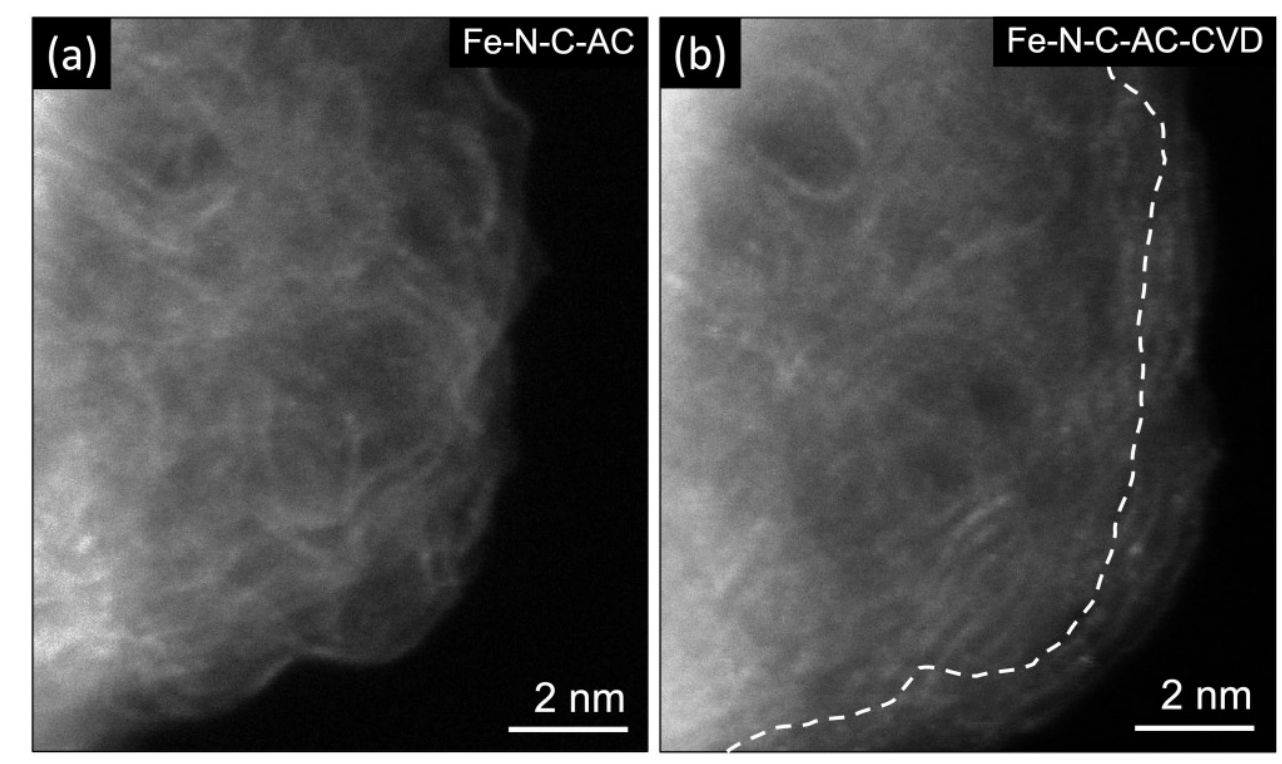

Figure S40. High-angle annular dark-field IL-STEM images (a, b) of the Fe-N-C-AC catalyst at location 2 before and after the CVD process, respectively. The dashed line indicates the location of the particle surface before CVD, showing that the CVD process adds material to the particle surface. 

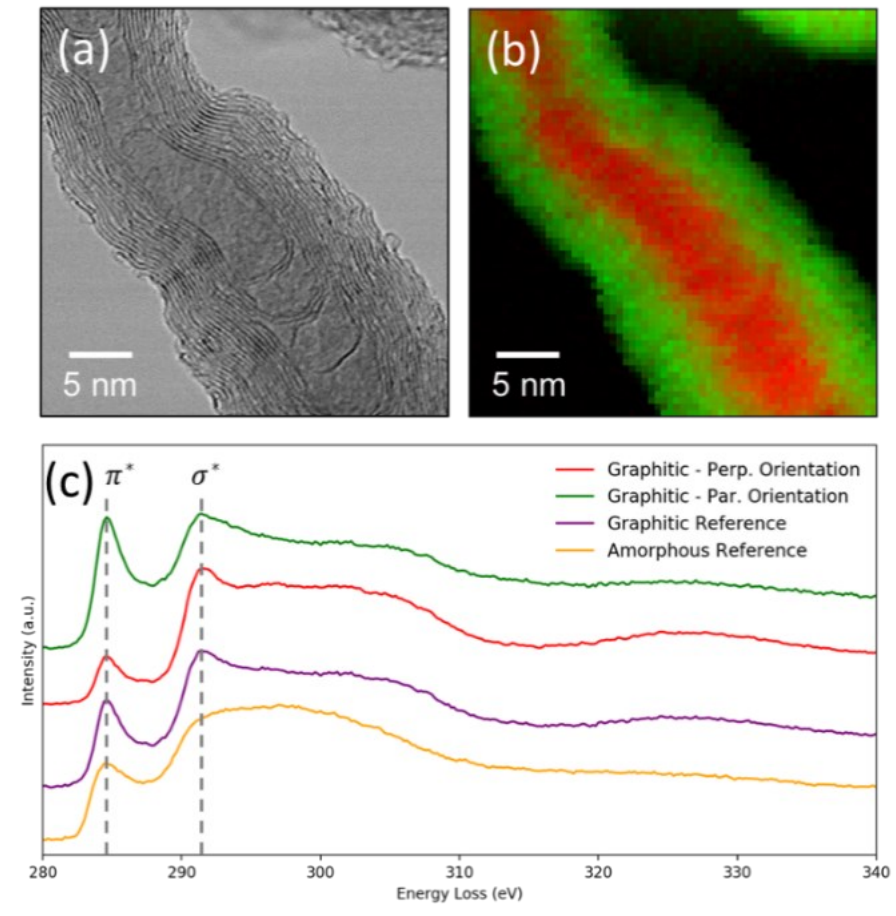

Figure S41. (a) Bright-field STEM image and (b) orientational map of a multi-walled carbon nanotube showing spatial components from EELS carbon K-edge multivariate curve resolution. The result shows that graphitic sheets parallel and perpendicular to the beam are identified. EELS carbon K-edge fine structure is sensitive to the orientation of graphitic sheets concerning the beam, which allows us to obtain information about the nanoscale structure of the graphitic materials by identifying regions with sheets parallel and perpendicular to the beam. Spectra from the edges and center of a reference multi-walled carbon nanotube, where the graphitic sheets are primarily parallel and perpendicular to the electron beam, respectively, have significantly different fine structures. (c) Multivariate curve resolution spectral components corresponding to the spatial components of the carbon nanotube displayed in (b), with a comparison to average reference spectra for graphitic (nanotube) and amorphous (lacey carbon support) carbon. Graphitic planes parallel to the beam result in stronger excitations to $\pi^{*}$ states than $\sigma^{*}$ states, and vice versa for planes perpendicular to the beam, allowing regions with these orientations to be differentiated. 

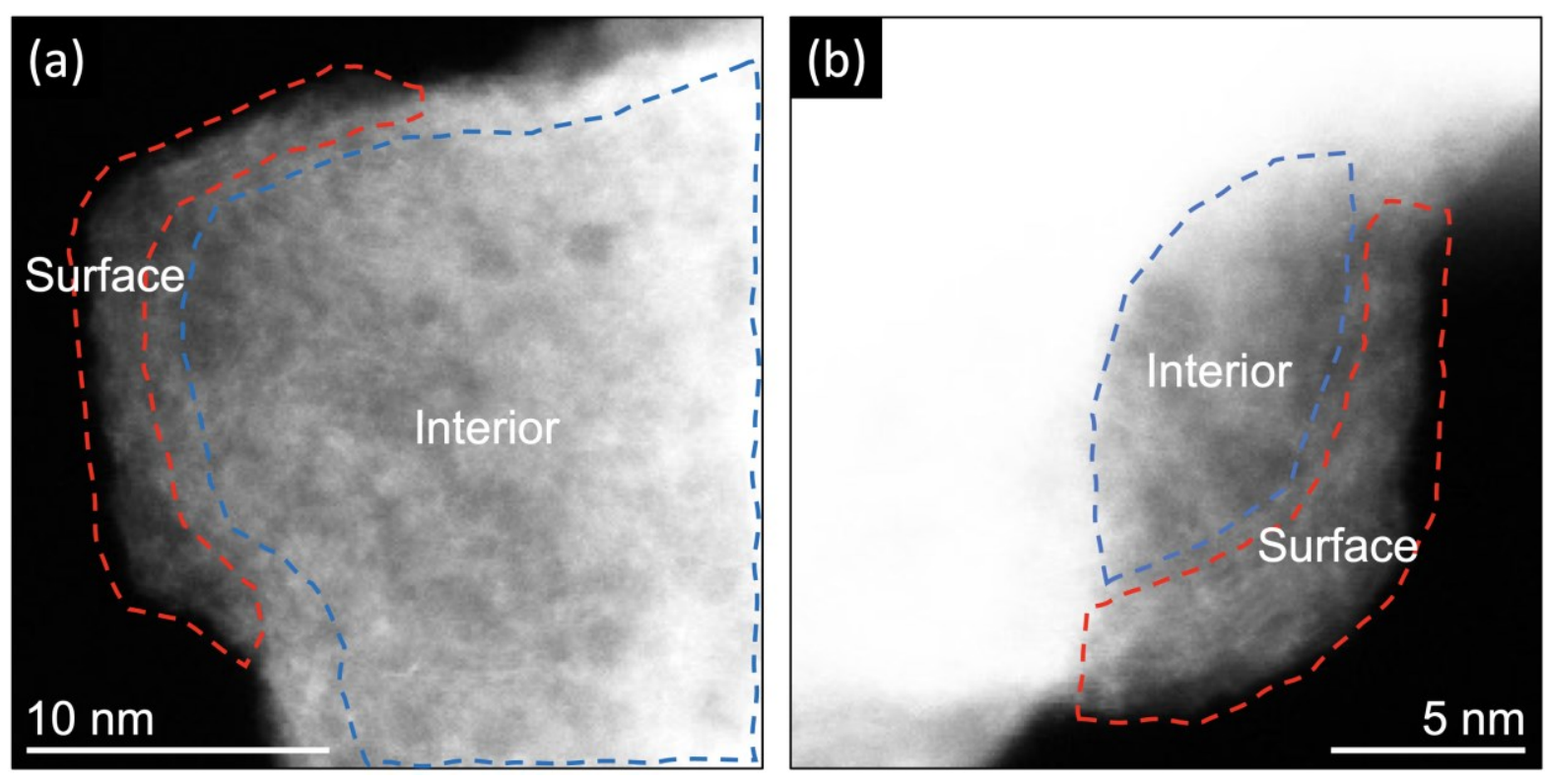

Figure S42. Regions of IL-STEM-EDS analysis at location 1 (a) and location 2 (b) of Fe-N-CAC-CVD catalyst.

Table S14. Elemental quantification of different locations and areas of the Fe-NC-AC-CVD catalysts by IL-STEM-EDS (at. \%).

\begin{tabular}{c|c|c|c|c}
\hline \multirow{2}{*}{ Atomic \% } & \multicolumn{2}{|c|}{ Location 1 } & \multicolumn{2}{c}{ Location 2 } \\
\cline { 2 - 5 } & Interior & Surface & Interior & Surface \\
\hline $\mathrm{C}$ & 95.3 & 93.3 & 95.5 & 93.8 \\
\hline $\mathrm{N}$ & 2.1 & 3.1 & 2.3 & 3.8 \\
\hline $\mathrm{O}$ & 2.6 & 3.6 & 2.2 & 2.4 \\
\hline
\end{tabular}


(a)

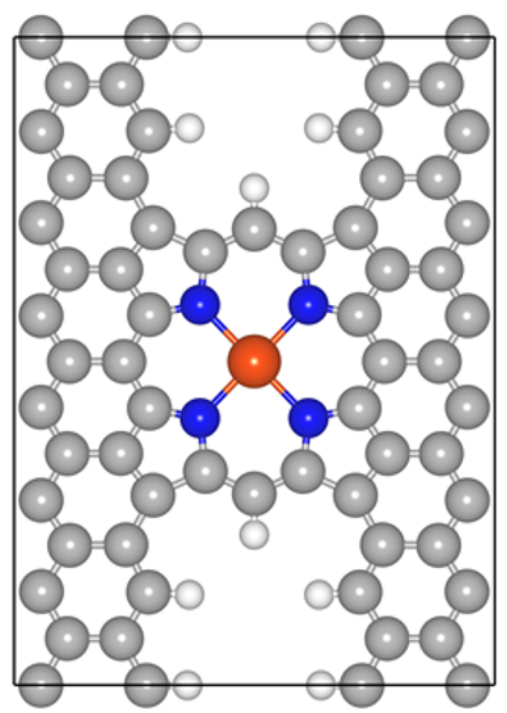

(b)

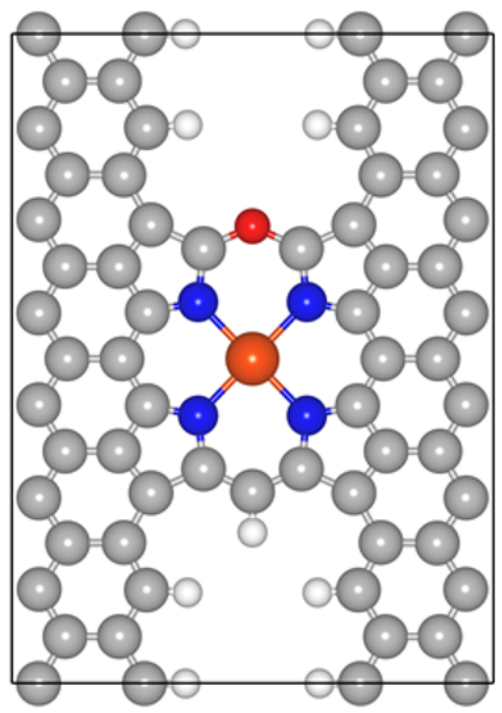

Figure S43. Modelled structures of (a) $\mathrm{FeN}_{4} \mathrm{C}_{12}$, and (b) $\mathrm{FeN}_{4} \mathrm{C}_{12}-\mathrm{O}$ active sites. In these figures, the gray, blue, orange, red, and white balls represent $\mathrm{C}, \mathrm{N}, \mathrm{Fe}, \mathrm{O}$, and $\mathrm{H}$ atoms, respectively.

(a)

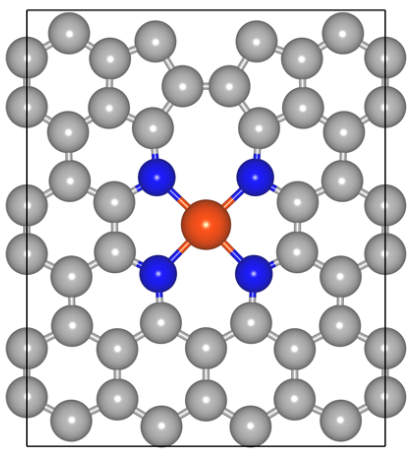

(b)

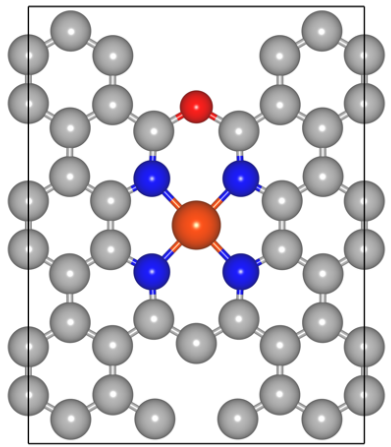

(c)

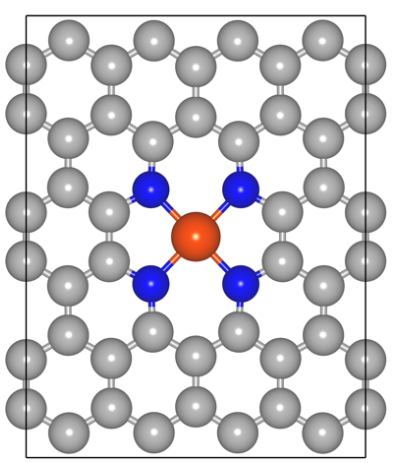

Figure S44. Modelled structures of (a) $\mathrm{FeN}_{4} \mathrm{C}_{10}-\mathrm{C}$, (b) $\mathrm{FeN}_{4} \mathrm{C}_{10}-\mathrm{O}$, and (c) $\mathrm{FeN}_{4} \mathrm{C}_{10}$ active sites. In these figures, the gray, blue, orange, and red balls represent $\mathrm{C}, \mathrm{N}, \mathrm{Fe}$, and $\mathrm{O}$ atoms, respectively.

As shown in Fig. 6, we propose a possible route for the formation of embedded O near S1 or S2 site during ORR. In our calculations, we constructed a $\mathrm{S} 1$ type $\mathrm{FeN}_{4}$ site hosted by micropore $\left(\mathrm{FeN}_{4} \mathrm{C}_{12}\right)$ and a $\mathrm{S} 2$ type $\mathrm{FeN}_{4}$ site with a Stone-Wales defect nearby $\left(\mathrm{FeN}_{4} \mathrm{C}_{10}-\mathrm{C}\right)$ to model the active site in $\mathrm{Fe}-\mathrm{N}-\mathrm{C}$ catalyst. Considering that the $\mathrm{NH}_{4} \mathrm{Cl}$ treatment would etch some carbon atoms in Fe-N-C catalyst, we subsequently used a $\mathrm{S} 1$ type and $\mathrm{S} 2$ type $\mathrm{FeN}_{4}$ containing some carbon vacancies (denoted as $\mathrm{FeN}_{4} \mathrm{C}_{12}$-vac and $\mathrm{FeN}_{4} \mathrm{C}_{10}$-vac) to model the active site in Fe-N-C- 
AC catalyst after $\mathrm{NH}_{4} \mathrm{Cl}$ treatment. We found that it was energetically favorable for ORR intermediate $* \mathrm{O}$ to reconfigure to a more stable $\mathrm{FeN}_{4}$ site with $\mathrm{O}$ located on the edge of pore. The enthalpy changes were predicted to be negative $4.23 \mathrm{eV}$ and $3.79 \mathrm{eV}$ for S1 and S2 type FeN4 site, respectively (Fig. S45). This result suggests that etched $\mathrm{FeN}_{4} \mathrm{C}_{12}$-vac and $\mathrm{FeN}_{4} \mathrm{C}_{10}$-vac site could reconfigure to $\mathrm{FeN}_{4} \mathrm{C}_{12}-\mathrm{O}$ and $\mathrm{FeN}_{4} \mathrm{C}_{10}-\mathrm{O}$ active site during $\mathrm{ORR}$ by introducing $\mathrm{O}$ to passivate the unsaturated carbon atoms near vacancies.

(a)

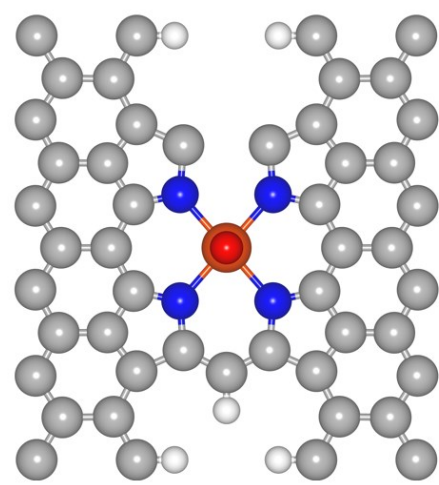

$-4.23 \mathrm{eV}$
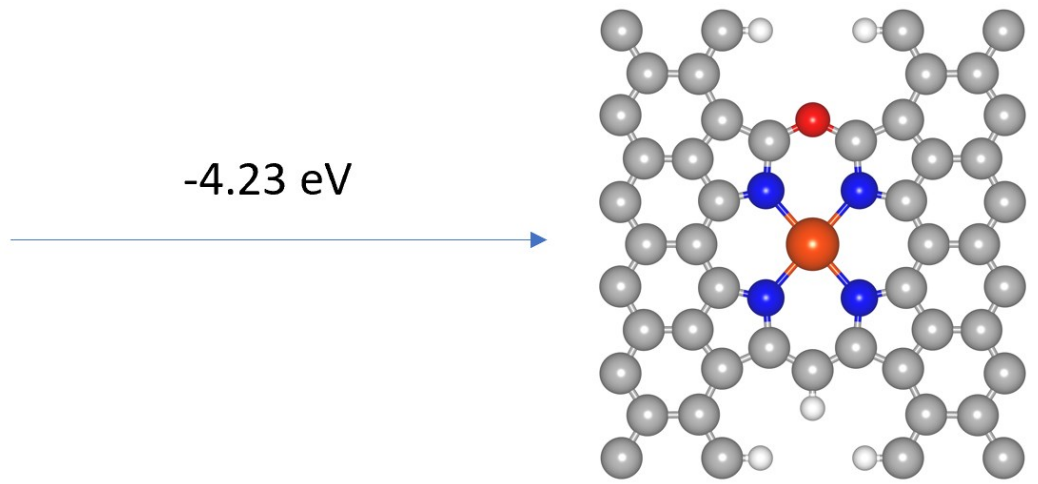

(b)

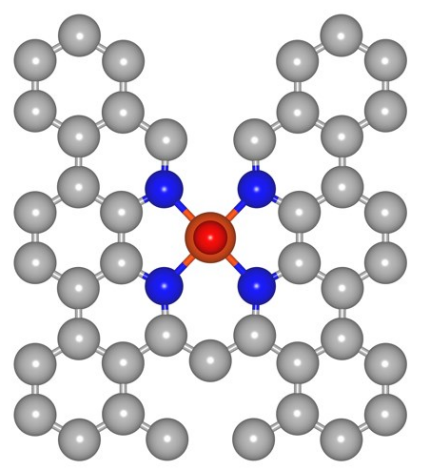

$-3.79 \mathrm{eV}$

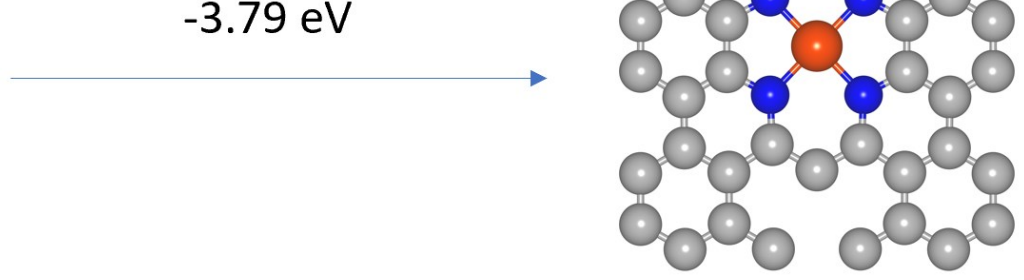

Figure S45. Atomistic structures of transfer step of * $\mathrm{O}$ on (a) $\mathrm{FeN}_{4} \mathrm{C}_{12}$-vac site, and (b) $\mathrm{FeN}_{4} \mathrm{C}_{10}$ vac site. In the figure, the gray, blue, orange, and red balls represent $\mathrm{C}, \mathrm{N}, \mathrm{Fe}$, and $\mathrm{O}$ atoms, respectively. 
Table S15. Predicted adsorption energies of various ORR species on various modelled $\mathrm{FeN}_{4}$ active sites. The adsorption energies are calculated as the difference in energy between the adsorption system and the corresponding isolated systems. Hence, negative value of the adsorption energy indicates attractive interaction between the ORR species and ORR active sites.

\begin{tabular}{lllll}
\hline$E_{a d}(\mathrm{eV})$ & $\mathrm{O}_{2}$ & $\mathrm{OOH}$ & $\mathrm{O}$ & $\mathrm{OH}$ \\
\hline $\mathrm{FeN}_{4} \mathrm{C}_{12}$ & -0.90 & -1.68 & -4.15 & -2.75 \\
$\mathrm{FeN}_{4} \mathrm{C}_{12}-\mathrm{O}$ & -0.61 & -1.37 & -3.82 & -2.52 \\
$\mathrm{FeN}_{4} \mathrm{C}_{10}-\mathrm{C}$ & -1.05 & -1.79 & -3.93 & -2.83 \\
$\mathrm{FeN}_{4} \mathrm{C}_{10}-\mathrm{O}$ & -0.74 & -1.50 & -4.06 & -2.73 \\
$\mathrm{FeN}_{4} \mathrm{C}_{10}$ & -0.98 & -1.76 & -4.25 & -2.81 \\
\hline
\end{tabular}

(a)

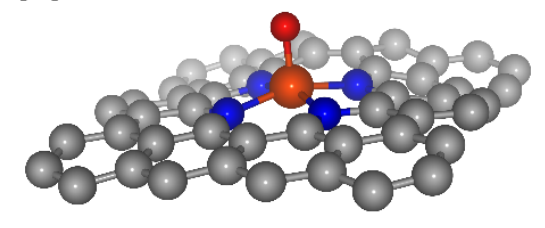

(b)

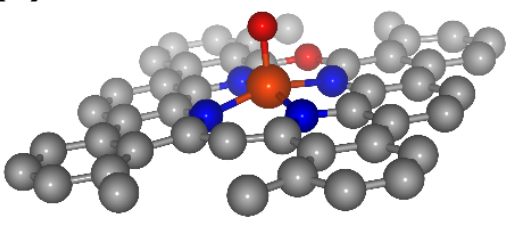

(c)

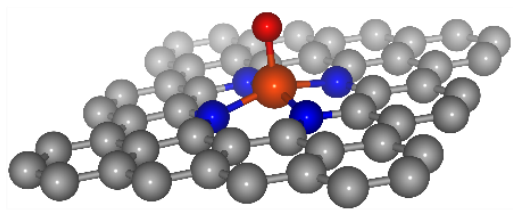

Figure S46. The optimized atomic structure of $\mathrm{O}$ adsorption on (a) $\mathrm{FeN}_{4} \mathrm{C}_{10}-\mathrm{C}$, (b) $\mathrm{FeN}_{4} \mathrm{C}_{10}-\mathrm{O}$, and (c) $\mathrm{FeN}_{4} \mathrm{C}_{10}$ active sites. In the figure, the gray, blue, orange, and red balls represent $\mathrm{C}, \mathrm{N}, \mathrm{Fe}$, and $\mathrm{O}$ atoms, respectively. 
(a)

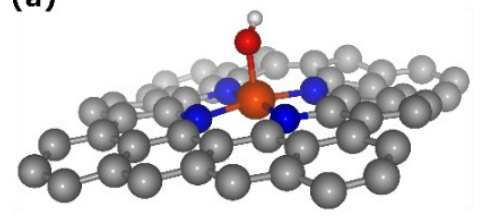

(b)

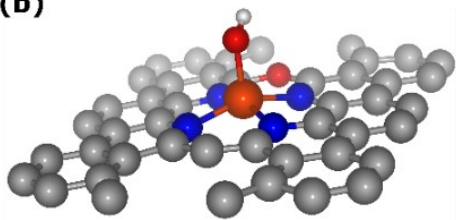

(c)

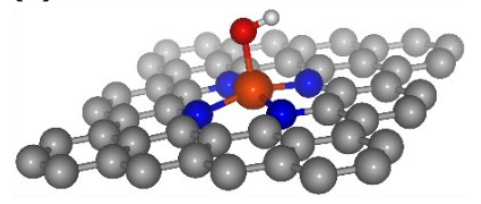

Figure S47. The optimized atomic structure of $\mathrm{OH}$ adsorption on (a) $\mathrm{FeN}_{4} \mathrm{C}_{10}-\mathrm{C}$, (b) $\mathrm{FeN}_{4} \mathrm{C}_{10}-\mathrm{O}$, and (c) $\mathrm{FeN}_{4} \mathrm{C}_{10}$ active sites. In the figure, the gray, blue, orange, red, and white balls represent $\mathrm{C}$, $\mathrm{N}, \mathrm{Fe}, \mathrm{O}$, and $\mathrm{H}$ atoms, respectively.

(a)

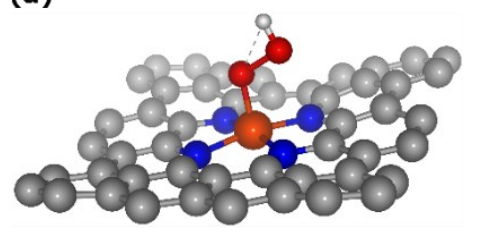

(b)

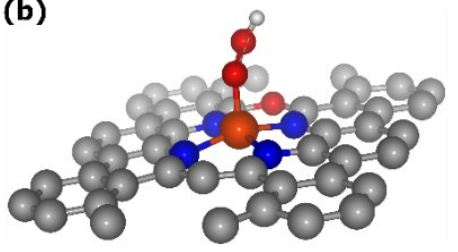

(c)

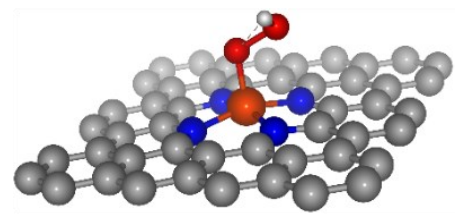

Figure S48. The optimized atomic structure of $\mathrm{OOH}$ adsorption on (a) $\mathrm{FeN}_{4} \mathrm{C}_{10^{-}} \mathrm{C}$, (b) $\mathrm{FeN}_{4} \mathrm{C}_{10^{-}}$ $\mathrm{O}$, and (c) $\mathrm{FeN}_{4} \mathrm{C}_{10}$ active sites. In the figure, the gray, blue, orange, red, and white balls represent $\mathrm{C}, \mathrm{N}, \mathrm{Fe}, \mathrm{O}$, and $\mathrm{H}$ atoms, respectively.

(a)

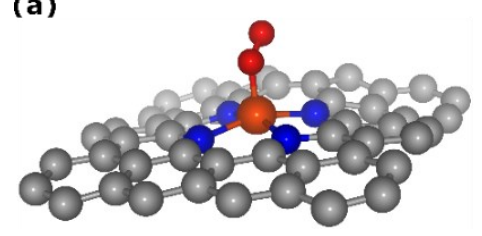

(b)

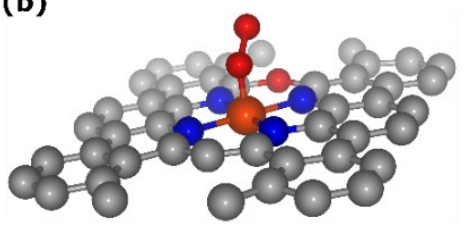

(c)

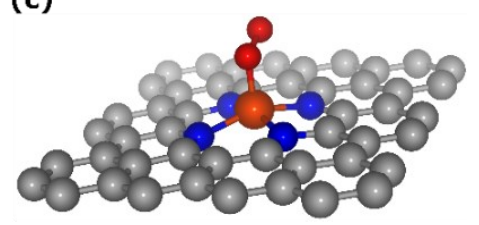

Figure S49. The optimized atomic structure of $\mathrm{O}_{2}$ adsorption on (a) $\mathrm{FeN}_{4} \mathrm{C}_{10}-\mathrm{C}$, (b) $\mathrm{FeN}_{4} \mathrm{C}_{10}-\mathrm{O}$, and (c) $\mathrm{FeN}_{4} \mathrm{C}_{10}$ active sites. In the figure, the gray, blue, orange, and red balls represent $\mathrm{C}, \mathrm{N}, \mathrm{Fe}$, and $\mathrm{O}$ atoms, respectively. 


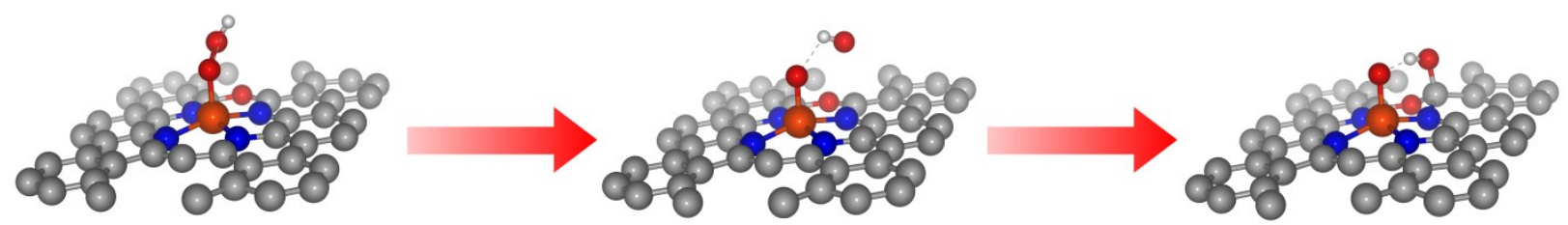

Figure S50. Optimized atomistic structures of the initial state (left), transition state (middle), and final state (right) for $\mathrm{OOH}$ dissociation on $\mathrm{FeN}_{4} \mathrm{C}_{10}-\mathrm{O}$ active site. In the figure, the gray, blue, orange, red, and white balls represent $\mathrm{C}, \mathrm{N}, \mathrm{Fe}, \mathrm{O}$, and $\mathrm{H}$ atoms, respectively.

\section{The calculation for demetallation of $\mathrm{Fe}$ from $\mathrm{FeN}_{4}$ site}

We first used the Fe ion in electrolyte as demetallized state to compute the free energy changes for the demetallation from $\mathrm{FeN}_{4}$ sites ( $\mathrm{S} 2$ site). The overall demetallation reaction and the free energy change expression are shown here.

$$
\begin{gathered}
\mathrm{FeN}_{4} \mathrm{C}_{10}+2 \mathrm{H}^{+}=\mathrm{H}_{2} \mathrm{~N}_{4} \mathrm{C}_{10}+\mathrm{Fe}^{2+} \\
\Delta G=G\left(\mathrm{H}_{2} \mathrm{~N}_{4} \mathrm{C}_{10}\right)+G\left(\mathrm{Fe}^{2+}\right)-G\left(\mathrm{FeN}_{4} \mathrm{C}_{10}\right)-2 * G\left(\mathrm{H}^{+}\right)
\end{gathered}
$$

Here, the free energy of $\mathrm{FeN}_{4} \mathrm{C}_{10}$, and $\mathrm{H}_{2} \mathrm{~N}_{4} \mathrm{C}_{10}$ were obtained from our DFT calculations. At 298 $\mathrm{K}$, the enthalpy, entropy and heat capacity were reported as $-92.5 \mathrm{~kJ} \mathrm{~mol}^{-1},-101.6 \mathrm{JK}^{-1} \mathrm{~mol}^{-1}$ and $33.05 \mathrm{JK}^{-1} \mathrm{~mol}^{-1}$ for $\mathrm{U}\left(\mathrm{Fe}^{2+} / \mathrm{Fe}\right)$ and $0.00 \mathrm{kJmol}^{-1}, 0.00 \mathrm{JK}^{-1} \mathrm{~mol}^{-1}$ and $0.00 \mathrm{JK}^{-1} \mathrm{~mol}^{-1}$ for $\mathrm{U}\left(\mathrm{H}^{+} / \mathrm{H}\right)$ (33). Based on these data, the free energy for demetallation of Fe from $\mathrm{FeN}_{4}$ was calculated to be $0.48 \mathrm{eV}$ at $298 \mathrm{~K}$ and the corresponding equilibrium constant was calculated as $7.6 \times 10^{-9}$ via equation $K=e^{-\frac{\Delta G}{R T}}$.

It should be mentioned that aforementioned calculation considers only the thermodynamics of the overall demetallation process. Taking some kinetic factors of the demetallation process into considerations, we regard the demetallation reaction consisting of two sequential steps. The first step is the demetallation of $\mathrm{Fe}$ from $\mathrm{FeN}_{4}$ active site to catalyst surface, i.e., the demetallation process proposed in this study. Subsequently, the Fe ion attached to the catalyst surface would desorb to form free Fe ion in electrolyte. In the first step, some Fe-N bonds need to be broken, which is the harder part of the two steps and hence identified as the rate determining step for the overall demetallation process. Therefore, we believe that the free energy change for the first step (i.e., transformation from $\mathrm{FeN}_{4}$ to $\mathrm{FeN}_{2}-\mathrm{H}_{2}$ ) adopted in this study could reflect the stability of FeN 4 site. 
(a)

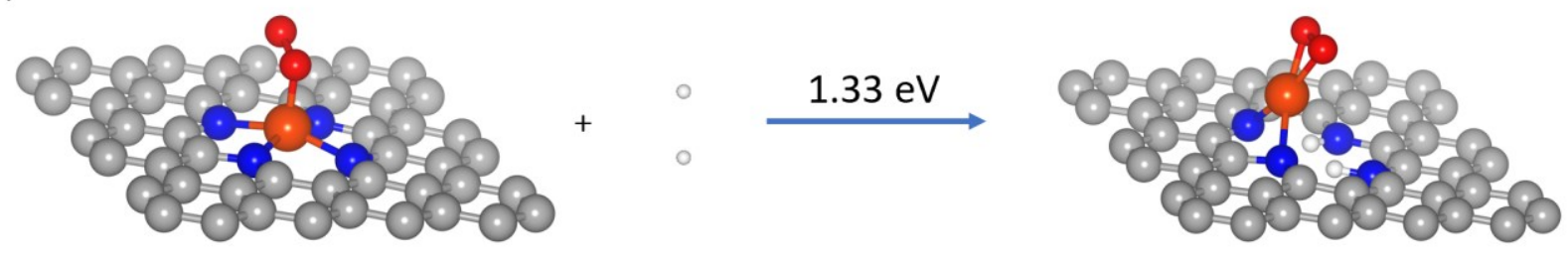

(b)

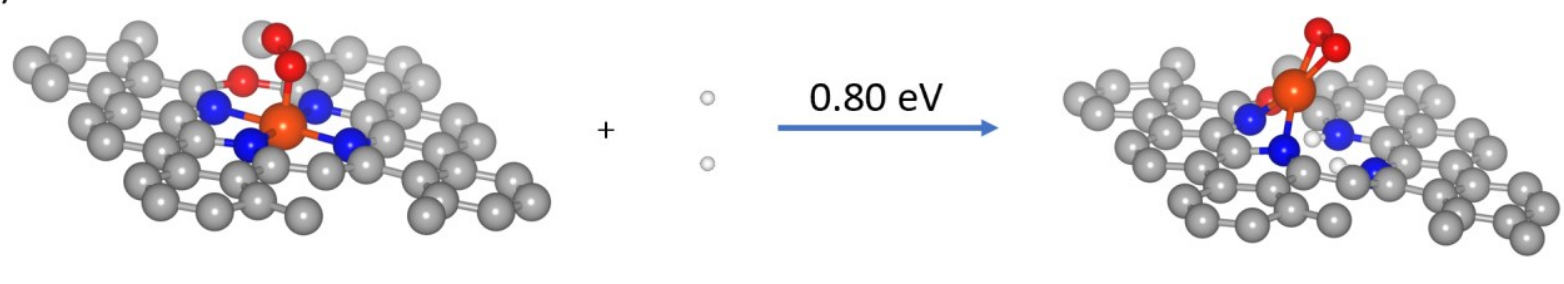

Figure S51. Atomistic structures of simulation models for demetallation of central $\mathrm{Fe}$ atom in (a) $\mathrm{FeN}_{4} \mathrm{C}_{10}$. (b) $\mathrm{FeN}_{4} \mathrm{C}_{10} \mathrm{O}$ active sites. In the figure, the gray, blue, orange, red, and white balls represent $\mathrm{C}, \mathrm{N}, \mathrm{Fe}, \mathrm{O}$, and $\mathrm{H}$ atoms, respectively.

Table S16. Predicted limiting potential, activation energy for $\mathrm{OOH}$ dissociation and free energy change $(\Delta G)$ for demetallation process on $\mathrm{FeN}_{4} \mathrm{C}_{12}$ and $\mathrm{FeN}_{4} \mathrm{C}_{12}-\mathrm{O}$ sites. Higher value of $\Delta G$ indicates better resistance to demetallation.

\begin{tabular}{llll}
\hline Active site & Limiting potential $(\mathrm{V})$ & $\begin{array}{l}\text { Activation } \\
\text { energy }(\mathrm{eV})\end{array}$ & $\begin{array}{l}\text { Free energy change for } \\
\text { demetallation }(\mathrm{eV})\end{array}$ \\
\hline $\mathrm{FeN}_{4} \mathrm{C}_{12}$ & 0.73 & 0.73 & 0.05 \\
$\mathrm{FeN}_{4} \mathrm{C}_{12}-\mathrm{O}$ & 0.81 & 0.71 & -0.05 \\
\hline
\end{tabular}


Table S17. Predicted limiting potential, the activation energy for $\mathrm{OOH}$ dissociation, and free energy change $(\Delta G)$ for demetallation process on $\mathrm{FeN}_{4} \mathrm{C}_{10}-\mathrm{C}, \mathrm{FeN}_{4} \mathrm{C}_{10}-\mathrm{O}$, and $\mathrm{FeN}_{4} \mathrm{C}_{10}$ site. A higher value of $\Delta G$ indicates a better resistance to demetallation.

\begin{tabular}{llll}
\hline Active site & Limiting potential $(\mathrm{V})$ & $\begin{array}{l}\text { Activation } \\
\text { energy }(\mathrm{eV})\end{array}$ & $\begin{array}{l}\text { Free energy change for } \\
\text { demetallation }(\mathrm{eV})\end{array}$ \\
\hline $\mathrm{FeN}_{4} \mathrm{C}_{10}-\mathrm{C}$ & 0.67 & 0.71 & 1.25 \\
$\mathrm{FeN}_{4} \mathrm{C}_{12}-\mathrm{O}$ & 0.75 & 0.59 & 0.80 \\
$\mathrm{FeN}_{4} \mathrm{C}_{10}$ & 0.65 & 0.59 & 1.33 \\
\hline
\end{tabular}

The predicted free energy evolutions for a 4e- associative ORR pathway on $\mathrm{S} 1$ type $\mathrm{FeN}_{4} \mathrm{C}_{12}$ and $\mathrm{FeN}_{4} \mathrm{C}_{12}-\mathrm{C}$ sites are shown in Fig. S52. The limiting potential of ORR are calculated to be $0.73 \mathrm{~V}$ on $\mathrm{FeN}_{4} \mathrm{C}_{12}$ and $0.74 \mathrm{~V}$ on the $\mathrm{FeN}_{4} \mathrm{C}_{12}-\mathrm{C}$ site, respectively. In comparison, the predicted limiting potential of ORR on the $\mathrm{FeN}_{4} \mathrm{C}_{10}$ site (a representative $\mathrm{S} 2$ site) was $0.65 \mathrm{eV}$, lower than those values on $\mathrm{S} 1$ sites. Moreover, we predicted that the activation energy for $\mathrm{OOH}$ dissociation was $0.73 \mathrm{eV}$ on $\mathrm{FeN}_{4} \mathrm{C}_{12}$ and $0.76 \mathrm{eV}$ on the $\mathrm{FeN}_{4} \mathrm{C}_{12}-\mathrm{C}$ site, respectively. This result implies that the $\mathrm{OOH}$ dissociation reaction is kinetically feasible on $\mathrm{S} 1$ sites. Regarding a higher limiting potential with surmountable activation energy for O-O bond-breaking on $\mathrm{S} 1$ type $\mathrm{FeN}_{4} \mathrm{C}_{12}$ and $\mathrm{FeN}_{4} \mathrm{C}_{12}-\mathrm{C}$ sites, our DFT results indicate that S1 sites could exhibit a higher ORR activity than S2 sites in Fe-N-C catalysts.

Furthermore, we also conducted DFT calculations to evaluate the tendency of demetallation from $\mathrm{S} 1$ type $\mathrm{FeN}_{4} \mathrm{C}_{12}$ and $\mathrm{FeN}_{4} \mathrm{C}_{12}-\mathrm{C}$ site. The proposed demetallation process on the $\mathrm{S} 1$ site is the same as that on S2 site, as presented in Fig.S47. As shown in Table S17, the Gibbs free energy change for the demetallation process was predicted to be $0.05 \mathrm{eV}$ on $\mathrm{FeN}_{4} \mathrm{C}_{12}$ and $0.00 \mathrm{eV}$ on the $\mathrm{FeN}_{4} \mathrm{C}_{12}$-C site. In contrast, the $\mathrm{FeN}_{4} \mathrm{C}_{10}$ site (S2 site) exhibits a higher value of free energy change for demetallation with $1.33 \mathrm{eV}$. These results suggest that the demetallation process would occur relatively easier on the two S1 sites than S2 site. In summary, our DFT results reveal that S1 site exhibits higher ORR activity but worse stability than S2 site in the Fe-N-C catalyst. 
(a)

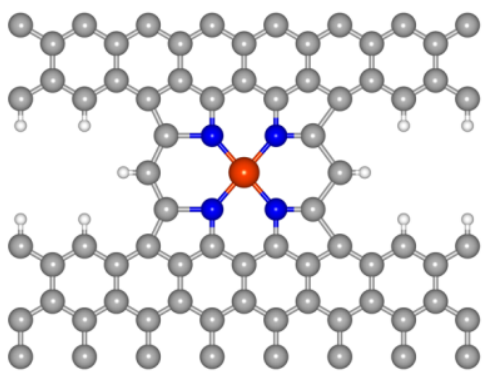

(b)

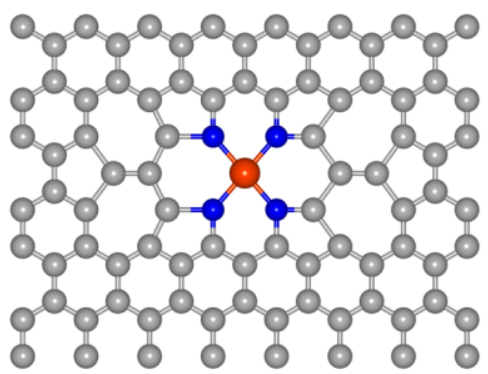

(c)

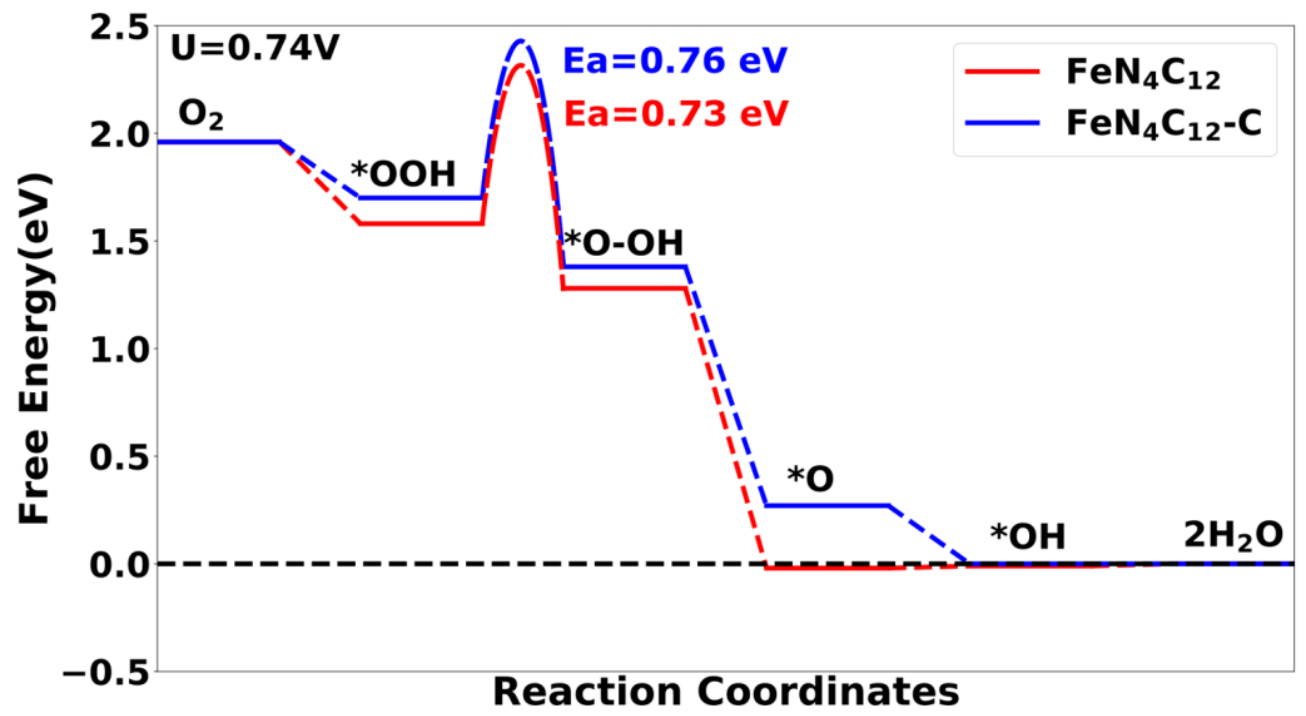

Figure S52. Atomistic structures of modelled (a) $\mathrm{FeN}_{4} \mathrm{C}_{12}$, and (b) $\mathrm{FeN}_{4} \mathrm{C}_{12}-\mathrm{C}$ active sites. In these figures, the gray, blue, orange, and white balls represent $\mathrm{C}, \mathrm{N}, \mathrm{Fe}$, and $\mathrm{H}$ atoms, respectively. (c) Calculated free energy evolution for ORR through $4 \mathrm{e}^{-}$associative pathway on $\mathrm{FeN}_{4} \mathrm{C}_{12}$ and $\mathrm{FeN}_{4} \mathrm{C}_{12}-\mathrm{C}$ sites under electrode potential of $\mathrm{U}=0.74 \mathrm{~V}$.

\section{References}

1. C. H. Camp Jr, pyMCR: A Python Library for MultivariateCurve Resolution Analysis with Alternating Regression (MCR-AR). J. Res. Nat. Ins. Standards Techno. 124, 1-10 (2019).

2. W. K. Epting, J. Gelb, S. Litster, Resolving the Three-Dimensional Microstructure of Polymer Electrolyte Fuel Cell Electrodes using Nanometer-Scale X-ray Computed Tomography. Adv. Func. Mater. 22, 555-560 (2012).

3. S. Komini Babu, H. T. Chung, P. Zelenay, S. Litster, Resolving Electrode Morphology's Impact on Platinum Group Metal-Free Cathode Performance Using Nano-CT of 3D Hierarchical Pore and Ionomer Distribution. ACS Appl. Mater. Interfaces 8, 32764-32777 (2016). 
4. J. P. Braaten, S. Ogawa, V. Yarlagadda, A. Kongkanand, S. Litster, Studying Pt-based fuel cell electrode degradation with nanoscale X-ray computed tomography. J. Power Sources 478, 229049 (2020).

5. A. Uddin et al., High Power Density Platinum Group Metal-free Cathodes for Polymer Electrolyte Fuel Cells. ACS Appl. Mater. Interfaces, (2020).

6. Y. He et al., Single Cobalt Sites Dispersed in Hierarchically Porous Nanofiber Networks for Durable and High-Power PGM-Free Cathodes in Fuel Cells. Adv. Mater., e2003577 (2020).

7. A. Tkachuk et al., X-ray computed tomography in Zernike phase contrast mode at $8 \mathrm{keV}$ with 50-nm resolution using $\mathrm{Cu}$ rotating anode X-ray source. Z Kristallogr 222, 650-655 (2007).

8. J. T. Gostick et al., PoreSpy: A python toolkit for quantitative analysis of porous media images. J. Open Source Software 4, 1296 (2019).

9. P. Hohenberg, W. Kohn, Inhomogeneous Electron Gas. Phys. Rev. B 136, B864-B871 (1964).

10. W. Kohn, L. J. Sham, Self-Consistent Equations Including Exchange and Correlation Effects. Phys. Rev. 140, 1133-1138 (1965).

11. G. Kresse, J. Furthmuller, Efficiency of ab-initio total energy calculations for metals and semiconductors using a plane-wave basis set. Computational Mater. Sci. 6, 15-50 (1996).

12. G. Kresse, J. Hafner, Ab initio molecular dynamics for liquid metals. Phys Rev B 47, 558561 (1993).

13. J. P. Perdew, K. Burke, M. Ernzerhof, Generalized gradient approximation made simple. Phys Rev Lett 77, 3865-3868 (1996).

14. H. J. Monkhorst, J. D. Pack, Special Points for Brillouin-Zone Integrations. Phys. Rev. B 13, 5188-5192 (1976).

15. G. Henkelman, B. P. Uberuaga, H. Jonsson, A climbing image nudged elastic band method for finding saddle points and minimum energy paths. J. Chem. Phys. 113, 9901-9904 (2000).

16. Z. Qiao et al., 3D polymer hydrogel for high-performance atomic iron-rich catalysts for oxygen reduction in acidic media. Appl. Cataly. B Environ. 219, 629-639 (2017).

17. J. Shui, M. Wang, F. Du, L. Dai, N-doped carbon nanomaterials are durable catalysts for oxygen reduction reaction in acidic fuel cells. Sci. Adv. 1, e1400129 (2015).

18. S. Liu et al., Chemical Vapor Deposition for Atomically Dispersed and Nitrogen Coordinated Single Metal Site Catalysts. Angew. Chem. Int. Ed. 59, 21698-21705. (2020).

19. H. T. Chung et al., Direct atomic-level insight into the active sites of a high-performance PGM-free ORR catalyst. Science 357, 479-484 (2017).

20. D. Zhao et al., Highly efficient non-precious metal electrocatalysts prepared from one-pot synthesized zeolitic imidazolate frameworks. Adv. Mater. 26, 1093-1097 (2014).

21. H. Zhang et al., High-performance fuel cell cathodes exclusively containing atomically dispersed iron active sites. Energy Environ. Sci. 12, 2548-2558 (2019).

22. X. Wan et al., Fe-N-C electrocatalyst with dense active sites and efficient mass transport for high-performance proton exchange membrane fuel cells. Nat. Catal. 2, 259-268 (2019).

23. J. Tian et al., Optimized synthesis of Fe/N/C cathode catalysts for PEM fuel cells: a matter of iron-ligand coordination strength. Angew. Chem. Int. Ed. 52, 6867-6870 (2013).

24. J. Li et al., Thermally Driven Structure and Performance Evolution of Atomically Dispersed $\mathrm{FeN}_{4}$ Sites for Oxygen Reduction. Angew. Chem. Int. Ed. 58, 18971-18980 (2019). 
25. X. Fu et al., Tailoring $\mathrm{FeN}_{4}$ Sites with Edge Enrichment for Boosted Oxygen Reduction Performance in Proton Exchange Membrane Fuel Cell. Carbon 9, 201706758 (2019).

26. J. Li et al., Evolution Pathway from Iron Compounds to Fe1(II)-N4 Sites through Gas-Phase Iron during Pyrolysis. J. Am. Chem. Soc. 142, 1417-1423 (2020).

27. M. Qiao et al., Hierarchically Ordered Porous Carbon with Atomically Dispersed FeN4 for Ultraefficient Oxygen Reduction Reaction in Proton-Exchange Membrane Fuel Cells. Angew. Chem. Int. Ed. 59, 2688-2694 (2020).

28. C. Zhang et al., Networking Pyrolyzed Zeolitic Imidazolate Frameworks by Carbon Nanotubes Improves Conductivity and Enhances Oxygen-Reduction Performance in Polymer-Electrolyte-Membrane Fuel Cells. Adv. Mater. 29, 1604556 (2017).

29. H. Zhang et al., Single Atomic Iron Catalysts for Oxygen Reduction in Acidic Media: Particle Size Control and Thermal Activation. J. Am. Chem. Soc. 139, 14143-14149 (2017).

30. M. Xiao et al., Climbing the Apex of the ORR Volcano Plot via Binuclear Site Construction: Electronic and Geometric Engineering. J. Am. Chem. Soc. 141, 17763-17770 (2019).

31. J. Li et al., Identification of durable and non-durable $\mathrm{FeNx}$ sites in $\mathrm{Fe}-\mathrm{N}-\mathrm{C}$ materials for proton exchange membrane fuel cells. Nat. Catal. 4, 10-19 (2020).

32. X. Yuan, H. Wang, J. Colin Sun, J. Zhang, AC impedance technique in PEM fuel cell diagnosis-A review. Int. J. Hydrogen Energy 32, 4365-4380 (2007).

33. V. P. Glibin, J.-P. Dodelet, Thermodynamic stability in acid media of FeN4-based catalytic sites used for the reaction of oxygen reduction in PEM fuel cells. J. Electrochem. Soc. 164, F948 (2017). 